\title{
WestVirginiaUniversity
}

THE RESEARCH REPOSITORY @ WVU

Graduate Theses, Dissertations, and Problem Reports

2000

\section{Seepage through longitudinal drainage trenches}

\author{
Benjamin T. Staud \\ West Virginia University
}

Follow this and additional works at: https://researchrepository.wvu.edu/etd

\section{Recommended Citation}

Staud, Benjamin T., "Seepage through longitudinal drainage trenches" (2000). Graduate Theses, Dissertations, and Problem Reports. 1056.

https://researchrepository.wvu.edu/etd/1056

This Thesis is protected by copyright and/or related rights. It has been brought to you by the The Research Repository @ WVU with permission from the rights-holder(s). You are free to use this Thesis in any way that is permitted by the copyright and related rights legislation that applies to your use. For other uses you must obtain permission from the rights-holder(s) directly, unless additional rights are indicated by a Creative Commons license in the record and/ or on the work itself. This Thesis has been accepted for inclusion in WVU Graduate Theses, Dissertations, and Problem Reports collection by an authorized administrator of The Research Repository @ WVU. For more information, please contact researchrepository@mail.wvu.edu. 


\author{
Benjamin T. Staud
}

\author{
Thesis \\ submitted to the College of Engineering and Mineral Resources at \\ West Virginia University \\ in partial fulfillment of the requirements for \\ the degree of \\ Master's of Science \\ in \\ Civil Engineering \\ Dr. Hema J. Siriwardane Ph.D., P.E., Chair \\ Dr. Udaya Halabe Ph.D., P.E. \\ Dr. George Hall Ph.D., P.E.
}

Department of Civil and Environmental Engineering

Morgantown, West Virginia

2000

Keywords: Longitudinal Trench Drains and Seepage 


\section{ABSTRACT \\ Seepage Through Longitudinal Drainage Trenches}

\section{Benjamin T. Staud}

Slope stability in West Virginia is a common problem in view of its hilly ground terrain. Shallow slope failures caused by seepage in particular are encountered frequently. Installation of longitudinal trench drains is potentially an inexpensive and effective solution to this problem. The stabilization method involves installing trench drains in the direction of maximum slope inclination within the sliding soil mass. The trench drains should be designed to reduce the destabilizing seepage forces in the slope, thereby increasing the factor of safety and reducing or eliminating the potential of the slope failure.

The objective of this study was to determine how the longitudinal drain system works under laboratory conditions. In this study, a bench-scale model was constructed to assess the flow patterns caused by a trench drain in a slope. The experimental variables include the trench spacing $(w)$, seepage depth $(\mathrm{h})$, and slope angle $(\theta)$. In the experimental program, four values of slope angle, three values of trench spacing and three values of seepage depth were considered. Each experiment was performed twice to ensure that the measurements are reproducible. The soil type for the experimental program was selected on the basis of hydraulic conductivity. The soil was placed in the experimental cell under dry conditions and the water was introduced at predetermined levels at the upstream end to maintain a constant head. Measurements of seepage volume were taken along the longitudinal direction of the trench after reaching steady state seepage conditions. The piezometric pressures at selected locations in the soil slope were measured.

The results show that a longitudinal trench drain system with appropriate drain spacing can be used to remove the majority of seepage from soil slope. Furthermore, the report contains laboratory data that provide quantitative information on the influence of different experimental parameters on the removal rate of seepage water. 


\section{ACKNOWLEDGMENTS}

The author would like to take this opportunity to thank the many people who helped in the completion of this thesis. Many thanks to Dr. Hema J. Siriwardane, his graduate advisor and committee chairperson, for his assistance and guidance in preparation of this thesis. The author also wishes to express appreciation to Dr. George Hall for his advice and participation on the committee. Thanks also goes to Dr. Udaya Halabe for his participation on the committee.

The financial support provided by the West Virginia Department of Transportation, Division of Highways for this project through a research contract to West Virginia University is gratefully acknowledged.

Additional thanks go to friends and family who gave necessary moral support throughout the work. 


\section{TABLE OF CONTENTS}

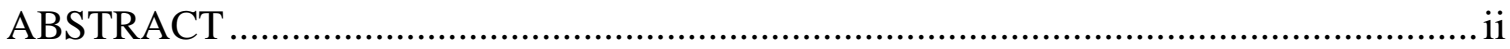

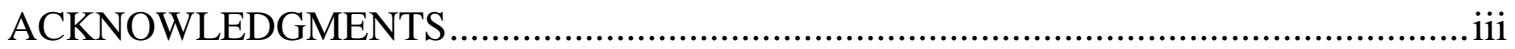

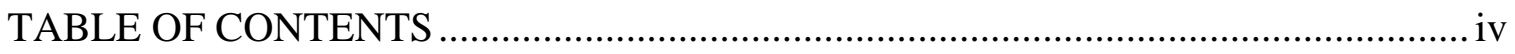

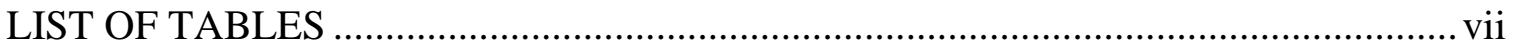

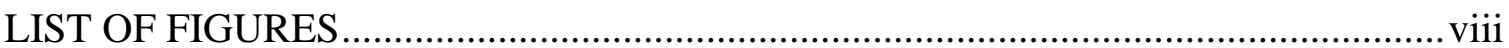

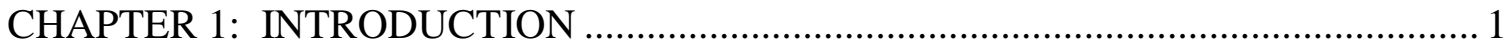

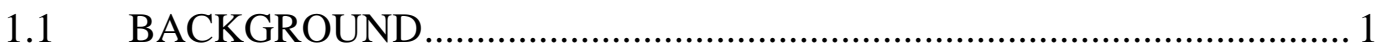

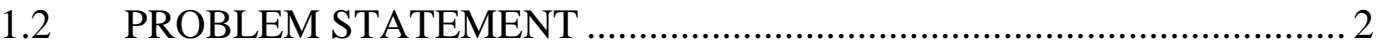

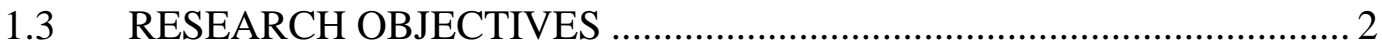

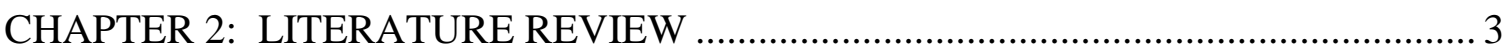

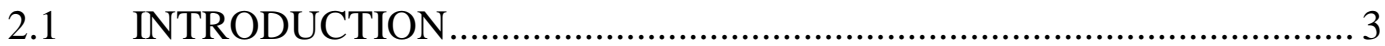

2.2 FLOW THROUGH POROUS MEDIA …………............................... 3

2.3 SLOPE STABILITY AND STABILIZATION METHODS ...................... 6

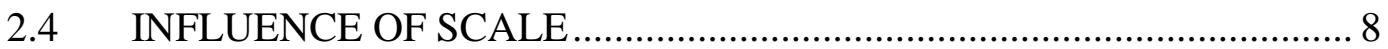

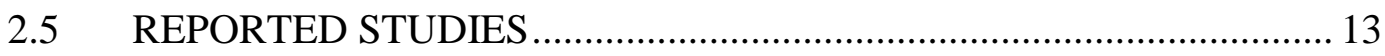

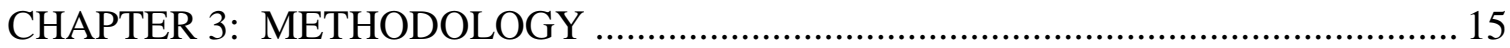

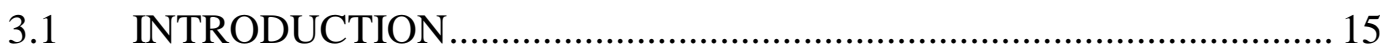

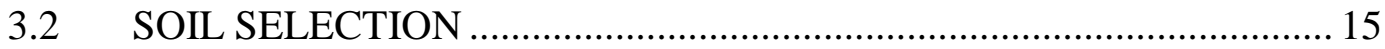

3.3 EXPERIMENTAL APPARATUS DESIGN ……..................................... 16

3.3.1 Boundary Conditions at the Line of Symmetry …….................... 21

3.3.2 Water Supply System ............................................................. 21

3.3.3 Segmented Longitudinal Drain .................................................... 23

3.3.4 Drainage Collection System......................................................... 25 
3.3.5 Terminus........................................................................ 25

3.3.6 Support Mechanism................................................................ 29

3.3.7 Piezometers ................................................................... 31

3.3.8 Geotextile Selection ........................................................... 31

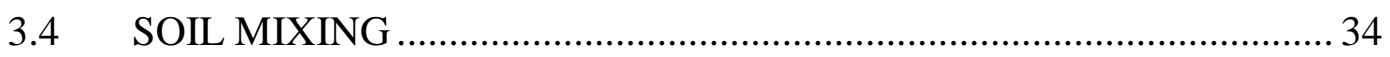

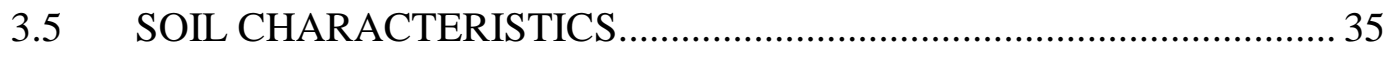

3.5.1 Hydraulic Conductivity .................................................. 35

3.5.2 Grain Size Analysis ...................................................... 36

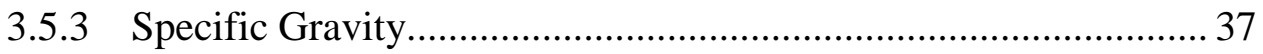

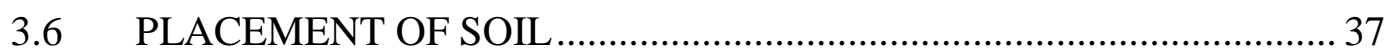

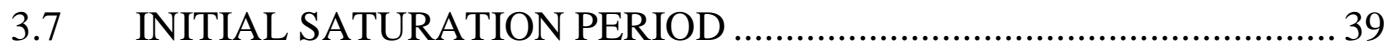

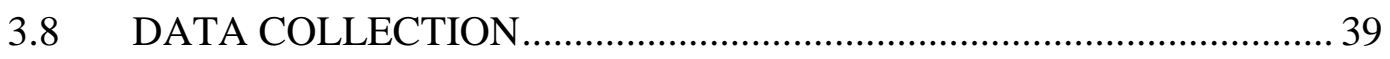

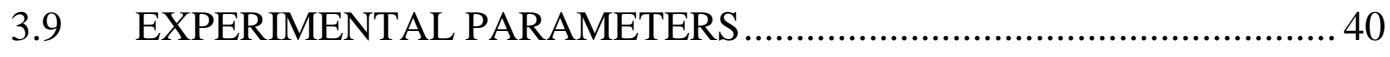

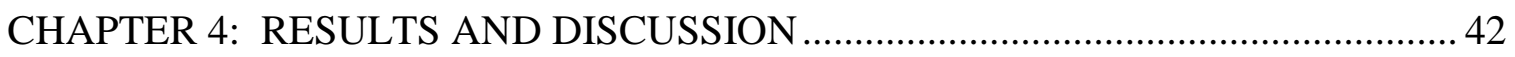

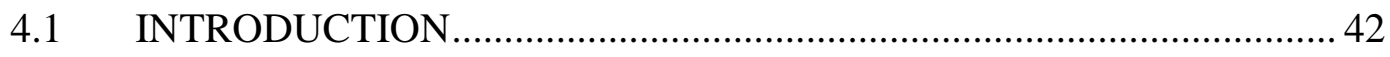

4.2 REPRODUCIBILITY OF EXPERIMENTAL DATA .......................... 43

4.3 INFLUENCE OF DRAIN LENGTH ............................................. 46

4.4 INFLUENCE OF SLOPE ANGLE .............................................. 48

4.5 INFLUENCE OF TRENCH SPACING ..................................... 51

4.6 INFLUENCE OF SEEPAGE DEPTH ............................................ 54

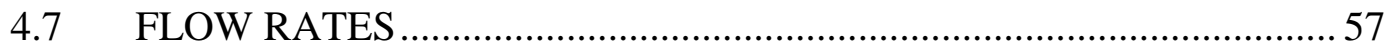

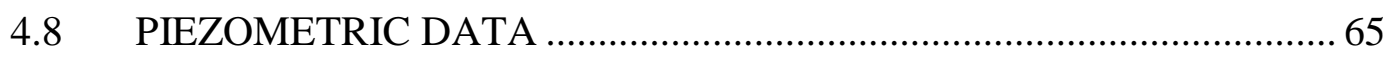


CHAPTER 5: CONCLUSIONS AND RECOMMENDATIONS

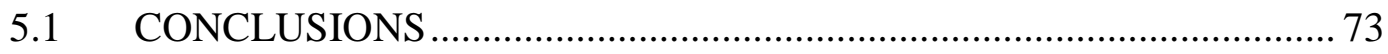

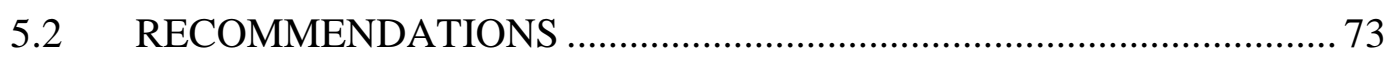

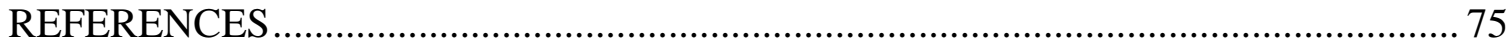

APPENDIX A: DRAINAGE VOLUMES COLLECTED............................................ 76

APPENDIX B: PLOTS OF THE HYDRAULIC CONDUTIVITY TESTS .................... 80

APPENDIX C: PLOTS OF THE PERCENT COLLECTED IN EACH DRAIN

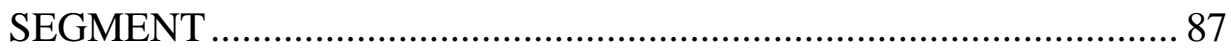

APPENDIX D: PLOTS OF THE FLOW RATE FOR EACH CHAMBER .................... 110

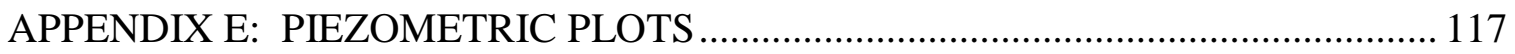

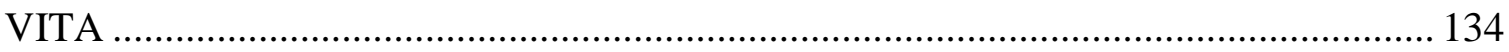

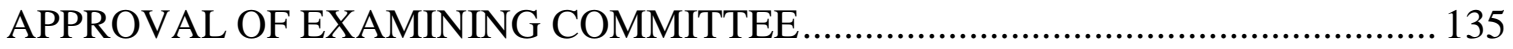




\section{LIST OF TABLES}

Table 2.1 Typical Values of Hydraulic Conductivity .............................................. 6

Table 3.1 Minimum Average Roll Values for Terrafix 400R ............................... 34

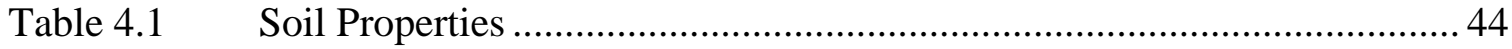

Table A.1 Volume of Seepage Collected in Each Drain Segment for 8 inch Seepage

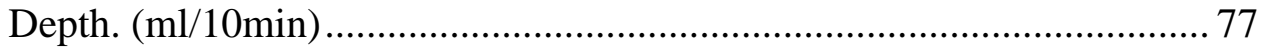

Table A.2 Volume of Seepage Collected in Each Drain Segment for 6 inch Seepage

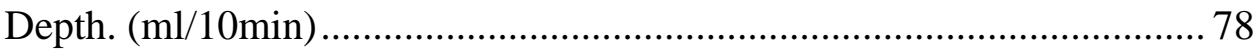

Table A.3 Volume of Seepage Collected in Each Drain Segment for 4 inch Seepage

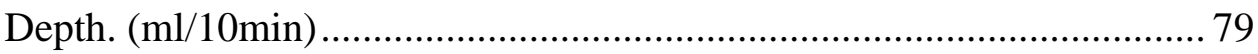




\section{LIST OF FIGURES}

Figure 3.1 Plan View of Two Parallel Longitudinal Drains ....................................... 17

Figure $3.2 \quad$ Experimental Apparatus ………………..................................... 18

Figure 3.3 A Picture of the Experimental Apparatus ............................................... 19

Figure 3.4 A Picture of the Moveable Wall........................................................... 20

Figure 3.5 A Picture of the Supply Tank ......................................................... 22

Figure 3.6 A Picture of the Segmented Longitudinal Drain ........................................2 24

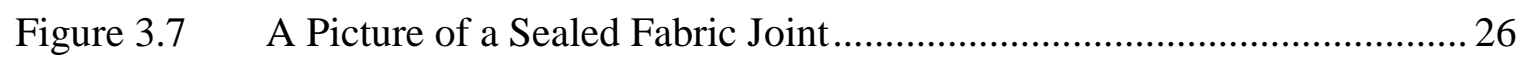

Figure $3.8 \quad$ A Picture of the Drainage Collection System ......................................... 27

Figure $3.9 \quad$ A Picture of the Terminus Drain .........................................................2 28

Figure 3.10 A Picture of the Support Mechanism ....................................................... 30

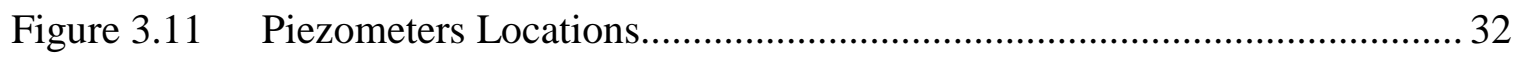

Figure 3.12 Apparatus for Piezometric Head Measurement. ....................................... 33

Figure 3.13 Picture of the Dry Sand Placement Apparatus .......................................... 38

Figure 3.14 Typical Cross-Section of a Longitudinal Drain ........................................ 41

Figure 4.1: Grain Size Distribution ....................................................................... 45

Figure 4.2: Influence of Length $(\mathrm{x})$ on Drainage Volume ............................................ 47

Figure 4.3: Influence of Slope Angle $(\theta)$ on Drainage Volume .................................. 49

Figure 4.4: Influence on Slope Angle $(\theta)$ on Drainage Volume in Each Section ....... 50

Figure 4.5: Influence on Trench Spacing (w) on Drainage Volume ........................... 52

Figure 4.6: Influence on Trench Spacing (w) on Drainage Volume in Each Section .53

Figure 4.7: Influence of Seepage Depth (h) on Drainage Volume ...............................55

Figure 4.8: Influence of Seepage Depth (h) on Drainage Volume in Each Section.... 56 
Figure 4.9: Influence of Slope Angle $(\theta)$ on Flow Rate $(18$ inch $(46 \mathrm{~cm}) \ldots \ldots \ldots \ldots \ldots . . . . . . .59$

Figure 4.10 Influence of Slope Angle $(\theta)$ on Flow Rate $(12$ inch $(30 \mathrm{~cm}) \ldots \ldots \ldots \ldots \ldots . . . . . . .60$

Figure 4.11 Influence of Slope Angle $(\theta)$ on Flow Rate $(6$ inch $(15 \mathrm{~cm}) \ldots \ldots \ldots \ldots \ldots \ldots . . . . . . . . .61$

Figure 4.12 Influence of Seepage Depth (h) on Flow Rate $(18$ inch $(46 \mathrm{~cm}) \ldots \ldots \ldots \ldots . . . .62$

Figure 4.13 Variation of the Flow Rate into the First Chamber ................................ 63

Figure 4.14 Influence of Trench Spacing (w) on Flow Rate $(6$ inch $(15 \mathrm{~cm}) \ldots \ldots \ldots \ldots . . .64$

Figure 4.15 Influence of Slope Angle on Piezometric Head at the Centerline Between

Drains

Figure 4.16 Influence of Trench Spacing on Piezometric Head at the Centerline

Between Drains

Figure 4.17 Influence of Seepage Depth on Piezometric Head at the Centerline

Between Drains

Figure 4.18 Influence of Slope Angle on Piezometric Surface at Cross Sections

Perpendicular to the Longitudinal Drain 70

Figure 4.19 Influence of Trench Spacing on Piezometric Surface at Cross Sections

Perpendicular to the Longitudinal Drain

Figure 4.20 Influence of Seepage Depth on Piezometric Surface at Cross Sections

Perpendicular to the Longitudinal Drain

Figure B.1 Plots of Hydraulic Conductivity for 6 inch Trench Spacing, Test \# 1..... 81

Figure B.2 Plots of Hydraulic Conductivity for 6 inch Trench Spacing, Test \# 2..... 82

Figure B.3 Plots of Hydraulic Conductivity for 12 inch Trench Spacing, Test \# 1....83

Figure B.4 Plots of Hydraulic Conductivity for 12 inch Trench Spacing, Test \# 2.... 84

Figure B.5 Plots of Hydraulic Conductivity for 18 inch Trench Spacing, Test \# 1... 85 
Figure B.6 Plots of Hydraulic Conductivity for 18 inch Trench Spacing, Test \# 2... 86

Figure C.1 Cumulative Drainage Volume for 8 inch Seepage Depth and Zero Slope

Angle. .88

Figure C.2 Drainage Volume for Each Section for 8 inch Seepage Depth and Zero

Slope Angle.

Figure C.3 Cumulative Drainage Volume for 6 inch Seepage Depth and Zero Slope

Angle.

Figure C.4 Drainage Volume for Each Section for 6 inch Seepage Depth and Zero

Slope Angle.

Figure C.5 Cumulative Drainage Volume for 4 inch Seepage Depth and Zero Slope

Angle.

Figure C.6 Drainage Volume for Each Section for 4 inch Seepage Depth and Zero

Slope Angle.

Figure C.7 Cumulative Drainage Volume for 8 inch Seepage Depth and 4:1 Slope

Angle.

Figure C.8 Drainage Volume for Each Section for 8 inch Seepage Depth and 4:1

Slope Angle. 95

Figure C.9 Cumulative Drainage Volume for 6 inch Seepage Depth and 4:1

Slope Angle. 96

Figure C.10 Drainage Volume for Each Section for 6 inch Seepage Depth and 4:1

Slope Angle. 
Figure C.11 Cumulative Drainage Volume for 4 inch Seepage Depth and 4:1 Slope Angle.

Figure C.12 Drainage Volume for Each Section for 4 inch Seepage Depth and 4:1

Slope Angle. 99

Figure C.13 Cumulative Drainage Volume for 8 inch Seepage Depth and 3:1 Slope

Angle. (See Figure 4.5)

Figure C.14 Drainage Volume for Each Section for 8 inch Seepage Depth and 3:1

Slope Angle. (See Figure 4.6)

Figure C.15 Cumulative Drainage Volume for 6 inch Seepage Depth and 3:1 Slope

Angle.

Figure C.16 Drainage Volume for Each Section for 6 inch Seepage Depth and 3:1

Slope Angle.

Figure C.17 Cumulative Drainage Volume for 4 inch Seepage Depth and 3:1 Slope

Angle.

Figure C.18 Drainage Volume for Each Section for 4 inch Seepage Depth and 3:1

Slope Angle.

Figure C.19 Cumulative Drainage Volume for 8 inch Seepage Depth and 2:1 Slope

Angle. 104

Figure C.20 Drainage Volume for Each Section for 8 inch Seepage Depth and 2:1

Slope Angle. 105

Figure C.21 Cumulative Drainage Volume for 6 inch Seepage Depth and 2:1 Slope

Angle. 106 
Figure C.22 Drainage Volume for Each Section for 6 inch Seepage Depth and 2:1

Slope Angle.

Figure C.23 Cumulative Drainage Volume for 4 inch Seepage Depth and 2:1 Slope

Angle. 108

Figure C.24 Drainage Volume for Each Section for 4 inch Seepage Depth and 2:1

Slope Angle. 109

Figure D.1 Flow Rates for Each Drain Section for 18 inch Trench Spacing, and 8 inch

Seepage Depth. (See Figure 4.9) 59

Figure D.2 Flow Rates for Each Drain Section for 18 inch Trench Spacing, and 6 inch Seepage Depth.

Figure D.3 Flow Rates for Each Drain Section for 18 inch Trench Spacing, and 4 inch Seepage Depth. 112

Figure D.4 Flow Rates for Each Drain Section for 12 inch Trench Spacing, and 8 inch Seepage Depth. (See Figure 4.10) 60

Figure D.5 Flow Rates for Each Drain Section for 12 inch Trench Spacing, and 6 inch Seepage Depth. 113

Figure D.6 Flow Rates for Each Drain Section for 12 inch Trench Spacing, and 4 inch Seepage Depth. 114

Figure D.7 Flow Rates for Each Drain Section for 6 inch Trench Spacing, and 8 inch

Seepage Depth. (See Figure 4.11)

Figure D.8 Flow Rates for Each Drain Section for 6 inch Trench Spacing, and 6 inch

Seepage Depth. 
Figure D.9 Flow Rates for Each Drain Section for 6 inch Trench Spacing, and 4 inch

Seepage Depth.

116

Figure E.1 Piezometric Head Along the Centerline Between Drains for 8 inch

Seepage Depth and 2:1 Slope Angle. (See Figure 4.16) ........................ 68

Figure E.2 Piezometric Head Along the Centerline Between Drains for 8 inch

Seepage Depth and 3:1 Slope Angle. ............................................. 118

Figure E.3 Piezometric Head Along the Centerline Between Drains for 8 inch

Seepage Depth and 4:1 Slope Angle.

Figure E.4 Piezometric Head Along the Centerline Between Drains for 6 inch

Seepage Depth and 2:1 Slope Angle.

Figure E.5 Piezometric Head Along the Centerline Between Drains for 6 inch

Seepage Depth and 3:1 Slope Angle.

Figure E.6 Piezometric Head Along the Centerline Between Drains for 6 inch

Seepage Depth and 4:1 Slope Angle.

Figure E.7 Piezometric Head Along the Centerline Between Drains for 4 inch

Seepage Depth and 2:1 Slope Angle.

Figure E.8 Piezometric Head Along the Centerline Between Drains for 4 inch

Seepage Depth and 3:1 Slope Angle.

Figure E.9 Piezometric Head Along the Centerline Between Drains for 4 inch

Seepage Depth and 4:1 Slope Angle.

Figure E.10 Piezometric Head Along Cross-Sections Perpendicular to the Longitudinal Drain for 8 inch Seepage Depth and 2:1 Slope Angle. (See Figure 4.19) 71 
Figure E.11 Piezometric Head Along Cross-Sections Perpendicular to the Longitudinal Drain for 8 inch Seepage Depth and 3:1 Slope Angle. 126

Figure E.12 Piezometric Head Along Cross-Sections Perpendicular to the Longitudinal Drain for 8 inch Seepage Depth and 4:1 Slope Angle.

Figure E.13 Piezometric Head Along Cross-Sections Perpendicular to the Longitudinal Drain for 6 inch Seepage Depth and 2:1 Slope Angle. 128

Figure E.14 Piezometric Head Along Cross-Sections Perpendicular to the Longitudinal Drain for 6 inch Seepage Depth and 3:1 Slope Angle. 129

Figure E.15 Piezometric Head Along Cross-Sections Perpendicular to the Longitudinal Drain for 6 inch Seepage Depth and 4:1 Slope Angle.

Figure E.16 Piezometric Head Along Cross-Sections Perpendicular to the Longitudinal Drain for 4 inch Seepage Depth and 2:1 Slope Angle.

Figure E.17 Piezometric Head Along Cross-Sections Perpendicular to the Longitudinal Drain for 4 inch Seepage Depth and 3:1 Slope Angle. 132

Figure E.18 Piezometric Head Along Cross-Sections Perpendicular to the Longitudinal Drain for 4 inch Seepage Depth and 4:1 Slope Angle. 


\section{CHAPTER 1 \\ INTRODUCTION}

\subsection{BACKGROUND}

From a geotechnical standpoint, the most ideal location for development such as roads or homes would be on level ground. However, in West Virginia building on flat land is not always possible, leading to the challenge of building in sloped areas. One of the potential problems with building on sloping land is slope instability caused by seepage forces. Seepage forces are a result of water moving through the spaces between soil grains. The force of this moving water in the hillside changes the balance of resisting and driving forces that keeps the slope from moving. Often these changes swing in favor of instability and the slope will move. With slower moving slopes remedial action can be taken to correct the problem before major damage occurs.

Current methods to correct slope instability problems caused by seepage are costly. A few such methods are: retaining walls, excavation and recompaction, deep drainage, cutoff trenches, and soil nailing. The West Virginia Division of Highways (WVDOH) in particular deals with slopes stability problems caused by seepage on a daily basis. The number of slope stability problems in West Virginia is estimated to be in the thousands. With such a large number of slope correction measures needed, it is desirable to find the most inexpensive but effective solutions to slope stability problems. 


\subsection{PROBLEM STATEMENT}

In an effort to provide an inexpensive but effective solution to common slope stability problems caused by seepage, a study was undertaken by West Virginia University under the sponsorship of the West Virginia Division of Highways. The basic idea behind this study involves placing drainage trenches on the slope face and in line with the maximum slope of the failing hillside. The aim of the drains is to decrease the destabilizing force of the hillside seepage by redirecting a majority of the seepage forces perpendicular to the slope of the hillside. The goal of this research project is to physically model the seepage through a soil slope to gain insight into the workings of longitudinal drains

\subsection{RESEARCH OBJECTIVES}

The overall goal of this project was to investigate the effectiveness of the longitudinal drain system in removing seepage from a hillside. The following objectives were identified to reach this goal:

1. Review all literature pertaining to the use of drains to increases slope stability.

2. Construct a model to study the effects of a longitudinal drainage system on drainage patterns for different slope angles $(\theta)$, drain spacing $(w)$ and seepage depths (h).

3. Develop a method of comparing the results predicted by the model analysis to actual slope stability problems. 


\section{CHAPTER 2}

\section{LITERATURE REVIEW}

\section{$2.1 \quad$ INTRODUCTION}

A review of literature was completed to identify any existing sources of information relating to the use of longitudinal drains in slopes. With the hope of identifying studies pertaining to the longitudinal drain system, a search of agriculturalbased drain systems was undertaken. Despite this exhaustive search effort only one article was found. A review of the basic principles involved with the longitudinal drain system and its modeling was also undertaken to help understand the underlying principles. The three main principles reviewed were:

1) Fluid flow through porous media.

2) The principles of slope stability and stabilization methods.

3) The effects of scale modeling.

A review of these principles and the article by Stanic is contained in the following sections.

\subsection{FLOW THROUGH POROUS MEDIA}

Soil consists of many individual grains of varying size. Because the individual grains that make up soil do not fit tightly together, voids form between the grains. These voids act as a semi-continuous conduit for the flow of water. Flow through these void spaces is called flow through porous media. One of the major destabilizing forces

resulting in slope instability is the flow of water in porous media. As water, or any fluid, flows through soil it exerts a force on the soil particles through friction (Cedergren, 1977). This seepage force can most readily be demonstrated in quick sand. In quick sand the force of the water moving up into the sand from below equals the downward force of 
the soil particles and results in a dense viscous fluid. The same forces seen in quick sand are also found in slopes that have seepage. While the seepage forces in slopes usually do not result in quick conditions, the forces can have a destabilizing influence. The primary law governing flow through porous media is Darcy's Law.

$$
v=k i \ldots \ldots \ldots \ldots \ldots . . E q .2 .1
$$

Where:

$$
\begin{aligned}
& \mathrm{v}=\quad \text { Discharge velocity, the amount of water flowing in a } \\
& \text { unit time through a unit cross-sectional area }(\mathrm{ft} / \mathrm{s} \text { or } \mathrm{cm} / \mathrm{s}) . \\
& \mathrm{k}=\quad \text { Hydraulic conductivity }(\mathrm{ft} / \mathrm{s} \text { or } \mathrm{cm} / \mathrm{s}) . \\
& \mathrm{i}=\quad \text { Hydraulic gradient }(\mathrm{ft} / \mathrm{ft} \text { or } \mathrm{cm} / \mathrm{cm}) .
\end{aligned}
$$

A more practical form of Darcy's Law can be obtained by multiplying through by the cross-sectional area A to yield:

$$
q=k i A \ldots \ldots \ldots \ldots \ldots \ldots q .2 .2
$$

Where:

$$
\begin{aligned}
& \mathrm{q}=\quad \text { Flow rate }\left(\mathrm{ft}^{3} / \mathrm{s} \text { or } \mathrm{m}^{3} / \mathrm{s}\right) . \\
& \mathrm{A}=\quad \text { Cross sectional area at right angles to the direction of flow }\left(\mathrm{ft}^{2} \mathrm{or} \mathrm{m}^{2}\right)
\end{aligned}
$$

This form of Darcy's law states that flow rate through a porous media is equal to the gradient multiplied by the cross sectional area and a constant $\mathrm{k}$, called the hydraulic conductivity. The gradient is defined as the ratio of the difference in head from one side of the specimen to the other and the length of the specimen. The term head is defined with Bernoulli's energy equation for incompressible steady flow of a fluid: 


$$
\frac{v_{1}^{2}}{2 g}+\frac{p_{1}}{\rho_{w} g}+z_{1}=\frac{v_{2}^{2}}{2 g}+\frac{p_{2}}{\rho_{w} g}+z_{2}+h_{f}=\text { constant total head }
$$

With:

$$
\begin{array}{ll}
\mathrm{v}= & \text { Velocity }(\mathrm{ft} / \mathrm{s} \text { or } \mathrm{cm} / \mathrm{s}) \\
\mathrm{g}= & \text { Gravitational constant }\left(32.17 \mathrm{ft} / \mathrm{s}^{2} \text { or } 9.807 \mathrm{~m} / \mathrm{s}^{2}\right) \\
\mathrm{p}= & \text { Pressure }(\mathrm{psi} \text { or } \mathrm{kPa}) \\
\rho_{\mathrm{w}}= & \text { Density of water }\left(\mathrm{lb} / \mathrm{ft}^{3} \text { or } \mathrm{kg} / \mathrm{m}^{3}\right) \\
\mathrm{z}= & \text { Elevation }(\mathrm{ft} \text { or } \mathrm{m}) \\
\mathrm{h}_{\mathrm{f}}= & \text { Head loss due to friction. }(\mathrm{ft} \text { or } \mathrm{m})
\end{array}
$$

The energy or head at one point is equal to the head at any another point minus the loss due to friction. The total head at any point is the sum of the velocity head (first term in equation 2-3), pressure head (second term), and elevation head (third term.) In flow through porous media the velocities in the void spaces between grains are usually small. For this reason, when the velocity head is compared with the pressure and elevation heads, the velocity head can safely be neglected. The head, at any point, can now be expressed as the sum of the head due to pressure and the head due to elevation.

$$
\frac{p}{\rho_{w} g}+z=\mathrm{h}_{\mathrm{t}} \ldots \ldots \ldots \ldots \ldots \ldots . . .2 q .2 .4
$$

The hydraulic conductivity $\mathrm{k}$, is determined experimentally and relates how well a fluid moves around the soil particles and through the spaces in the soil matrix. The hydraulic conductivity of a particular soil primarily depend on grain size and porosity. Porosity is a term relating what percentage of the total volume of soil is void space. 
The porosity of a soil depends on the grain size of the soil and how well it has been compacted. Hydraulic conductivity can vary for the same soil type under different degrees of compaction. Table 2.1 gives typical values of hydraulic conductivity for different soil types.

Table 2.1 Typical Values of Hydraulic Condutivity (Das, 1993)

\begin{tabular}{|c|c|c|}
\hline \multirow{2}{*}{ Soil Type } & \multicolumn{2}{|c|}{$\mathrm{k}$} \\
\cline { 2 - 3 } & $\mathrm{cm} / \mathrm{s}$ & $\mathrm{ft} / \mathrm{s}$ \\
\hline Clean Gravel & $1.0-100$ & $2.0-200$ \\
Coarse Gravel & $1.0-0.01$ & $2.0-0.02$ \\
Fine Sand & $0.01-0.001$ & $0.02-0.002$ \\
Silty Clay & $0.001-0.00001$ & $0.002-0.00002$ \\
Clay & Less than 0.000001 & Less than 0.000002 \\
\hline
\end{tabular}

Darcy's Law was developed through experiments using clean sands. Despite this seemingly restrictive condition, it has been shown that Darcy's Law holds true for most soil types (Holtz, 1981).

\subsection{SLOPE STABILITY AND STABILIZATION METHODS}

Earthen slopes can either be engineered or natural. An engineered slope can be a natural slope that has been modified, like a cut for a highway, or a entirely constructed slope, like a dam. Whether the slope is engineered or natural, it is subject to the law of gravity and landslides are possible. Slides can be divided into two different classes, deep seated or shallow. A deep slide involves the movement of soil well below the surface of the slope, while shallow slides only involve the top layer of soil. Regardless of the type of failure the stability of constructed or natural slopes depends on the balance of resisting forces to driving forces. Resisting forces are all of the forces that are acting to keep the 
soil mass from sliding. The primary force resisting the movement of slopes comes from the shear strength of the soil. Shear strength is a soil property determined experimentally and represents the maximum resistance of the material to shear deformation. A slope with higher shear strength has greater resisting forces than a comparable slope with lower shear strength. Other objects that can lead to higher resisting forces are: other soil masses, geotextile layers, retaining walls, and piles. The sum of these resisting forces is countered by driving forces. Unchecked, driving forces cause the soil mass to move in response to gravity, the most prominent of these is the soil mass itself. Other forces that drive the instability are seepage forces or loads placed on top of the slope. The ratio of resisting forces to driving forces is called the factor of safety. Many properly designed slopes have a factor of safety greater than 1.25 . A slope with a factor of safety of 1.25 has $25 \%$ more resistive forces than driving forces. Slope stability analysis is done using estimates of the real in-situ conditions. Large portions of the resistive forces in a slope come from the shear strength of the soil. To determine shear strength, experimental tests are done on soil samples either taken from the existing slope or from the soil that will eventually become the slope. The accuracy of these tests in predicting the real in-situ conditions could vary considerably. For existing man-made or natural slopes the actual groundwater conditions in the slope may have to be estimated from a limited number of observations. For these reasons a large factor of safety is necessary to offset the uncertainty associated with slope stability analysis.

In a failing slope, the driving forces have equaled or exceeded the resistive forces. Commonly the additional driving forces causing the failure are attributed to seepage. A reduction of the seepage force can be accomplished by redirecting the flow paths of the 
seepage in the slope. Several methods exist that accomplish this goal. One such method for deep seated failures is horizontals wells. Horizontal wells are inserted below the failing soil mass and direct the seepage force vertically down. Another method to reduce seepage in shallow failures is cut-off trenches. Cut-off trenches are typically placed parallel to the top or crest of a slope and remove seepage from the slope if the water table can be intersected before groundwater moves into the slope. If the water table cannot be intercepted before the slope begins, longitudinal trenches parallel to each other and in the direction of maximal slope inclination can be used (Stanic, 1984). The effect of these trenches is to direct the seepage force perpendicular to the fall of the slope. With the drains installed, a majority of the seepage force is eliminated from the sum of the resisting forces therefore increasing the factor of safety.

\subsection{INFLUENCE OF SCALE}

Because a model was intended for use, the influence of scale was investigated. For simplicity, the law approach was used, where the pertinent pi-numbers and scale factors are derived directly from the applicable governing laws to determine the proper proportions necessary to maintain similitude (Schuring, 1977). Similitude can only be achieved if each of the model elements is scaled using the same "scale factor." For example, q represents any primary quantity, such as length, time, or mass, of the situation to be modeled, and q' is any corresponding primary quantity of the model. For the model to have similitude, each of the primary quantities must be related by the corresponding scale factor, $\mathrm{q}^{*}$ as follows:

$$
q^{*}=\frac{q}{q^{\prime}} \ldots \ldots \ldots \ldots \ldots \ldots . . . \ldots q .2 .5
$$


If the primary quantity is length, the length scale factor, $l^{*}$ must be used to relate all lengths in the model to the situation to be modeled. Similarly, any time or mass must also satisfy the same requirements but, with the matching scale factor. The individual scale factors can be combined to create secondary scale factors. An example would be velocity where:

$$
v^{*}=\frac{l^{*}}{t^{*}} \ldots \ldots \ldots \ldots \ldots . . . \ldots q .2 .6
$$

Any velocity in the model would have the scale factor dictated by this relationship. The primary scale factors for length and time can be inserted into Equation 2.6 to get:

$$
\frac{v}{v^{\prime}}=\frac{l}{l^{\prime}} \frac{t^{\prime}}{t} \ldots \ldots \ldots \ldots \ldots \ldots . . . \ldots q .2 .7
$$

Rearranging the previous equation by separating the model quantities from the quantities representing the situation to be modeled yields:

$$
\frac{v t}{l}=\frac{v^{\prime} t^{\prime}}{l^{\prime}}=\pi_{v} \ldots \ldots \ldots \ldots \ldots \ldots \ldots . \ldots q .2 .8
$$

Dimensionless products of the above nature are required to be equal to maintain similitude. These products are given the name "pi-numbers." Pi-numbers dictate how the different primary and secondary quantities should relate to each other if a scale model is to be meaningful. Every model has a different set of pi-numbers that relates primary and secondary quantities to each other. The method selected to determine these pi- 
numbers is the law approach. The law approach begins with the identification of all relevant laws governing the phenomena to be modeled. For the longitudinal drain system, Darcy's law, as discussed in Section 2.2, is the governing equation describing flow through porous media. Because the flow is three dimensional, Darcy's law is expanded into three equations.

$$
\begin{aligned}
& q_{x}=k_{x} \frac{\Delta h}{x} A_{y z} \ldots \ldots \ldots E q \cdot 2.9 \\
& q_{y}=k_{y} \frac{\Delta h}{y} A_{x z} \ldots \ldots \ldots E q \cdot 2.10 \\
& q_{z}=k_{z} \frac{\Delta h}{z} A_{x y} \ldots \ldots \ldots E q \cdot 2.11
\end{aligned}
$$

The next step is to set the equations to zero, as was ultimately done with the velocity example. This procedure yields three pi-numbers.

$$
\begin{aligned}
& \pi_{x}=\frac{q_{x}}{k_{x} \frac{h}{x} A_{y z}} \ldots \ldots \ldots E q \cdot 2 \cdot 12 \\
& \pi_{y}=\frac{q_{y}}{k_{y} \frac{h}{y} A_{x z}} \ldots \ldots \ldots E q \cdot 2 \cdot 13 \\
& \pi_{z}=\frac{q_{z}}{k_{z} \frac{h}{z} A_{x y}} \ldots \ldots . . . E q \cdot 2.14
\end{aligned}
$$


Substituting:

$$
\begin{aligned}
& A_{y z}=y z \ldots \ldots \ldots \ldots q \cdot 2.15 \\
& A_{x z}=x z \ldots \ldots \ldots \ldots q \cdot 2.16 \\
& A_{x y}=x y \ldots \ldots \ldots \ldots E q .2 .17
\end{aligned}
$$

And,

$$
q_{x y z}=\frac{x y z}{t} \ldots \ldots \ldots \ldots \ldots \text { Eq.2.18 }
$$

For isotropic conditions,

$$
k=k_{x}=k_{y}=k_{z} \ldots \ldots \ldots \ldots \ldots \ldots \text {. Eq.2.19 }
$$

Yields:

$$
\begin{aligned}
& \pi_{x}=\frac{x^{2}}{t k h} \ldots \ldots \ldots \ldots \text { Eqs. } 2.20 \\
& \pi_{y}=\frac{y^{2}}{t k h} \ldots \ldots \ldots . . . E q s .2 .21 \\
& \pi_{z}=\frac{z^{2}}{t k h} \ldots \ldots \ldots \ldots \text { Eqs. } 2.22
\end{aligned}
$$


Now the different pi-numbers can be combined to provide the relationship between primary quantities that need to be maintained for similitude. By dividing any two of the pi-numbers and canceling time because of the steady state conditions and hydraulic conductivity because the same material is used in the model as would be used in the field yields:

$$
\frac{\pi_{x}}{\pi_{y}}=\frac{x^{2}}{y^{2}} \ldots \ldots \ldots \ldots \ldots \ldots . E q .2 .23
$$

Using the relation between the model quantities and the situation to be modeled that resulted in the pi-number, yields:

$$
\frac{x^{\prime 2}}{y^{\prime 2}}=\frac{x^{2}}{y^{2}} \ldots \ldots \ldots \ldots \ldots \ldots . . E q .2 .24
$$

Taking the square root of both sides and rearranging:

$$
\frac{x^{\prime}}{x}=\frac{y^{\prime}}{y} \ldots \ldots \ldots \ldots \ldots \ldots . . . \ldots q .2 .25
$$

A relationship similar to this can be obtained for $\pi_{\mathrm{y}}$ and $\pi_{\mathrm{z}}$. The three equations can now be assembled with the following relation.

$$
\frac{x^{\prime}}{x}=\frac{y^{\prime}}{y}=\frac{z^{\prime}}{z} \ldots \ldots \ldots \ldots \ldots \ldots . . . \ldots q .2 .26
$$

Using these relations, it follows that for the model to have similitude the scale factors for each of the directions must be equal. 


\section{$2.5 \quad$ REPORTED STUDIES}

A study by Stanic, 1984 was the only literature directly pertaining to longitudinal drain systems that could be found. Stanic completed a finite element analysis of a longitudinal drain system to calculate the piezometric level in the slope. The calculated piezometric levels were then used to determine the effects of the drainage system on the factor of safety against sliding. The modeling assumptions are listed below.

1. The slope is infinite in all directions with inclination $\beta$ with the horizontal.

2. The potential failure surface is impermeable and at a constant depth below the surface.

3. The direction of seepage in the slope before the drains are installed is parallel to the slope face and steady with respect to time.

4. The soil in the slope is homogeneous and isotropic with respect to hydraulic conductivity.

5. The drains will be parallel to each other in the direction of maximal slope inclination and will extend to the failure surface.

The model was tested at different slope angles $(\theta)$ and drain spacing (w). The results of the finite element analysis to determine the piezometric surface are normalized by dividing the piezometric level by the depth of flow (h) in the slope prior to drain placement. The author summarizes the results by determining the average and maximum piezometric level in the slope for different angles and drain spacing. As the drain spacing to depth ratio, w/h, decreases, the effectiveness of the drain in lowering the average and maximum piezometric level is increased. A greater influence on average piezometric levels can be seen at lower $\mathrm{w} / \mathrm{h}$ ratios with a diminishing return as the $\mathrm{w} / \mathrm{h}$ ratios are 
continually increased. The same trend is seen in the maximum piezometric level calculations but, the influence of $w / h$ ratio diminishes quicker than in the average piezometric level. Slope angle also influences the reductions in piezometric levels. For any $\mathrm{w} / \mathrm{h}$ ratio, as the slope angle decreases, the reduction in piezometric levels, both average and maximum, are decreased as well. A diminishing influence on piezometric levels is also seen as the slope angle decreases.

The author then uses the results of the finite element analysis to rationalize an increase in the factor of safety based on the reduction in piezometric levels obtained for different combinations of normalized drain spacing and slope angles. 


\section{CHAPTER 3}

\section{METHODOLOGY}

\subsection{INTRODUCTION}

The overall goal of this research project was to study the effectiveness of a longitudinal drain system. To meet this goal, a methodology was designed to provide a framework that would allow for accurate data collection. This chapter describes the soil selection, experimental apparatus design, testing procedure, data collection procedure, and data reduction methods.

\subsection{SOIL SELECTION}

The criteria for the soil used in the testing was based on two parameters, hydraulic conductivity and reproducibility. A hydraulic conductivity on the order of $10^{-2} \mathrm{~cm} / \mathrm{s}$ was chosen. A soil with this hydraulic conductivity has characteristics allowing quick response to changes in slope angle $(\theta)$ or water depth while keeping the rate of seepage low. Reproducibility of soil was necessary because of the large volume of soil required to perform the testing.

Ohio River sand was chosen because of availability and low cost. In it's natural state, Ohio River sand has a hydraulic conductivity of $1 \mathrm{~cm} / \mathrm{s}$. In order to help adjust the river sand to the desired hydraulic conductivity only the portion passing the \# $20(.85 \mathrm{~mm}$ opening) sieve was used, which has a hydraulic conductivity of $10^{-1} \mathrm{~cm} / \mathrm{s}$. To obtain the desired hydraulic conductivity of $10^{-2} \mathrm{~cm} / \mathrm{s}$, it was necessary to add $5 \%$ kaolinite clay by oven dry weight of the sorted Ohio River sand passing the \#20 (.85 mm opening) sieve. Again, kaolinite was used because of availability and low cost. 


\subsection{EXPERIMENTAL APPARATUS DESIGN}

In order to test the effectiveness of longitudinal drain systems, it was necessary to construct a model to simulate the drainage patterns that occur in the soil mass between parallel longitudinal drains (See Figure 3.1). The flow between the drains is assumed to be symmetric with respect to the centerline between the two parallel drains. Because of this symmetry a no-flow boundary was used simulate the dividing line between the two symmetrical halves (Figure 3.2 and Figure 3.3 (Part A)). The boundary was constructed using a sheet of plexi-glass that ran parallel to the drain and concurrent with the line of symmetry (Section 3.3.1). A constant head or water level was required for the upper boundary to simulate the saturated soil conditions up-stream of the drain system (Figure 3.2 and Figure 3.3 (Part B)). This was achieved by using a perforated dividing plate between the soil mass and the supply tank. The water supply system is covered in detail in Section 3.3.2. The longitudinal drain (Figure 3.2 and Figure 3.3 (Part C)) was simulated using perforated plexi-glass and is discussed in Section 3.3.3 The collection system for the longitudinal drain system is discussed in Section 3.3.4. The terminus of the testing apparatus is discussed in Section 3.3.5. A support mechanism (Figure 3.10) was constructed to allow the slope of the drain-soil system to be adjusted (Section 3.3.6.) to assess the effects of slope angle $(\theta)$. Piezometers were installed to help study the phreatic surface and are covered in Section 3.3.7. 


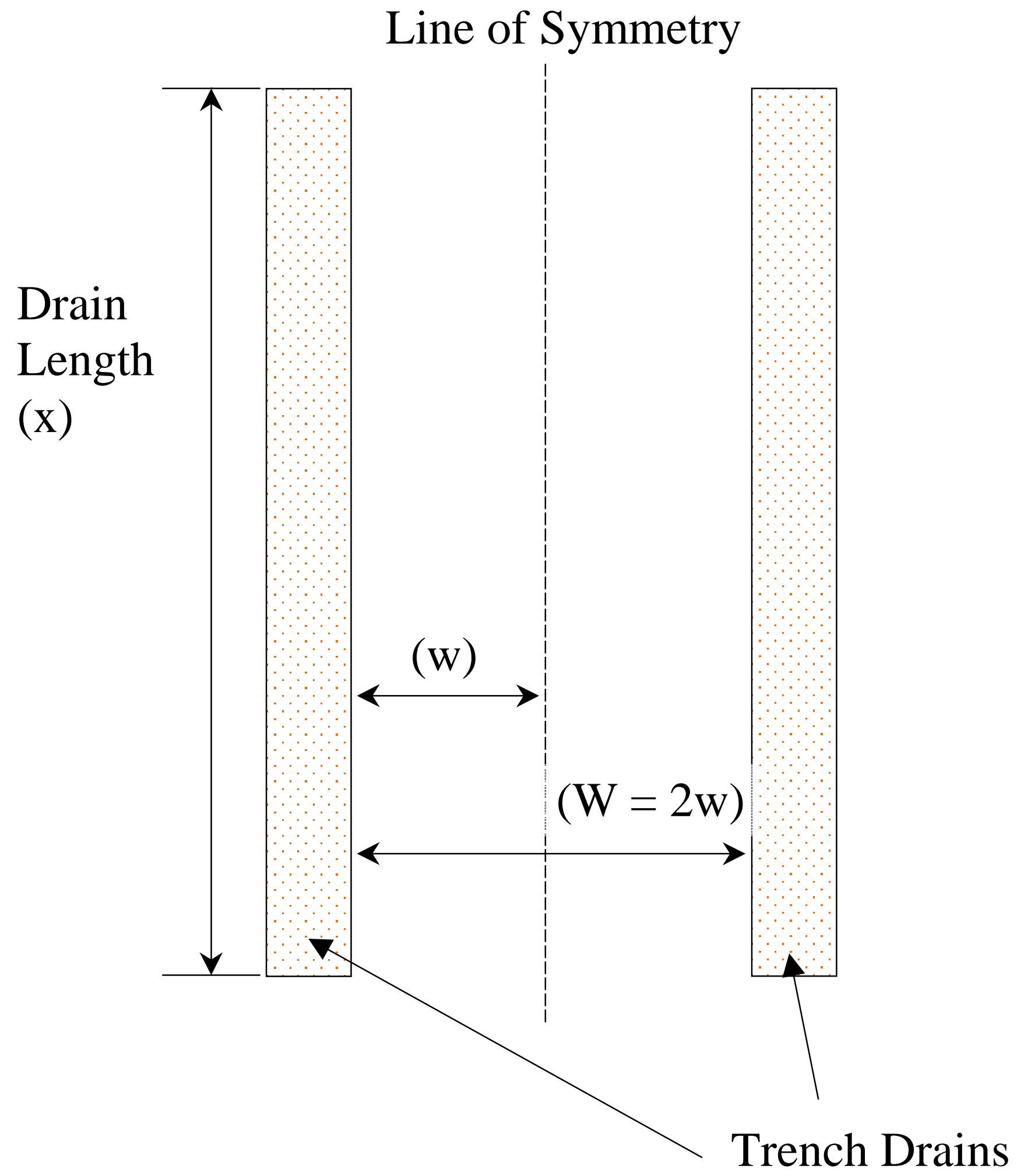

Figure 3.1 Plan View of Two Parallel Longitudinal Drains 


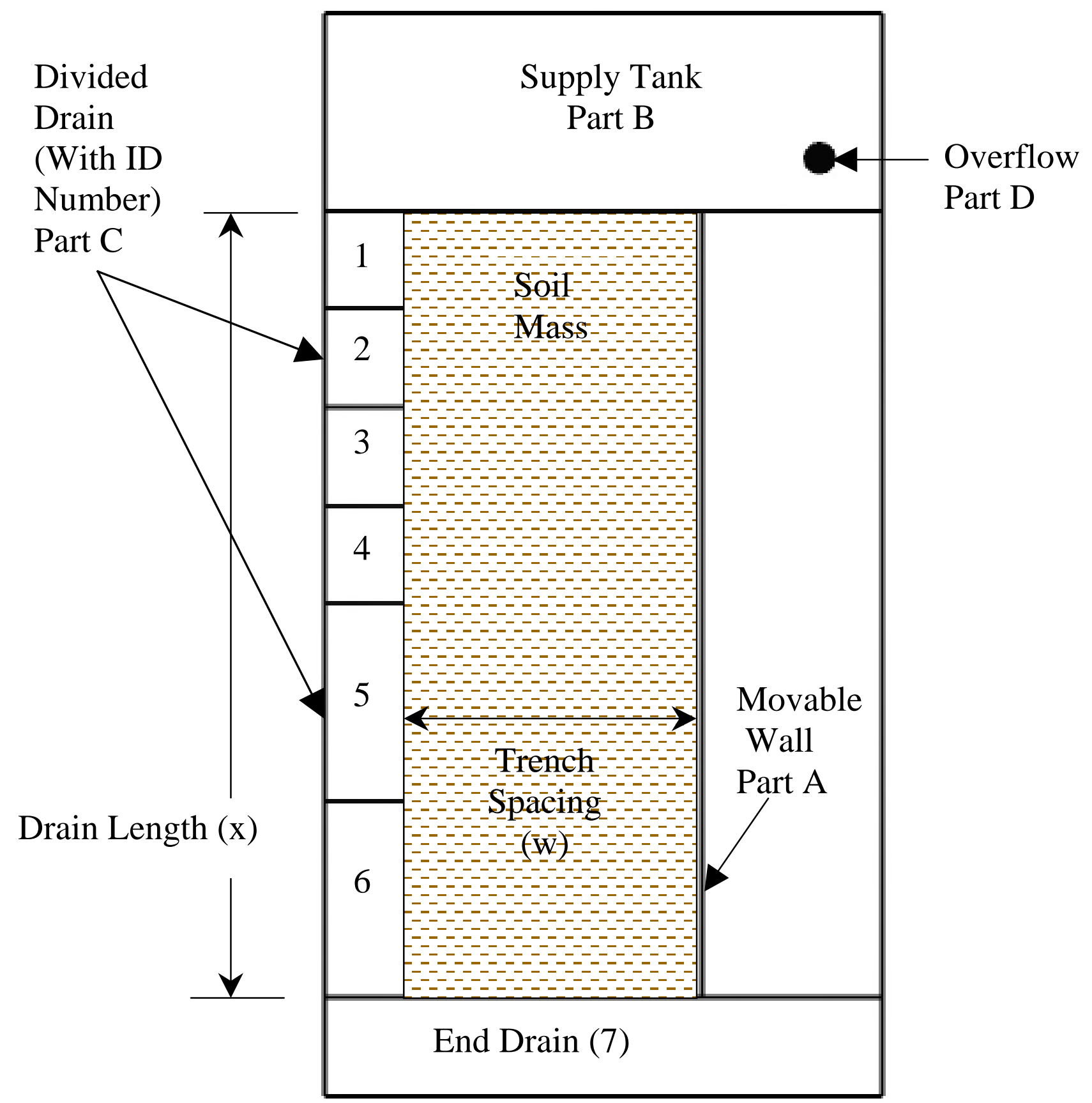

Figure 3.2 Experimental Apparatus 


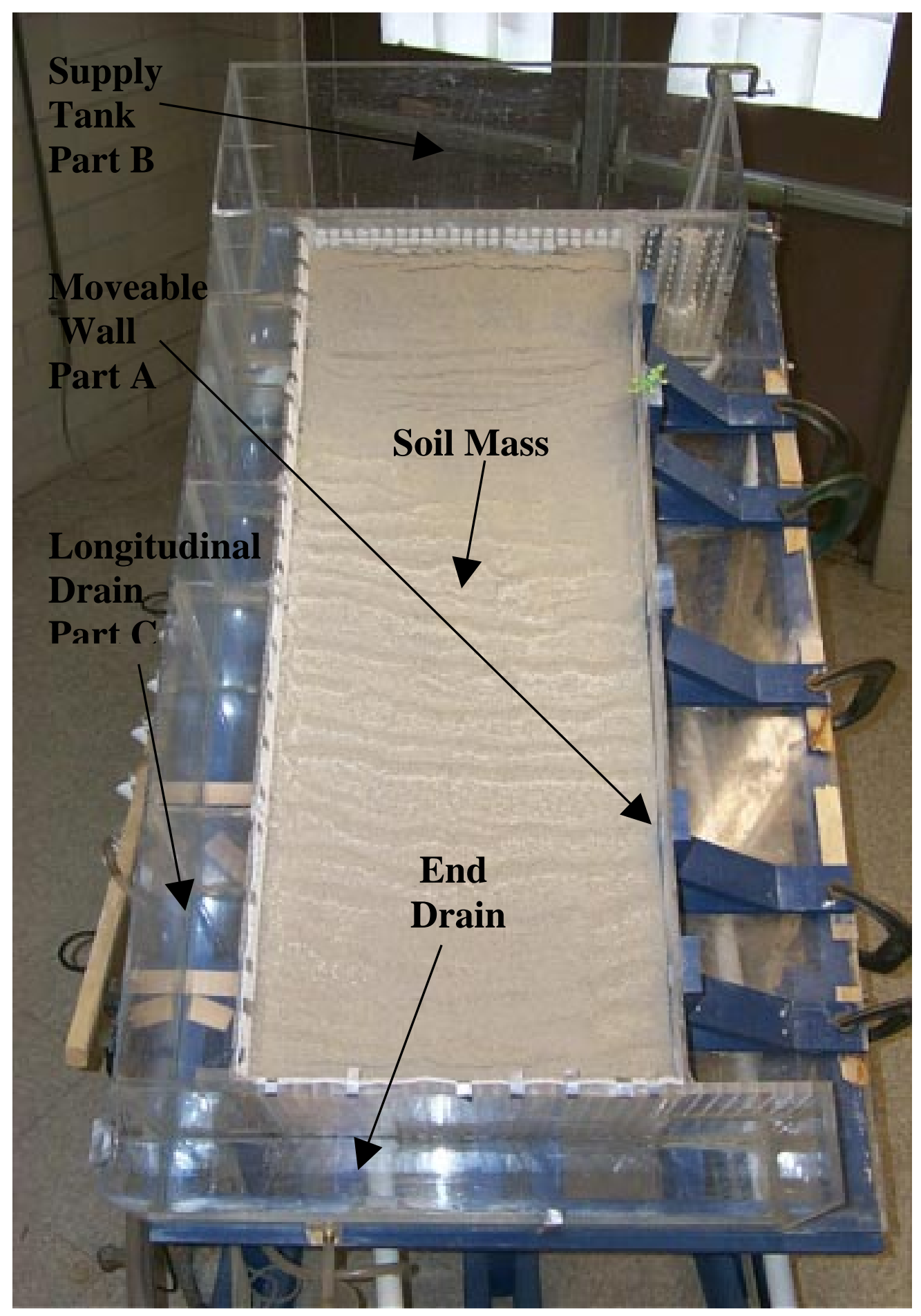

Figure 3.3 A Picture of the Experimental Apparatus 


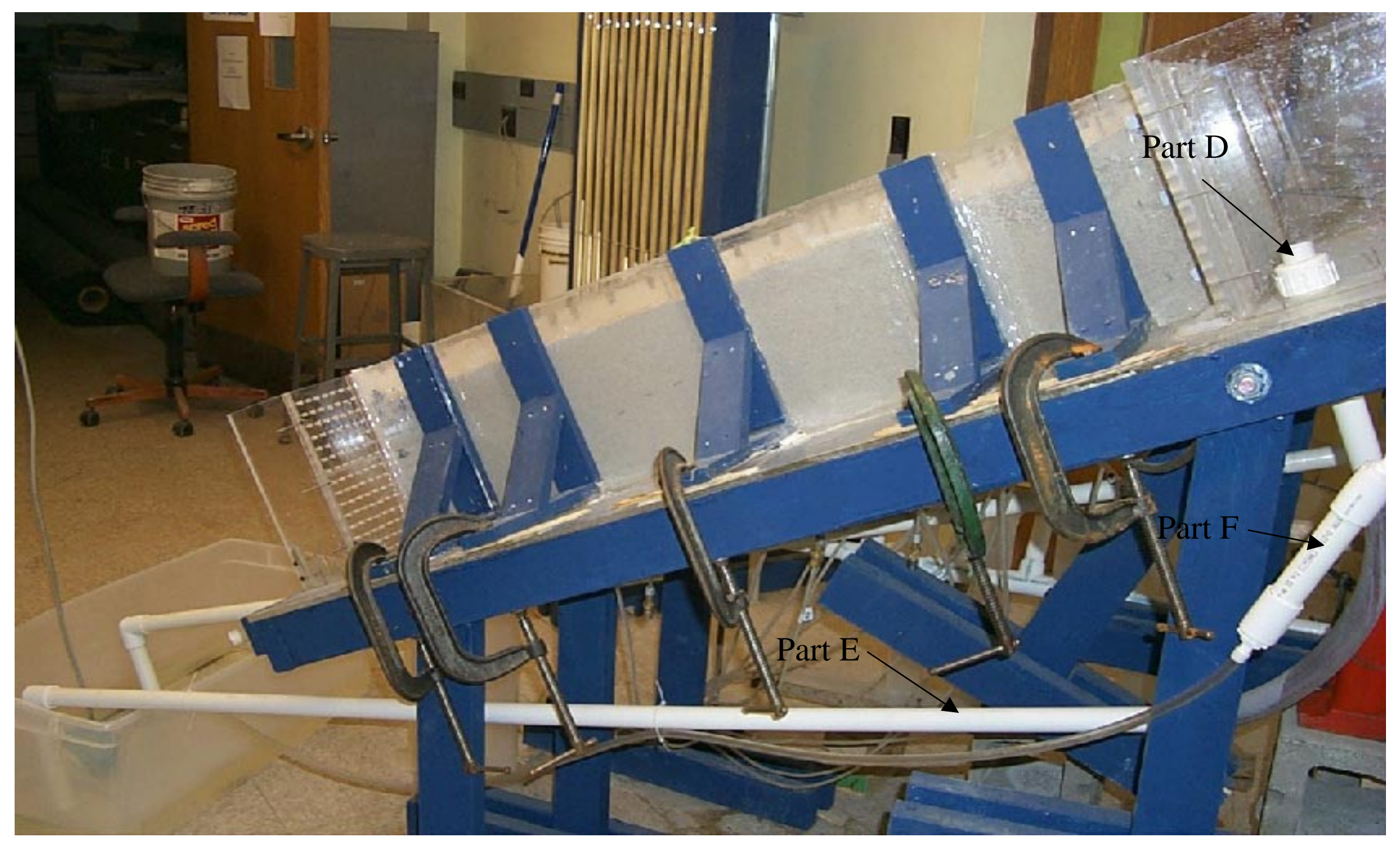

Figure 3.4 A Picture of the Movable Wall 


\subsubsection{Boundary Condition at the Line of Symmetry}

The boundary at the symmetry line was designed to move so that the width (halfwidth) could be varied from 0 to 18 inches $(46 \mathrm{~cm})$. The movable wall consisted of a 4 foot X 1 foot X $1 / 4$ inch $(121 \mathrm{X} 30 \mathrm{X} .64 \mathrm{~cm})$ thick plexi-glass sheet supported by wooden L-brackets on the outside surface as shown in Figure 3.3 and Figure 3.4. The upper boundary was the supply tank and the lower boundary was the terminating drain. In addition to the five C-clamps to hold the L-brackets into place, silicon caulk was used to further immobilize the wall and to provide a watertight seal at the base and sides.

\subsubsection{Water Supply System}

A 1 foot $X 2$ foot $(30 \times 61 \mathrm{~cm})$ tank formed the up-stream end of the soil mass and drain areas (Figure 3.5). Water was supplied to the soil mass by a matrix of holes spaced $3 / 4$ inch $(1.9 \mathrm{~cm})$ apart and $3 / 8$ inch $(.95 \mathrm{~cm})$ in diameter. Half circles were drilled into the base of the plexi-glass wall separating the tank and the soil. These half circles provided free seepage at the beginning of the soil mass. The portion of the supply tank wall intersecting the upper end of the drain did not have any holes. During testing of widths less than 18 inches $(46 \mathrm{~cm})$, the sections of supply tank wall that were not being used to supply water to the soil were covered with plexi-glass pieces and sealed into place. The remaining holes that were used to supply water were covered on the soil side of the tank by $1 / 2$ inch $(1.3 \mathrm{~cm})$ squares of geotextile fabric to prevent soil from washing back into the supply tank. It was observed in preliminary trials that without separate fabric squares for each hole water would travel transversely through the continuous fabric and short circuit into the first drain section. 


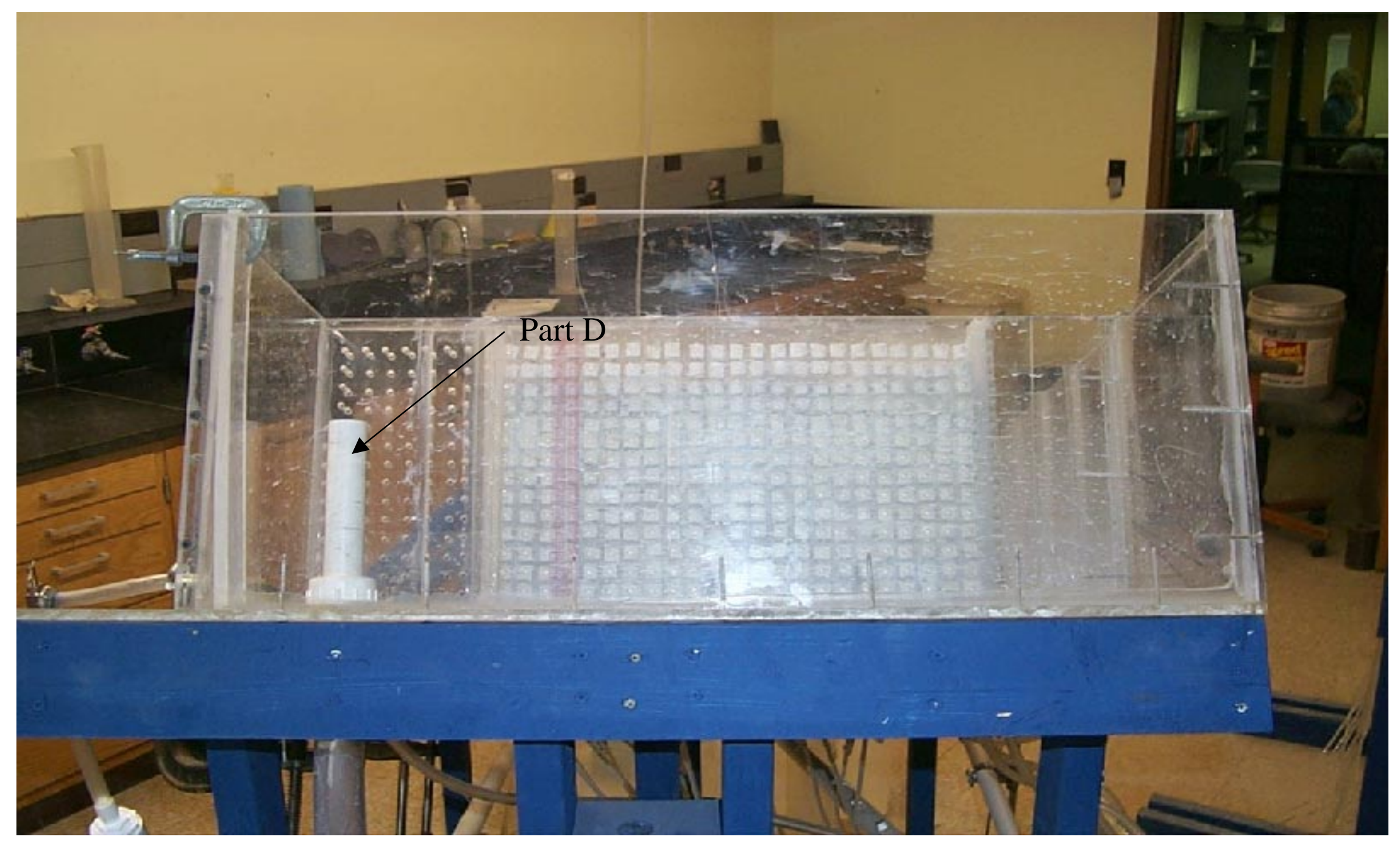

Figure 3.5 A Picture of the Supply Tank 
This water would be in excess of that normally collected by the drain. Therefore, it was necessary to cover each of the holes with a separate piece of fabric to prevent a direct link from the supply tank to the first drain section.

A 1 inch $(2.5 \mathrm{~cm})$ diameter polyvinyl chloride $(\mathrm{PVC})$ pipe and compression fitting mounted into the bottom of the supply tank provided a means to vary the water level in the tank and provide a steady head level once adjusted (Figure 3.2 and Figure 3.5 (Part D)). The 1 inch $(2.5 \mathrm{~cm}) \mathrm{PVC}$ pipe in the bottom of the supply tank was connected to a storage basin via a flexible section of tubing and another strait section of 1 inch $(2.5 \mathrm{~cm})$ PVC pipe (Figure 3.4 (Part E)). Any excess water above that taken by the soil, was recycled through this 1 inch $(2.5 \mathrm{~cm})$ PVC pipe into the storage basin. A centripetal pump and 5/8 inch $(1.6 \mathrm{~cm})$ tubing was used to complete the recycle loop from the storage basin back into the supply tank.

\subsubsection{Segmented Longitudinal Drain}

To determine the efficiency of the drainage system with respect to length, the longitudinal drain was divided into six separately drained sections with the use of $1 / 4$ inch $(.64 \mathrm{~cm})$ thick plexi-glass baffles (Figure 3.2 and Figure 3.6). In anticipation that the first half of the longitudinal drainage system would collect a majority of the seepage, the spacing of the sections was made 6 inches $(15 \mathrm{~cm})$ within the first half and 12 inches (30 $\mathrm{cm}$ ) in the latter half. A permanent drain was used to help facilitate and simplify construction of the experimental apparatus. The drain consisted of a perforated sheet of $1 / 4$ inch $(.64 \mathrm{~cm})$ plexi-glass attached to the face of the baffles to which sections of geotextile were fixed to prevent soil loss into the drain. 


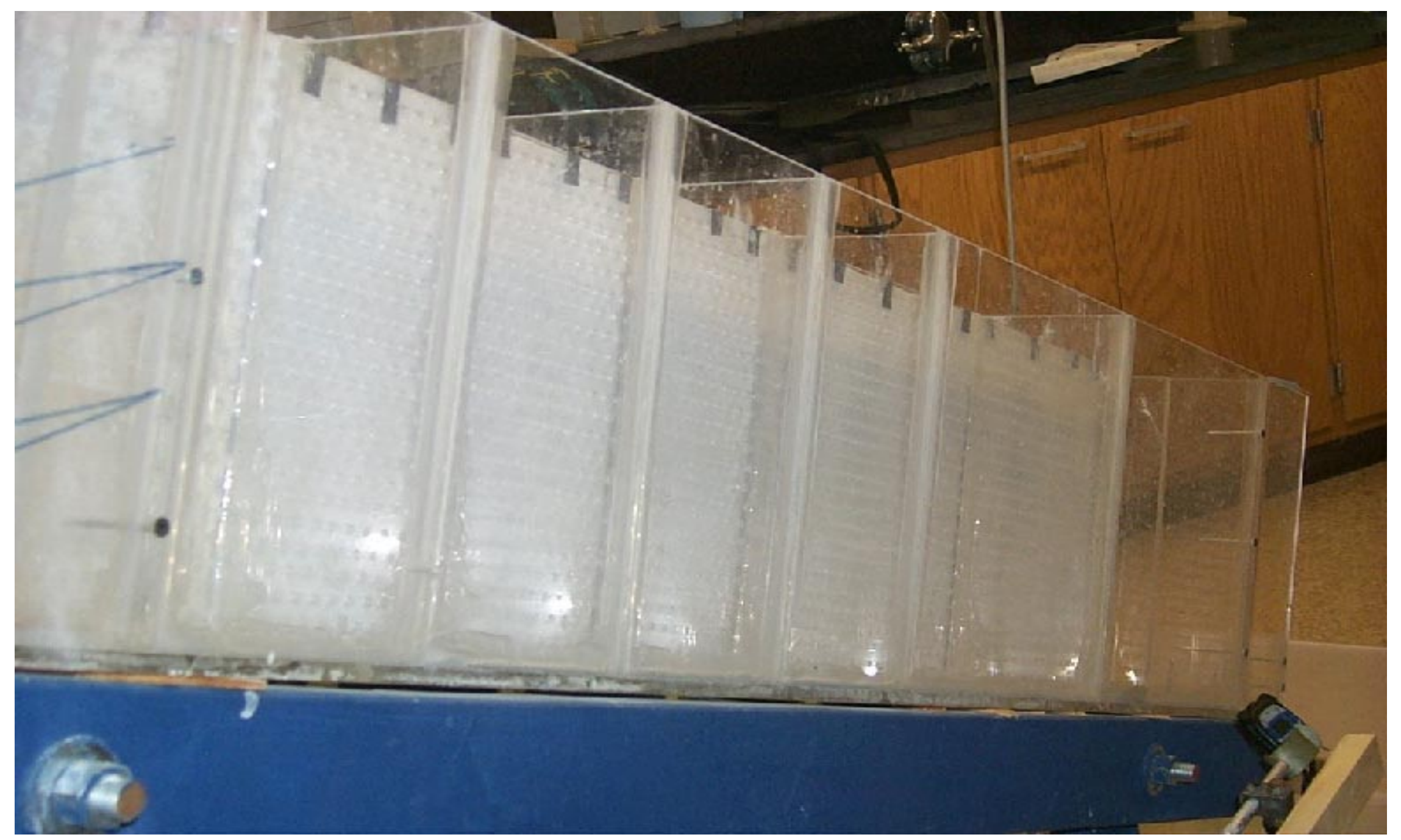

Figure 3.6 A Picture of the Segmented Longitudinal Drain 
Sections of fabric were used instead of a continuous sheet of fabric, because the fabric possesses an in-plane hydraulic conductivity that transmits the collected seepage from one section to another. The $1 / 4$ inch $(.64 \mathrm{~cm})$ gap between the fabric sections was sealed with silicon (Figure 3.7). The silicon sealant provided an effective barrier against lateral transmission of collected seepage.

\subsubsection{Drainage Collection System}

On the downstream side of each drainage chamber a fitting was inserted to which $5 / 8$ inch $(1.6 \mathrm{~cm})$ Tygon tubes were connected to drain the seepage into the collection system. The first five of these drainage tubes was connected to a wooden beam. The beam, with connected tubes, was used to simultaneously start the collection from each of the drainage sections into 1 liter graduated cylinders (Figure 3.8). The remaining two drain sections were started by hand because of the distance separating them from the first five sections. When a graduated cylinder filled up, it was replaced and the collected seepage was recorded for the respective drain section. Between collection periods the drain section tubes were allowed to drain freely into a PVC collection manifold connected to the storage basin (Figure 3.8).

\subsubsection{Terminus}

A perforated sheet of plexi-glass similar to the supply tank face formed the terminus of the apparatus at the opposite end from the supply tank (Figure 3.9). This end of the tank was covered with a continuous sheet of fabric and sealed in place with silicon sealant. The terminus served to collect any remaining seepage from the soil mass. 


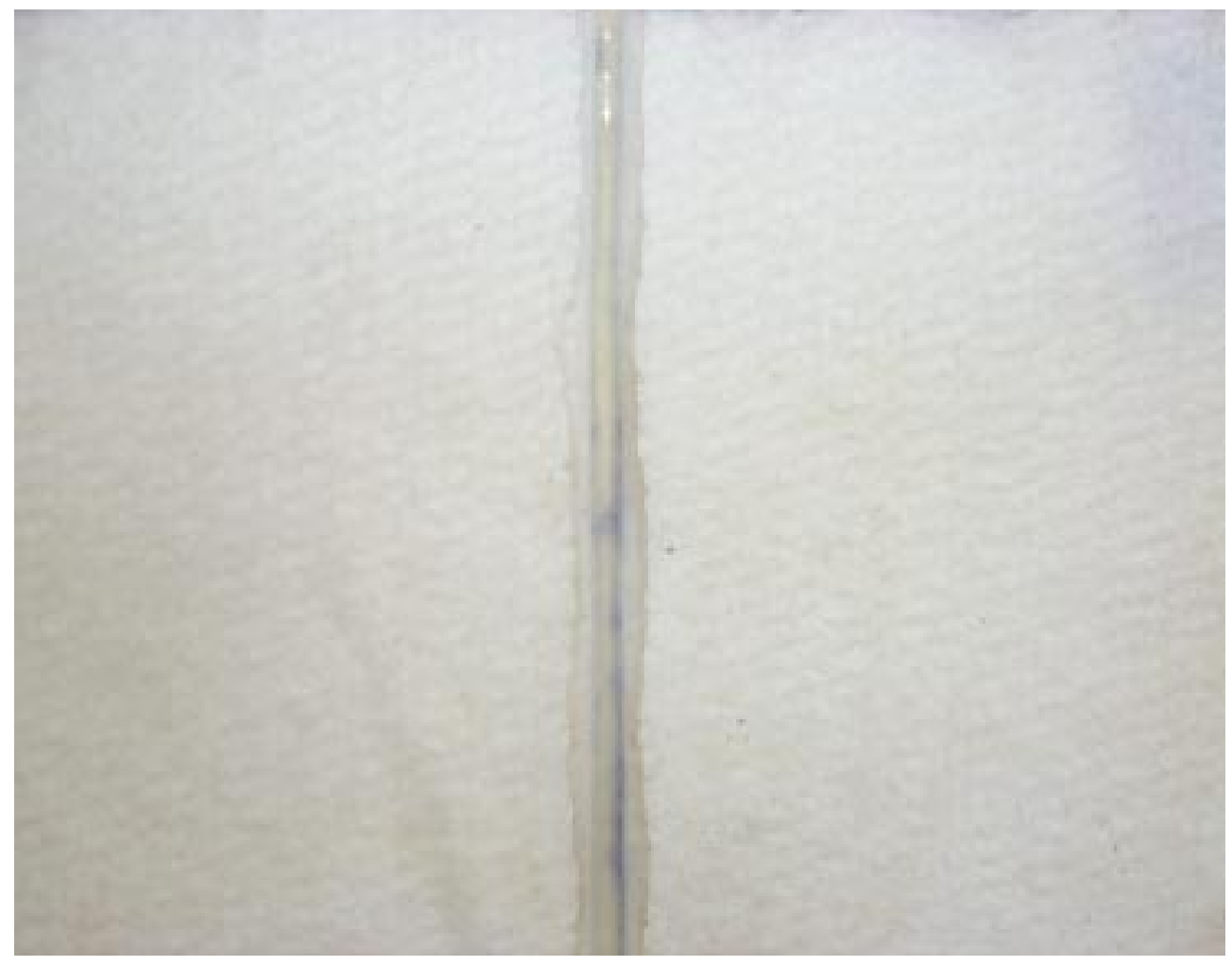

Figure 3.7 A Picture of a Sealed Fabric Joint 


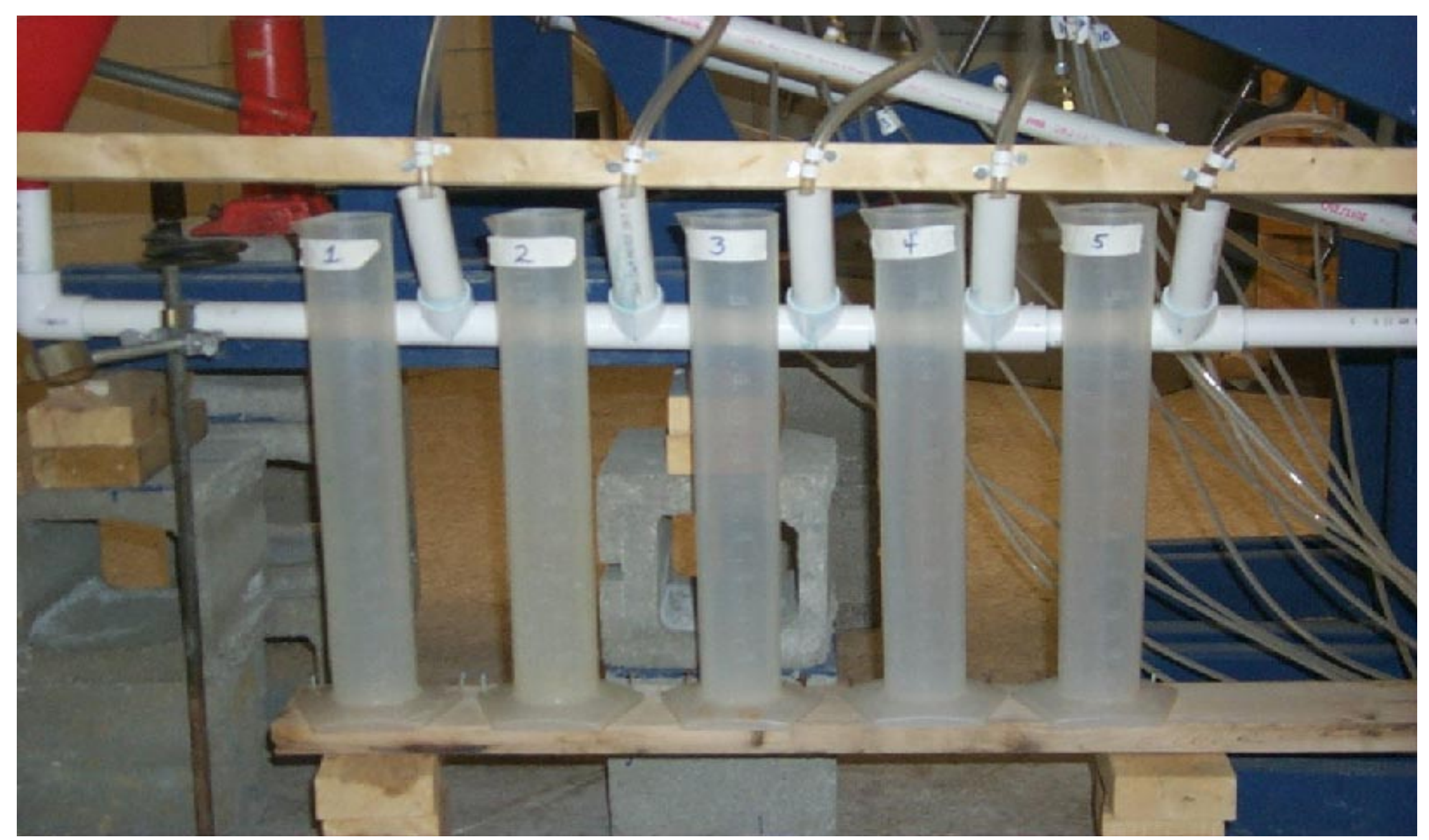

Figure 3.8 A Picture of the Drainage Collection System 


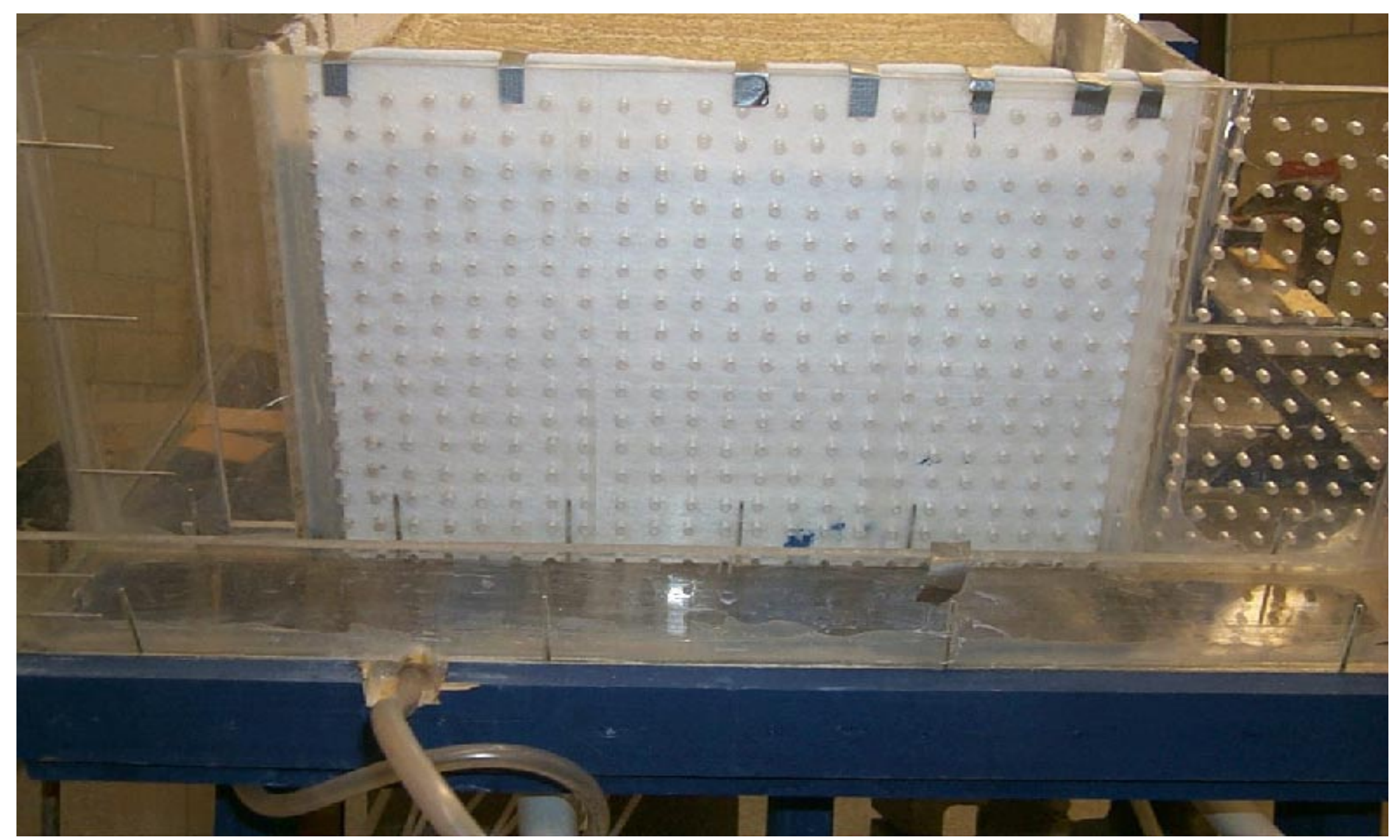

Figure 3.9 A Picture of the Terminus Drain 


\subsubsection{Support Mechanism}

The base of the apparatus was formed by a 3 foot X 5.5 foot X $3 / 4$ inch (91 X 168 $\mathrm{X} 1.9 \mathrm{~cm}$ ) piece of plexi-glass. Each of the permanent plexi-glass sides was attached to the base with acrylic cement and 2 inch $(5 \mathrm{~cm})$ deck screws. A frame made with 2 inch $(5 \mathrm{~cm}) \times 4$ inches $(10 \mathrm{~cm})$ wood beams supported the base, with three legs on each end. The legs were attached via a $3 / 4$ inch $(1.9 \mathrm{~cm})$ screw thread that passed from side to side. Nuts and washers were used to hold the legs to the 2 inch $(5 \mathrm{~cm}) \times 4$ inches $(10 \mathrm{~cm})$ frame. The use of nuts and washers allowed the base angle to be varied while keeping the legs vertical. Adjustment of the base angle was achieved with a hydraulic jack and blocks (Figure 3.10). The base angle was determined by using geometry. The elevations of the leg bolts from the floor and the distance between these bolts was used to calculate the required elevation for the up-stream end bolts for a specific slope angle $(\theta)$. After the hydraulic jack adjusted the height of the end bolt to the desired level, concrete and wooden blocks were used to shore-up the legs. The nuts on the legs were then tightened to further stabilize the apparatus. 


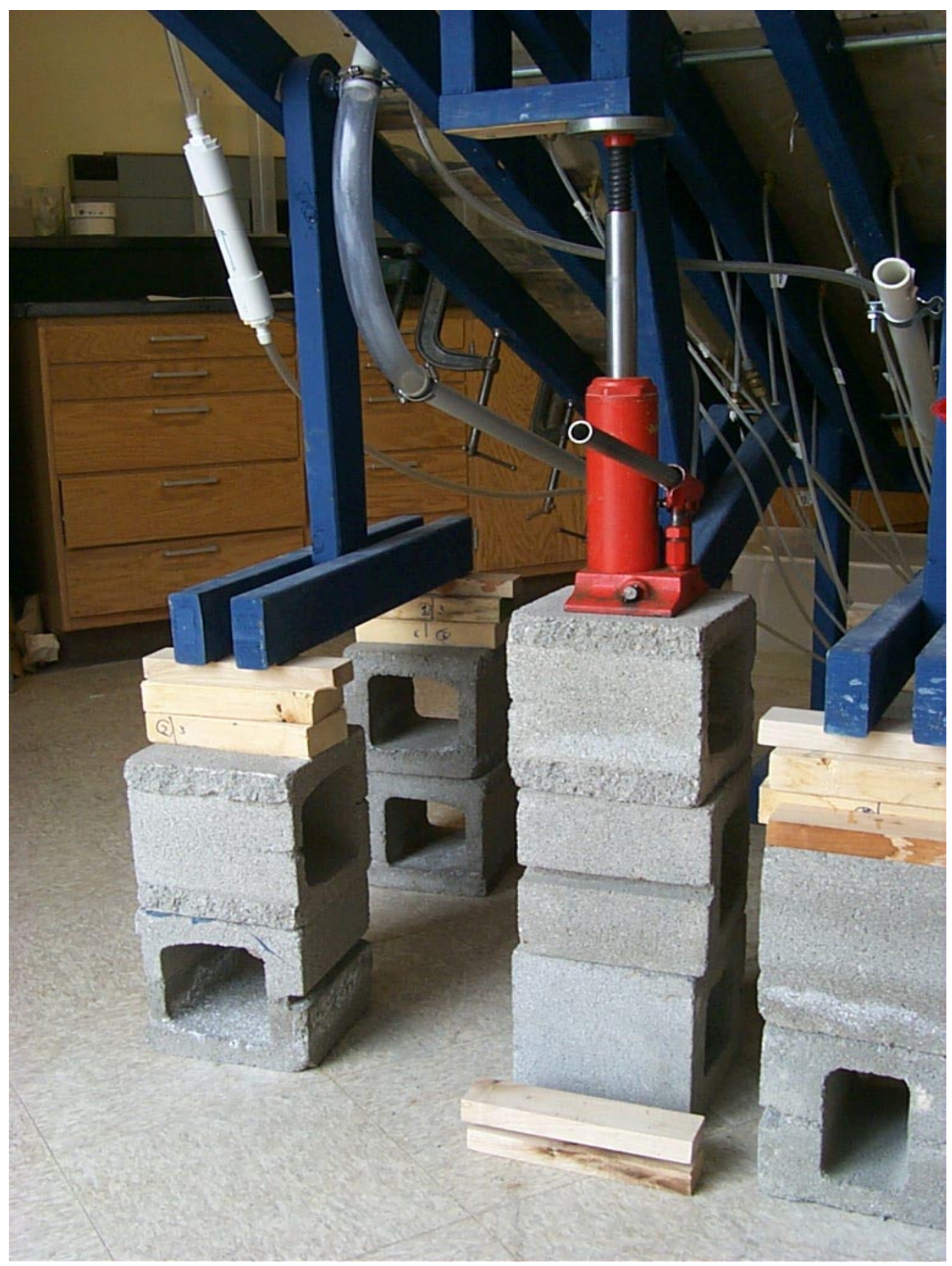

Figure 3.10 A Picture of the Support Mechanism 


\subsubsection{Piezometers}

The plexi-glass base of the experimental apparatus was fitted with piezometric tubes to help define the piezometric surface in the soil mass during testing. Figure 3.11 shows the layout of the piezometers for each of the selected widths. Wire cloth squares were placed at the entrance to the piezometers on the bottom of the experimental apparatus to prevent excessive soil loss into the piezometers. Before any soil was placed into the apparatus the piezometers lines were filled with water. After the soil mass had become saturated and prior to any head readings the piezometers were allowed to drain to remove any air bubbles or soil buildup in the lines. A picture of the apparatus used to measure the piezometric head is shown in Figure 3.12.

\subsubsection{Geotextile Selection}

A geotextile was selected with at least a 10 fold difference in hydraulic conductivity from the soil selected to avoid any build up in head that might have resulted from differences in the hydraulic conductivity of the fabric and soil. The fabric chosen was Terrafix 400R from Terrafix ${ }^{\circledR}$. Fabric specifications can be found in Table 3.1. The various pieces of fabric used during the testing were changed in response to the flow rate through each segment. The $1 / 2$ inch $(1.3 \mathrm{~cm})$ fabric squares that cover the tank end of the apparatus were changed every time a new test was run. This was necessary to ensure that the soil mass was supplied with an unimpeded flow of water. A pump was used to recycle the water from the storage basin back into the supply tank. It was noted in preliminary runs that significant clogging of the $1 / 2$ inch $(1.3 \mathrm{~cm})$ fabric squares could arise if the recycle flow was not filtered to remove dust and silt particles. To eliminate this risk an in-line filter was used (Figure 3.4 (Part F)). 


\section{Piezometric \\ Measurement Locations}

6 inch Width

12 inch Width

18 inch Width

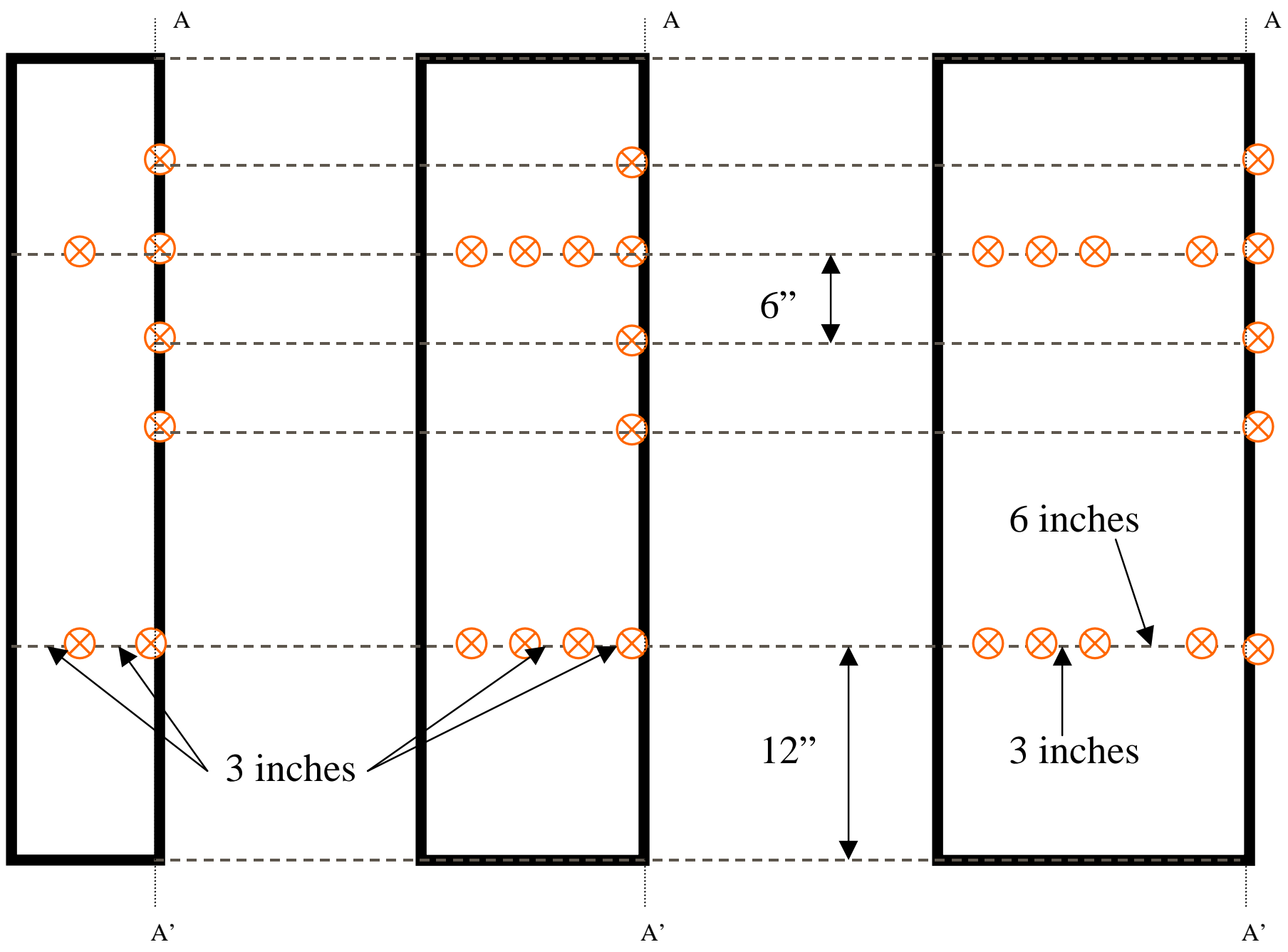

Figure 3.11 Piezometer Locations 


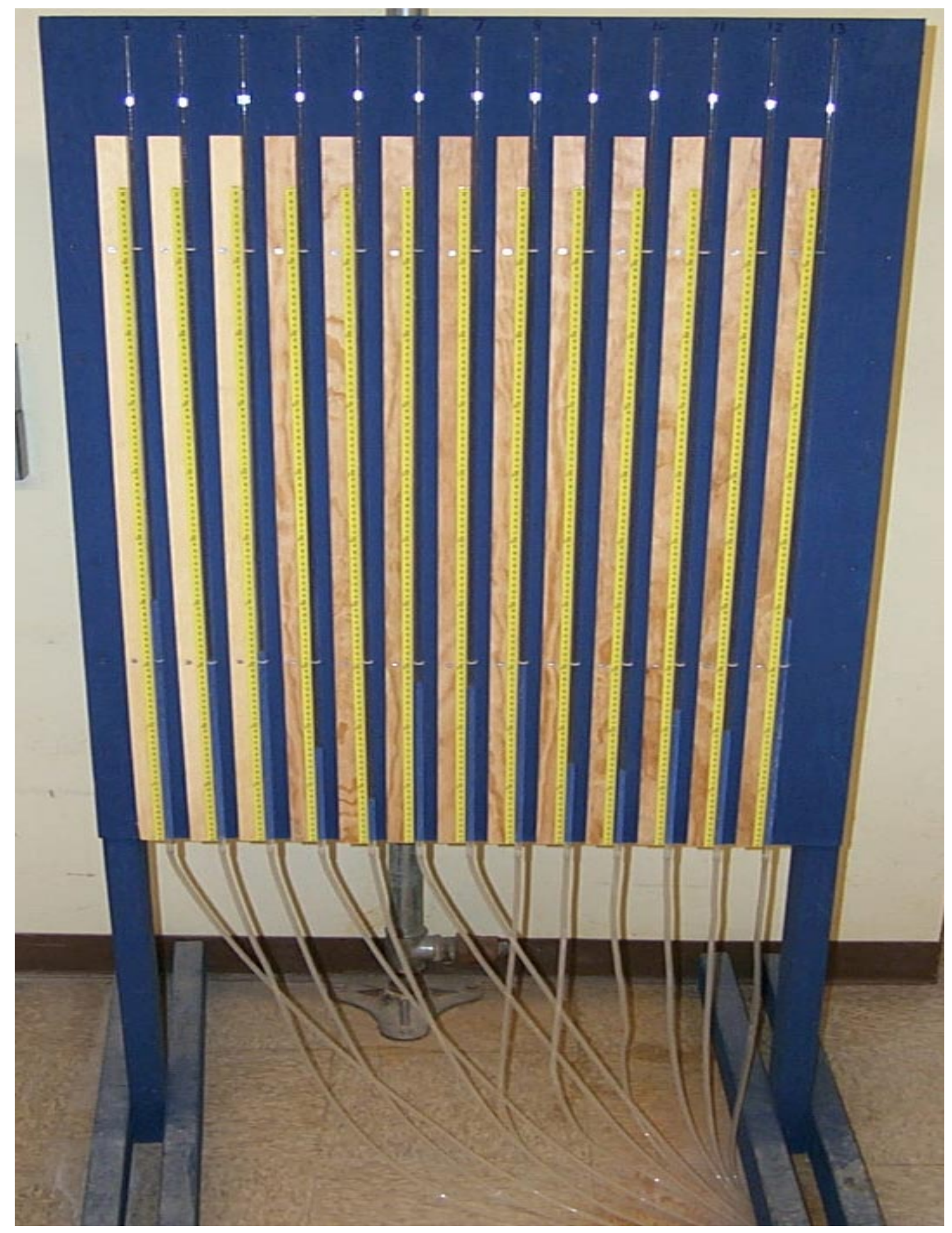

Figure 3.12 Apparatus for Piezometric Head Measurement 
This filter consisted of 8 inches $(20 \mathrm{~cm})$ section of PVC pipe with appropriate fittings into which a "comet" of geosynthetic cloth, 4 inches $(10 \mathrm{~cm}) \times 4$ inches $(10 \mathrm{~cm})$, was inserted with the head of the comet pointing in the up stream direction. The head of the comet was stuffed with four $1 / 2$ inch $(1.3 \mathrm{~cm})$ X 4 inches $(10 \mathrm{~cm})$ strips of geosynthetic cloth. The "comet" was replaced periodically during the testing to ensure adequate flow to the supply tank.

The remaining drain side and terminus end cloth was replaced according to the flow rate through each section. It was discovered, during analysis of preliminary test results, that the high flow rates encountered in the first half of the drain caused significant clogging of the geotextile fabric after repeated tests without replacement. Replacing the fabric in the first half of the drain after every test prevented a consistent reduction of flow into these drain sections. All of the fabric was changed every other test as a precaution. Table 3.1 Minimum Average Roll Values for Terrafix 400R

\begin{tabular}{|c|c|}
\hline Parameter & Value \\
\hline E.O.S $(\mu \mathrm{m})$ & 50 to 150 \\
\hline Hydraulic Conductivity k $(\mathrm{cm} / \mathrm{s})$ & $2.8 \times 10^{-1}$ \\
\hline
\end{tabular}

\subsection{SOIL MIXING}

After the composition of the soil was determined, large scale mixing was begun. The size of the batch varied as the width of the apparatus was increased. Every 6 inches $(15 \mathrm{~cm})$ of width in the 4 foot $(122 \mathrm{~cm})$ long testing apparatus was equal to 1.7 cubic feet $\left(.05 \mathrm{~m}^{3}\right)$ of soil.

The Ohio River sand was spread out in large trays and allowed to air dry. The air-dried sand was then seperated on the \# 20 (.85 mm opening) sieve. The minus \# 20 (.85 mm opening) fraction was saved and stockpiled. After sufficient sand was 
accumulated, batches of sand were mixed with a $5 \%$ by oven-dry weight with kaolinite clay. Due to previous moisture, the clay hardened and required milling to provide a powder that was easy to mix. Samples were taken from the milled clay stock and the airdried sand stock to determine the moisture content. The weights of the two materials were then adjusted to achieve a 5\% oven-dry weight mixture. The individual batches were then thoroughly mixed to provide a homogeneous soil. Two separate batches were mixed to allow one to dry while the other was being used. As the width of the apparatus was increased more sand was mixed in the aforementioned manner and blended with the existing soil.

\subsection{SOIL CHARACTERISTICS.}

Composite samples were taken during the soil placement phase for each of the setups. To ensure the soil used during the testing did not change in character, the samples collected were analyzed for hydraulic conductivity according to ASTM standard D 5084 -90 "Standard Test Method for Permeability of Granular Soils”,grain size according to ASTM standard D 422 -63 "Standard Method for Particle-Size Analysis of Soil” and specific gravity according to ASTM standard D 854 -92 "Standard Test Method for Specific Gravity of Soils."

\subsubsection{Hydraulic Conductivity}

The hydraulic conductivity was measured by using a constant head test. The soil was placed in either a 3 inch $(8 \mathrm{~cm})$ or 4 inch $(10 \mathrm{~cm})$ diameter by 3 foot $(91 \mathrm{~cm})$ high testing cylinder (the difference in diameters is a consequence of using available materials to construct the constant head devices) using the same dry placement method used in the inplane drainage setup. Dry placement was achieved by using a 5/8 inch $(1.6 \mathrm{~cm})$ Tygon 
tube connected to a funnel. The plastic tube extended to the bottom of testing cylinder. The soil was then continuously poured into the funnel until the desired depth of 12 inch $(30 \mathrm{~cm})$ was achieved. For each of the hydraulic conductivity tests a gradient of approximately 2 was used, 12 inches $(30 \mathrm{~cm})$ of soil and 24 inches $(60 \mathrm{~cm})$ of head. The base of the tube was covered by \# 20 (.85 mm opening) mesh screen and a circle of geosynthetic fabric to prevent soil loss. The soil was then saturated from the top. The sample was allowed to saturate for several hours before readings were taken. Readings were then taken at 24-hour intervals until the calculated hydraulic conductivity stabilized. The amount of water collected within a given time was used to calculate the hydraulic conductivity using Darcy's law as shown below.

$$
k=\frac{q}{i A} \ldots \ldots \ldots \ldots \ldots \ldots . . . . .1 .1
$$

Where:

$$
\begin{array}{ll}
\mathrm{q}= & \text { Flow rate of water through the soil specimen. }\left(\mathrm{ft}^{3} / \mathrm{s} \mathrm{or} \mathrm{cm}^{3} / \mathrm{s}\right) . \\
\mathrm{i}= & \text { Hydraulic gradient }(\mathrm{ft} / \mathrm{ft} \text { or } \mathrm{cm} / \mathrm{cm}) \\
\mathrm{A}= & \text { Cross sectional area of the soil specimen }\left(\mathrm{ft}^{2} \mathrm{or} \mathrm{cm}^{2}\right) \\
\mathrm{k}= & \text { hydraulic conductivity }(\mathrm{ft} / \mathrm{s} \text { or } \mathrm{cm} / \mathrm{s})
\end{array}
$$

The hydraulic conductivity was determined at different times until a stable value was recorded.

\subsubsection{Grain Size Analysis}

Grain size analysis was used to determine the range of particle sizes in the soil. The results from grain size analysis can be used to estimate the engineering behavior of a soil. The grain size analysis of the soil used in the testing was completed following ASTM standard D 422 -63 "Standard Test Method for Particle-Size Analysis of Soils." 
Washing the soil on the \# 200 (.075 mm opening) sieve began the gradation of the samples. The washings were allowed to settle and then decanted. The course fraction and the fine fraction were then oven dried. The course fraction, consisting of the plus \#200 (.075 mm opening) sieve, was sieved according to ASTM standard D 422 -63. The grain size distribution of the fine fraction, minus \#200 (.075 mm opening) sieve, was determined through hydrometer analysis according to ASTM standard D $422-63$.

\subsubsection{Specific Gravity}

In addition to the hydraulic conductivity and grain size distribution tests, specific gravity of the soil solids was determined to further describe the soil. The specific gravity is defined as the unit weight of soil solids to the unit weight of water. The specific gravity of the soil solids was determined by using ASTM Standard D $854-92$.

\subsection{PLACEMENT OF SOIL}

Dry placement of the soil into the testing apparatus was used to ensure isotropic hydraulic conductivity. This placement method minimizes the chance that horizontal channels would occur at the interface of the compaction lifts and cause greater mobility of the seepage in the horizontal direction. The apparatus was kept in the level position during the placement.

A long funnel, a bucket, and a stopcock were used to place the air-dried soil (Figure 3.13). The stopcock was first placed into the bucket to prevent the soil from spilling onto the floor. Next the bucket was filled with dry soil and lifted into the soil chamber of the testing apparatus. With a distance of 4 inches $(10 \mathrm{~cm})$ being kept between the funnel end and the placed soil, the stopcock was removed. The soil was placed in even longitudinal strips so that the thickness of the soil remained constant as placement proceeded. 


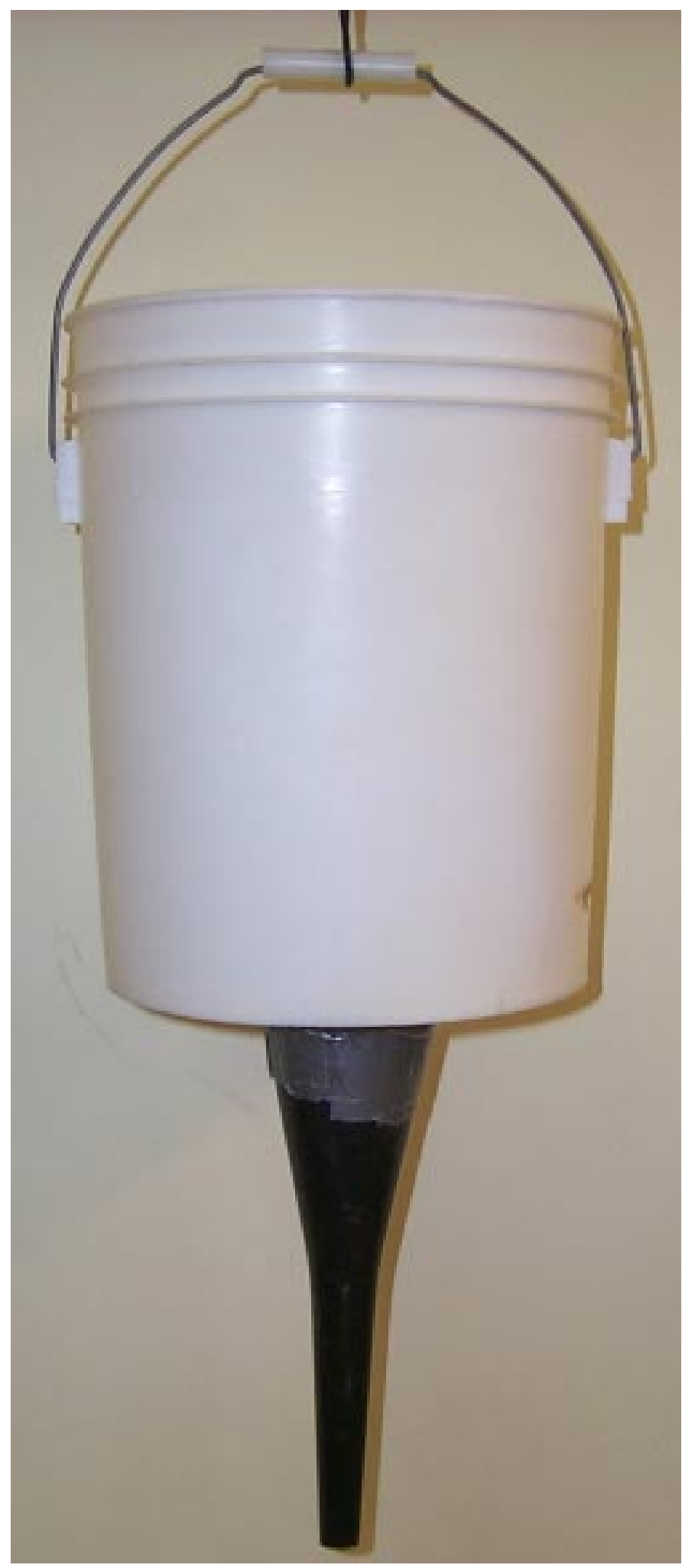

Figure 3.13 A Picture of Dry Sand Placement Apparatus 
After the required soil thickness was achieved, taking into consideration the effects of saturation induced compaction, a trowel was used to smooth the surface. It must be noted that the troweling did not occur until after all of the dry soil was placed.

\subsection{INITIAL SATURATION PERIOD}

After the soil was placed, and the apparatus was still in the level position, the saturation of the now dry soil mass was begun. The water pump supplying the upper tank was turned on and allowed to fill to a maximum depth of 8 inches $(20 \mathrm{~cm})$. The soil mass was allowed to saturate for three days. During this time readings were taken of both piezometric head and volume of water collected from each of the drain sections over ten minutes. This information was used to ensure that the seepage patterns had stabilized and were at steady state conditions.

\subsection{DATA COLLECTION}

After the initial saturation period, with the water height at 8 inches $(20 \mathrm{~cm})$, one final reading was taken of piezometric head and collected volumes from the drain sections. If the data indicated steady state conditions, the water level in the supply chamber was dropped to 6 inches $(15 \mathrm{~cm})$. Through preliminary observations it was determined that 30 minutes was necessary to regain steady state conditions with the new water level. Readings were taken after thirty minutes and recorded. Thirty minutes were again allowed to elapse before a second reading was taken at the given water level. The two sets of readings were compared to determine if steady state conditions had been reached. If the conditions were steady, the water level was dropped to 4 inches $(10 \mathrm{~cm})$ and the procedure repeated. Once the readings at the 4 inches $(10 \mathrm{~cm})$ level were taken, the angle of the table was increased to 4:1 (4 horizontal to 1 vertical), and the water level 
in the soil was returned to 8 inches $(20 \mathrm{~cm})$ in depth. One hour was given so the flow patterns in the soil could be reestablished. Readings of head and volumes collected were recorded in the same manner as previously stated for all three of the water depths.

Similarly the angle of the apparatus was varied from level, 4:1, 3:1, and 2:1.

Each of the readings taken was recorded in a uniform fashion. Each set of readings was given an ID number consisting of the width of the apparatus, the depth of the water, the slope angle $(\theta)$, and the set-up number all separated by dashes. The number was then given an ending of . $\mathrm{x}$ where $\mathrm{x}$ is the number of the observation. The first observation was recorded as “.0." An example of this would be 12-6-3-15.1. The width would be 12 inches $(30 \mathrm{~cm})$. The depth of water would be 6 inches $(15 \mathrm{~cm})$. The slope angle $(\theta)$ would be $3: 1$. The setup number would be 15 . And the observation number would be 1 or the second of two observations. All of this information was entered into a Microsoft Access database.

\subsection{EXPERIMENTAL PARAMETERS}

The following notation is used to describe the experimental parameters used in this study.

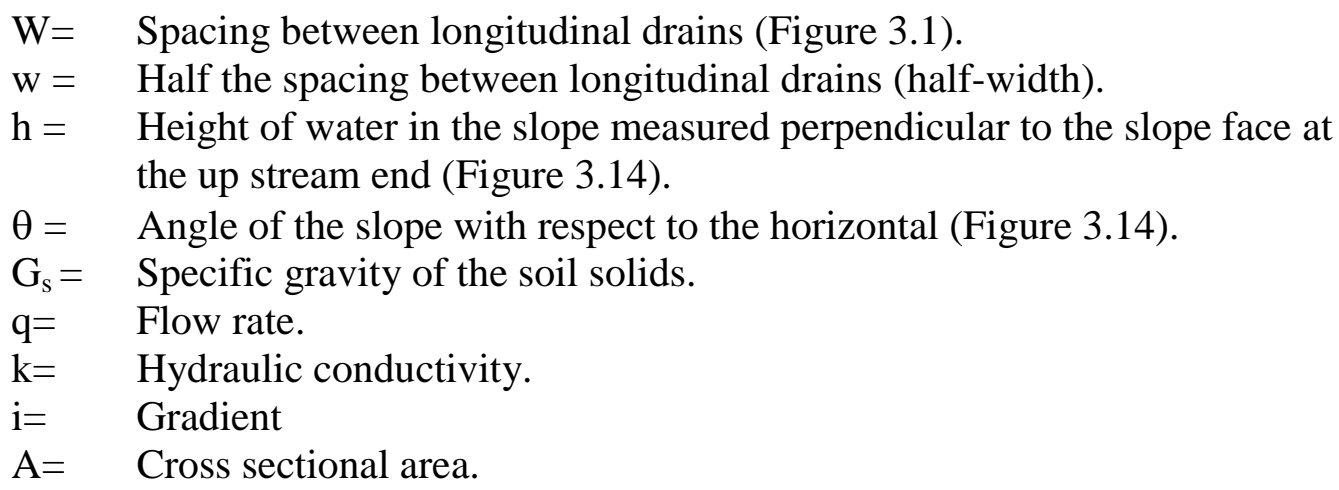




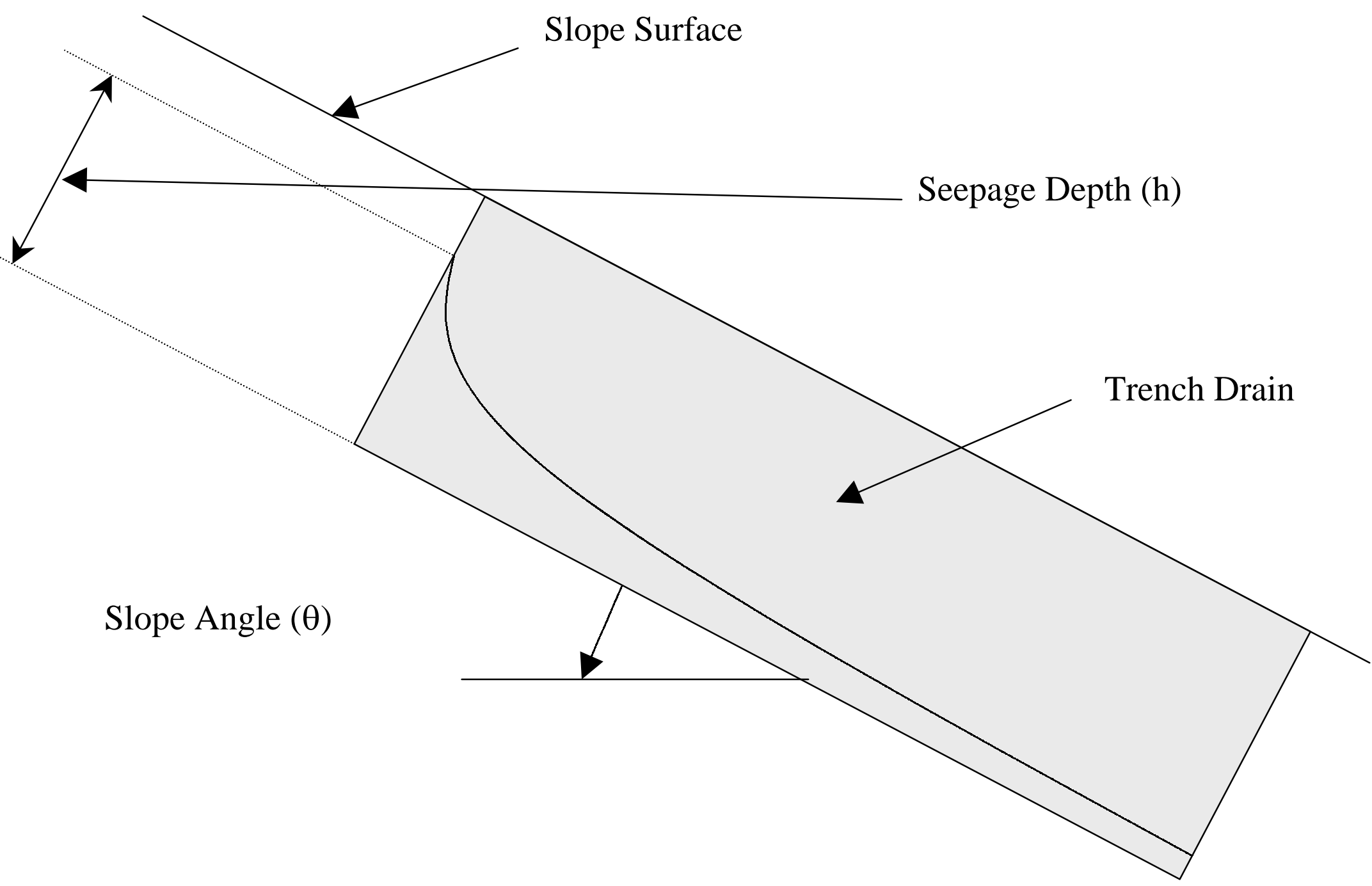

Figure 3.14 Typical Cross-Section of a Longitudinal Trench Drain. 


\section{CHAPTER 4}

\section{RESULTS AND DISCUSSION}

\subsection{INTRODUTION}

This study was undertaken to determine the performance of a longitudinal drain system that can be used to capture seepage water in an earth slope in order to improve stability. A physical model of the drain system was constructed as described in Chapter 3 of this report. The following assumptions were made in this study:

1. Longitudinal trench drains are placed parallel to each other and in the direction of maximum slope angle $(\theta)$.

2. The flow pattern between parallel trench drains is symmetric with respect to the centerline between the two drains (Figure 3.1).

The model was tested at different combinations of slope angle $(\theta)$, seepage depth (h) and trench spacing (w). Slope angles used were: Zero, 4:1, 3:1 and 2:1 with respect to the horizontal (Ratio of horizontal to vertical distance). The seepage depth was varied as 4 inches $(10 \mathrm{~cm}), 6$ inches $(15 \mathrm{~cm})$ and 8 inches $(20 \mathrm{~cm})$. The trench spacing was measured as half the distance from the centerlines of the drains (Figure 3.1) Trench spacing of 6 inches $(15 \mathrm{~cm}), 12$ inches $(30 \mathrm{~cm})$ and 18 inches $(46 \mathrm{~cm})$ were used. Measurements were made of the quantity of seepage collected in each of the segmented trench drain sections. The quantity of seepage that remained in the soil mass after passing the drain section was determined by collecting the seepage from the down stream terminus end of the apparatus. The collection interval was set to ten minutes. The sum of the collected seepage from all of the sections, including the end, was used to calculate the percentages collected in each section $\left(\mathrm{Q}_{\mathrm{i}}\right)$ (Figure 3.2). The percentages represent the portion of the total seepage that was either collected in the drain or remained in the soil 
mass. The individual drainages were then added, starting from the first drain section and moving downstream, to give a cumulative drainage collected at a given distance (x). Graphs of the cumulative drainage versus distance (x) were plotted for various combinations of seepage depth, slope angles, and drain spacing (Appendix C). Bar graphs of the drainage collected at each segment were also produced (Appendix C). The volume of seepage collected in the 10 minute interval was used to calculate flow rates for each of the chambers (Appendix D). Plots of the measured piezometric surface were also made (Appendix E). The influence of each of the independent variables on the percentages collected, flow rates, and piezometric surfaces is discussed in detail in the following sections. The next section of this chapter deals with reproducibility of experimental data.

\subsection{REPRODUCIBILITY OF EXPERIMENTAL DATA}

During testing, measures were taken to ensure that the test results were repeatable. Each testing configuration, consisting of: a trench spacing (w), saturated thickness (h), and slope angle $(\theta)$ was repeated after the soil was removed and replaced. The measurements of the drainage volumes (Appendix A) and piezometric data (Appendix E) were compared to determine variability in the data between similar experiments. A variation of more than $5 \%$ in the percentages collected or the piezometric head was considered excessive. The average difference between two identical tests with different soil placements is about $0.3 \%$, which demonstrates that the measurements are reproducible. 
Three different soil property tests were completed on a sample from each of the six separate tests. The aim of these tests was to determine if the character of the soil was different between tests. The hydraulic conductivity, grain size distribution, and specific gravity of each of the samples were determined. The results of these tests are also shown in Tables 4.1. The grain size distribution graphs are shown in Figure 4.1.

Table 4.1 Comparison of Soil Properties

\begin{tabular}{|l|l|l|}
\hline Individual Test Setup & $\mathrm{k}(\mathrm{cm} / \mathrm{s})$ & $\mathrm{G}_{\mathrm{s}}$ \\
\hline 6 in Trench Spacing Setup \# 1 & $3.2 \times 10^{-2}$ & 2.685 \\
\hline 6 in Trench Spacing Setup \# 2 & $2.0 \times 10^{-2}$ & 2.675 \\
\hline 12 in Trench Spacing Setup \# 1 & $3.3 \times 10^{-2}$ & 2.683 \\
\hline 12 in Trench Spacing Setup \# 2 & $3.0 \times 10^{-2}$ & 2.685 \\
\hline 18 in Trench Spacing Setup \# 1 & $2.5 \times 10^{-2}$ & 2.665 \\
\hline 18 in Trench Spacing Setup \# 2 & $2.0 \times 10^{-2}$ & 2.684 \\
\hline
\end{tabular}

The results of the constant head tests indicate only a small variation in the magnitude of the hydraulic conductivity $(\mathrm{k})$. This variation may be attributable to the testing method used to determine $(\mathrm{k})$ and therefore may not be indicative of changes in the soil tested. Plots of the calculated hydraulic conductivity (k) versus time may be found in Appendix B. 


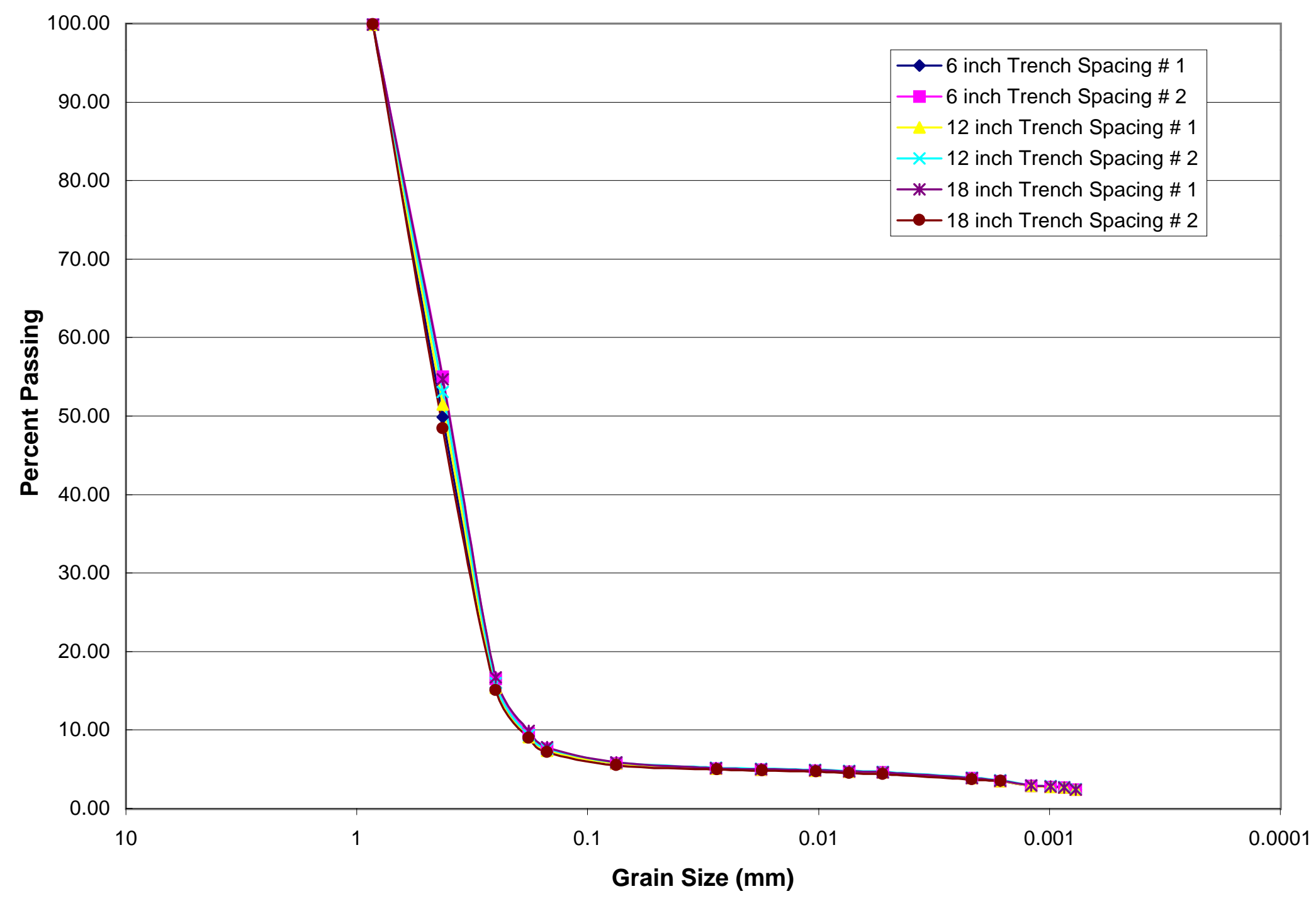

Figure 4.1 Grain Size Distributions 
Grain size distributions for all of the soil samples are shown in Figure 4.1. All of the distributions are grouped tightly together suggesting that the grain size distribution did not change significantly between tests.

The results of the specific gravity test show a small amount of variation. The test for specific gravity is highly susceptible to small errors in the testing procedure and the variation seen in the results are attributable to experimental error. Given this variation, the results from the specific gravity tests show no major differences between individual placements of soil.

\subsection{INFLUENCE OF DRAIN LENGTH (x)}

The influence of drain length $(\mathrm{x})$ on the seepage removal rate (i.e. drainage rate $\mathrm{Q}_{\mathrm{i}}$ ) is shown in Figure 4.2. The removal patterns for all of the combinations tested show the same general trend (Appendix C). For any given drain spacing (w), slope angle $(\theta)$ and seepage depth $(\mathrm{h})$, the first 6 inches $(15 \mathrm{~cm})$ provides the single largest percent removal. The removal achieved by the remaining portion of drain is progressively less as the distance from the start of the drain increases. This trend can be illustrated by examining the two different slopes on the removal curve (Figure 4.2). The initial gradient of the graph at the beginning of the drain, is distinctively steeper than the gradient of the next portion of the curve. The extent of the steep gradient at the beginning of the curve is a function of the three variables: drain spacing, seepage depth, and slope angle. The gradient of the next portion is also a function of the three variables, but is often abruptly stopped at the end of the drain because all of the seepage is not removed from the slope through the drains. 


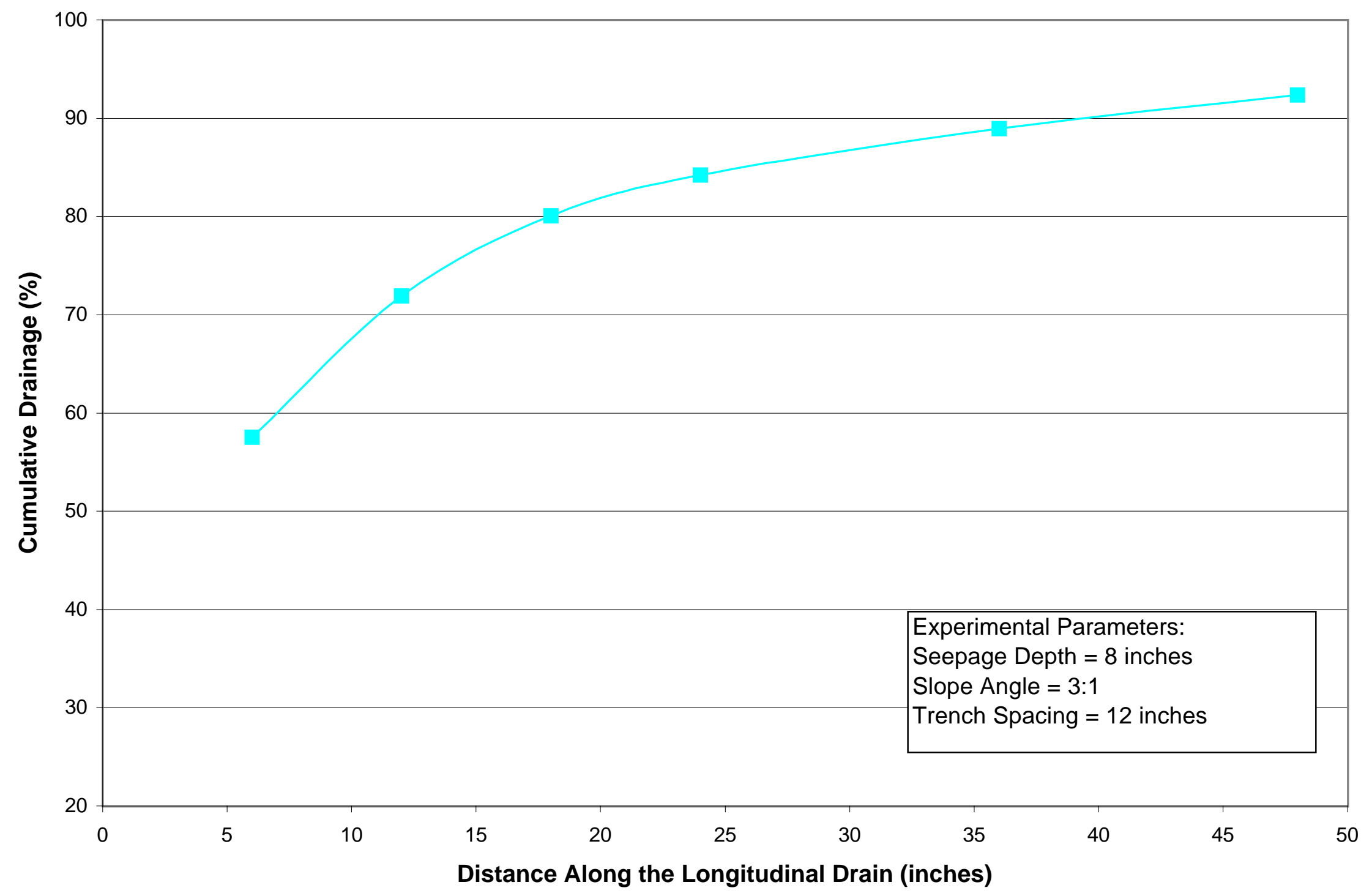

Figure 4.2: Influence of Trench Spacing on Drainage Volume. 
The maximum percent removal in the first 6 inches $(15 \mathrm{~cm})$ of drain length was $80 \%$ when the slope angle was zero, the saturated thickness was 8 inches $(20 \mathrm{~cm})$, and the drain spacing was 6 inches $(15 \mathrm{~cm})$. The minimum percent removed was $25 \%$, when the slope angle was $2: 1$, the saturated thickness was 4 inches $(10 \mathrm{~cm})$, and the drain spacing was 18 inches $(46 \mathrm{~cm})$.

For all slope angles greater than zero, the length of drain used, 48 inches (122 $\mathrm{cm})$, did not remove all (>99\%) of the seepage from the slope. When the drain spacing was 18 inches $(46 \mathrm{~cm})$ and the slope was zero, the drain also did not remove all of the seepage. The portion of seepage that was not removed from the slope in the 48-inch (122 $\mathrm{cm})$ length, increased with the slope angle.

\subsection{INFLUENCE OF SLOPE ANGLE ( $\theta)$}

The influence of slope angle $(\theta)$ on the removal rate can be seen in Figure 4.3 and Figure 4.4 These two graphs are for a test with 8 inches $(20 \mathrm{~cm})$ of seepage depth $(\mathrm{h})$ and 6 inches $(15 \mathrm{~cm})$ of drain spacing $(w)$. The slope angle is varied from zero to 2:1. Figure 4.3 is a plot of the cumulative seepage (drainage volume) versus drainage length (x).

Figure 4.4 is a plot of the seepage collected in each drain segment. This test configuration is typical of all the combinations tested and will be used to demonstrate trends seen in all of the tests.

As the slope angle is increased for a given drain spacing and seepage depth, the removal rate in the first chamber (i.e. drain section within the first 6 inches $(15 \mathrm{~cm})$ from the start) is reduced. The removal rate in other chambers (i.e. $>6$ inches $(15 \mathrm{~cm}))$ increases with the slope angle. The magnitude of this difference as the slope angle changes is the greatest in the first 6 inches $(15 \mathrm{~cm})$ of drain length $(\mathrm{x})$. 


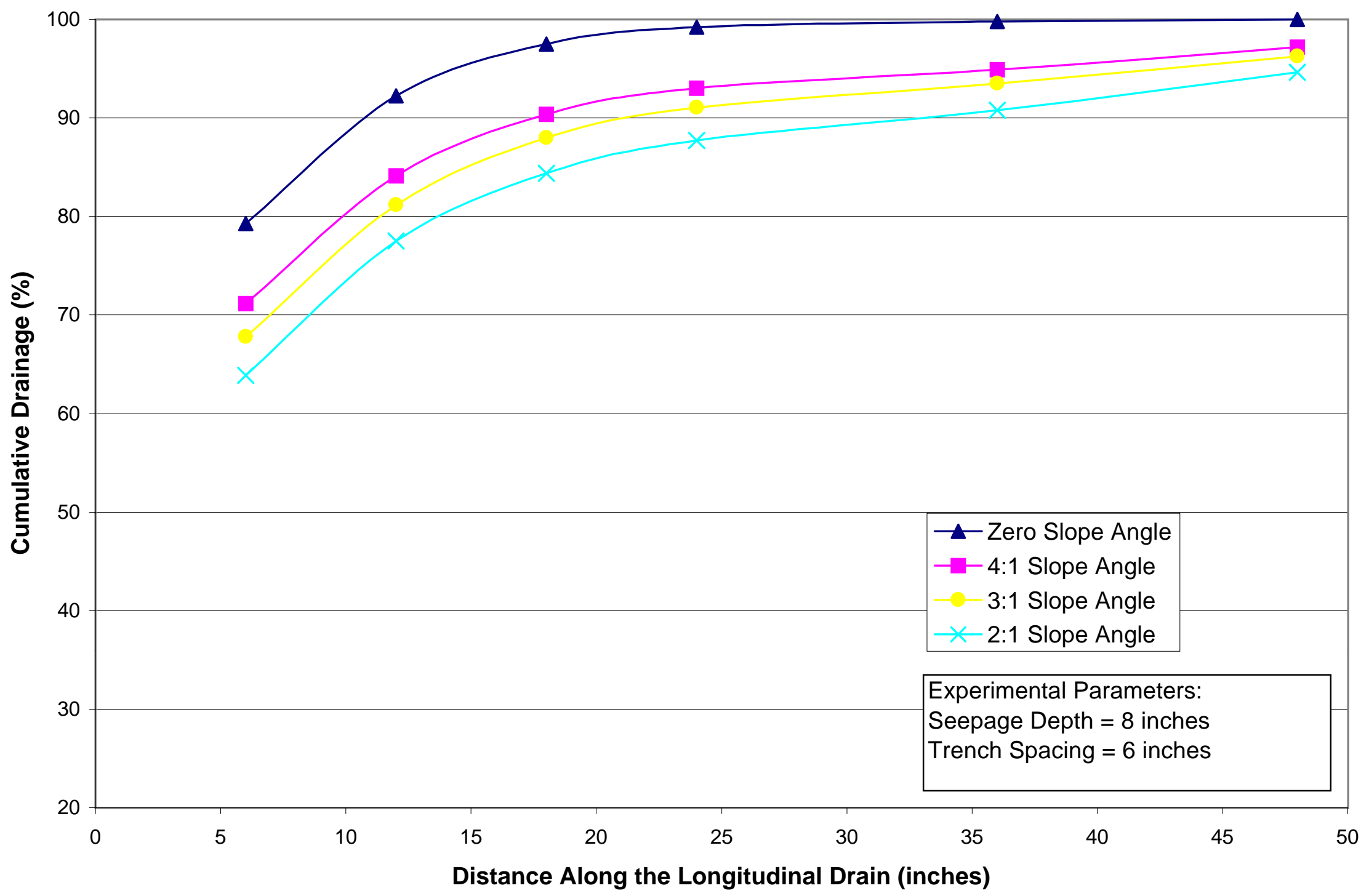

Figure 4.3: Influence of Slope Angle on Drainge Volume. 


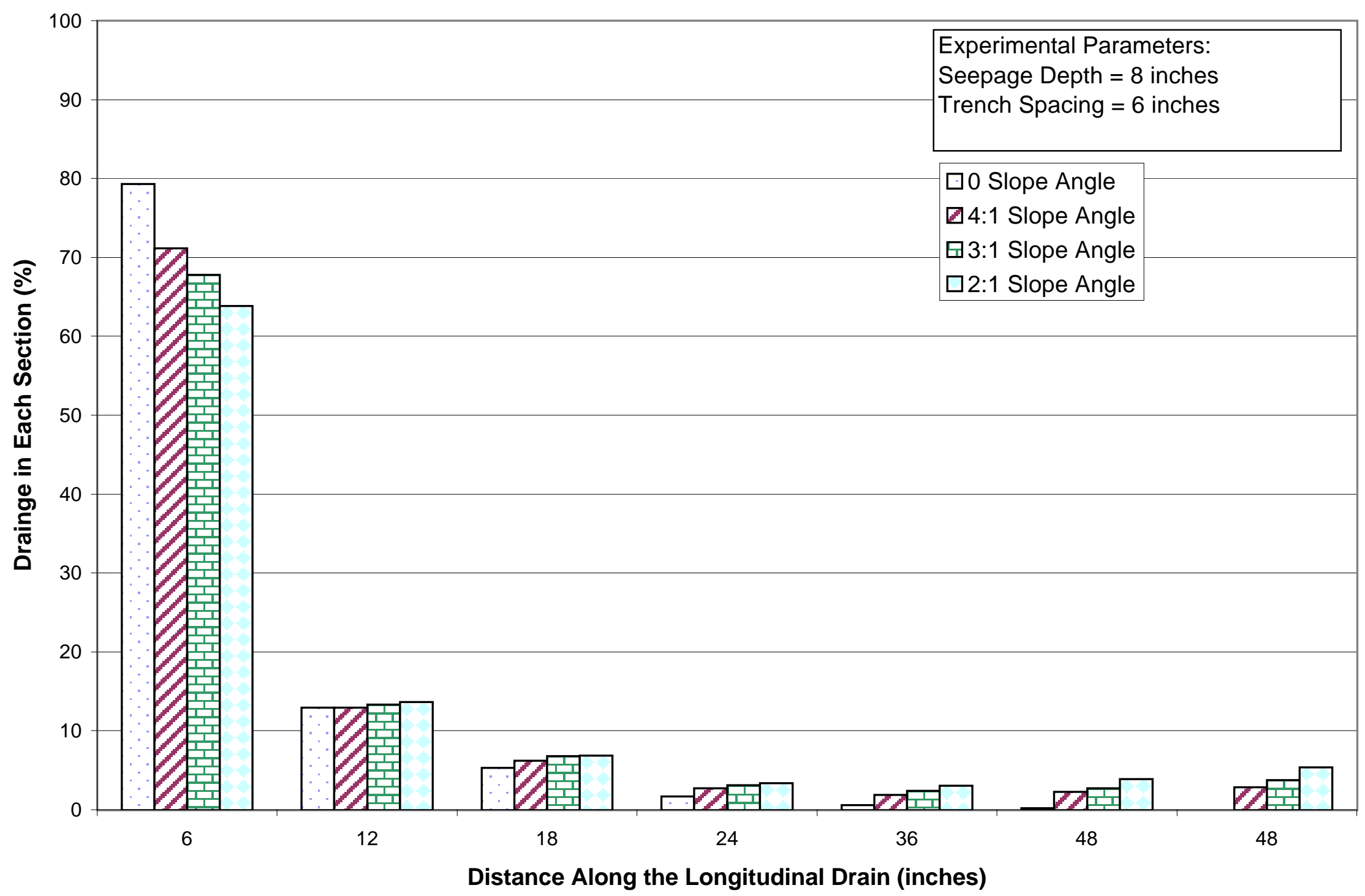

Figure 4.4: Influence of Slope Angle on Drainge Volume in Each Section. 
After 12 inches $(30 \mathrm{~cm})$ in drain length, the difference in removal rates is much smaller, less than 5\%. The remaining differences in removal rates, as the slope is increased, are no larger than $2 \%$. In other words, most of the drainage takes place in the first 3 chambers $(\mathrm{x}<18$ inches $(46 \mathrm{~cm}))$.

\subsection{INFLUENCE OF TRENCH SPACING (w)}

The influence of trench spacing (w) (half-width) can be seen in Figure 4.5 and Figure 4.6. The two graphs are from the same set of tests for which the slope angle $(\theta)$ is 3:1 and the seepage depth $(\mathrm{h})$ is 8 inches $(20 \mathrm{~cm})$. Trench spacing was varied from 6 inches $(15 \mathrm{~cm})$ to 18 inches $(46 \mathrm{~cm})$. Figure 4.5 is a plot of the cumulative seepage (drainage) versus drain length (x). Figure 4.6 is a plot of the percent collected at each drain segment. Trends illustrated by this set of data are typical for all combinations of trench spacing, slope angle, and seepage depth.

As the width of the trench is increased the removal rate in the first 6 inches (15 $\mathrm{cm})$ of drain length is reduced. After 12 inches $(30 \mathrm{~cm})$ the removal rate does not show an increase or decrease with increasing width. However, with increasing trench spacing, the portion of seepage remaining in the slope after the drain increases (i.e. drainage at the down-stream end). 


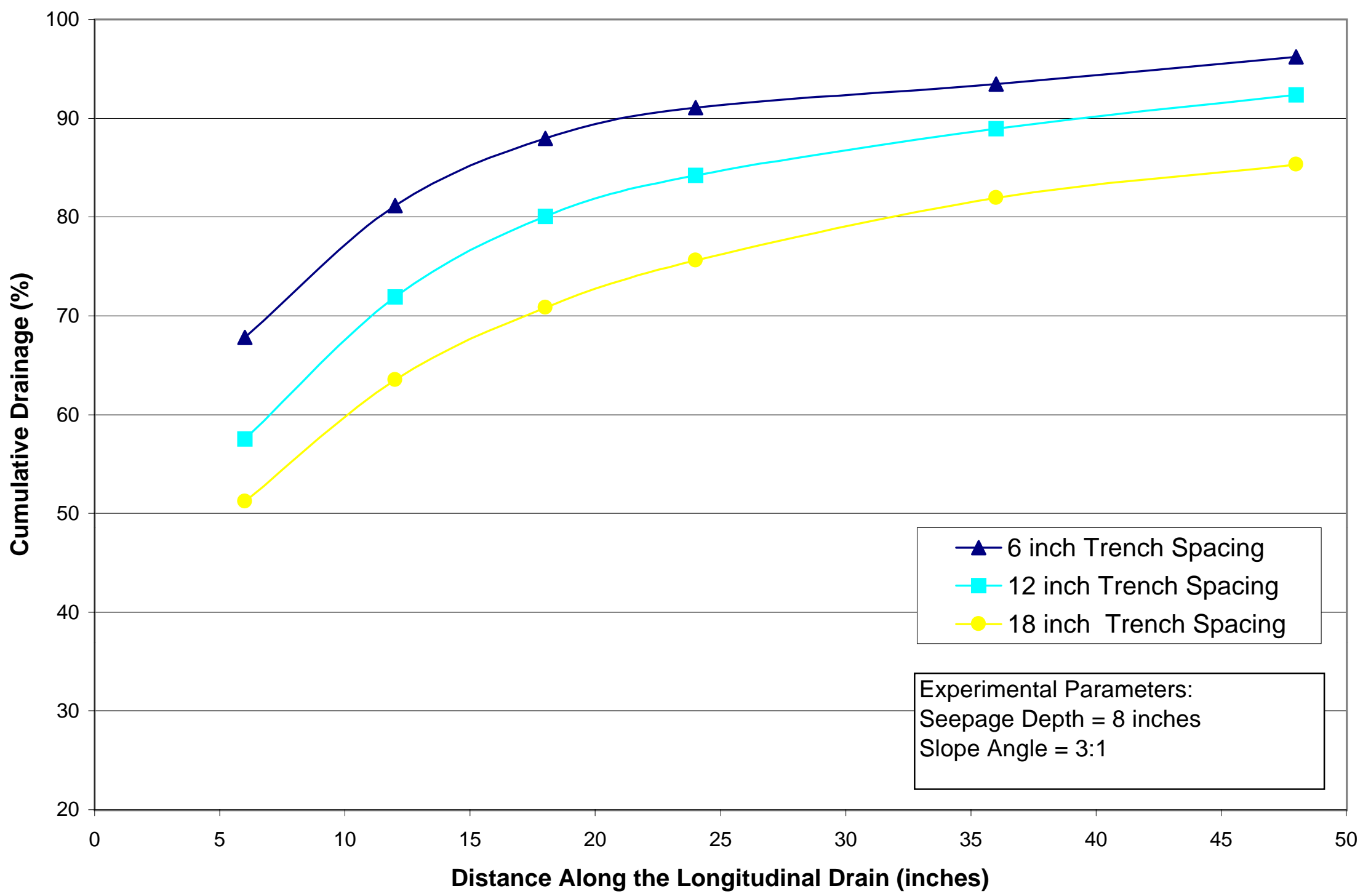

Figure 4.5: Influence of Trench Spacing on Drainage Volume. 


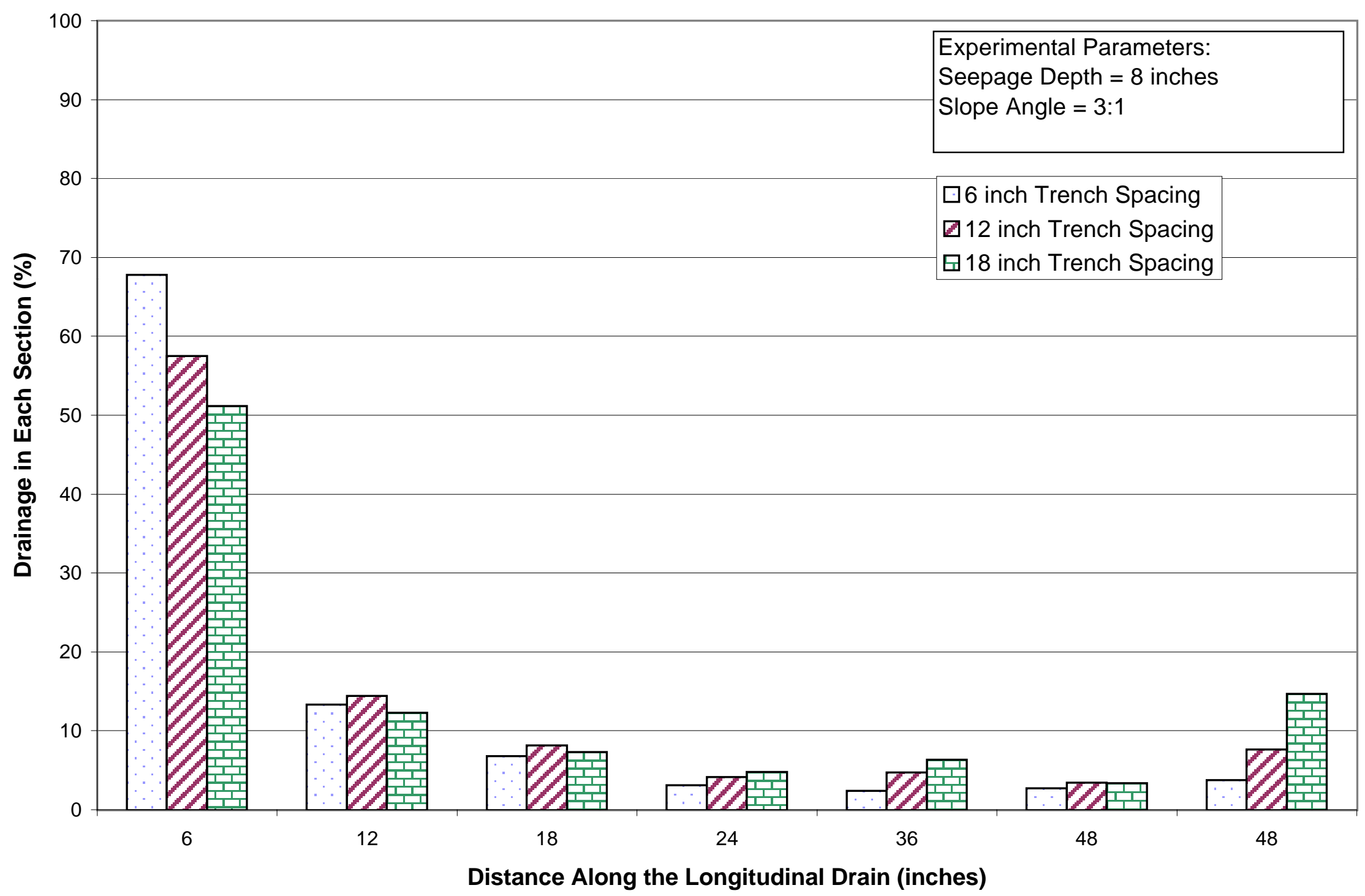

Figure 4.6: Influence of Trench Spacing on Drainage Volume in Each Section. 


\subsection{INFLUENCE OF SEEPAGE DEPTH (h)}

The influence of the seepage depth (h) can be seen in Figure 4.7 and Figure 4.8. The two graphs are for the same set of tests for which the slope angle $(\theta)$ is $3: 1$ and the trench spacing $(w)$ is 18 inches $(46 \mathrm{~cm})$. The seepage depth was varied from 4 inches $(10$ $\mathrm{cm})$ to 8 inches $(20 \mathrm{~cm})$.

Figure 4.8 is a plot of the cumulative seepage collected versus drain length (x). Figure 4.9 is a plot of the drainage at each drain segment. Trends illustrated by this set of data are typical for all combinations of seepage depth, slope angle, and trench spacing.

As the seepage depth is increased the removal rate in the first 6 inches $(15 \mathrm{~cm})$ of drain length is increased. After 12 inches $(30 \mathrm{~cm})$, the removal rate decreases with increasing seepage depth. Although the percentages collected in any one section decrease with increasing seepage depth, the flow rates do increase correspondingly (Section 4.7). The reason for this trend can be traced to the total flow rate through the soil mass. As the depth increases the total flow rate increases, this causes the individual percentages to decrease with (h). 


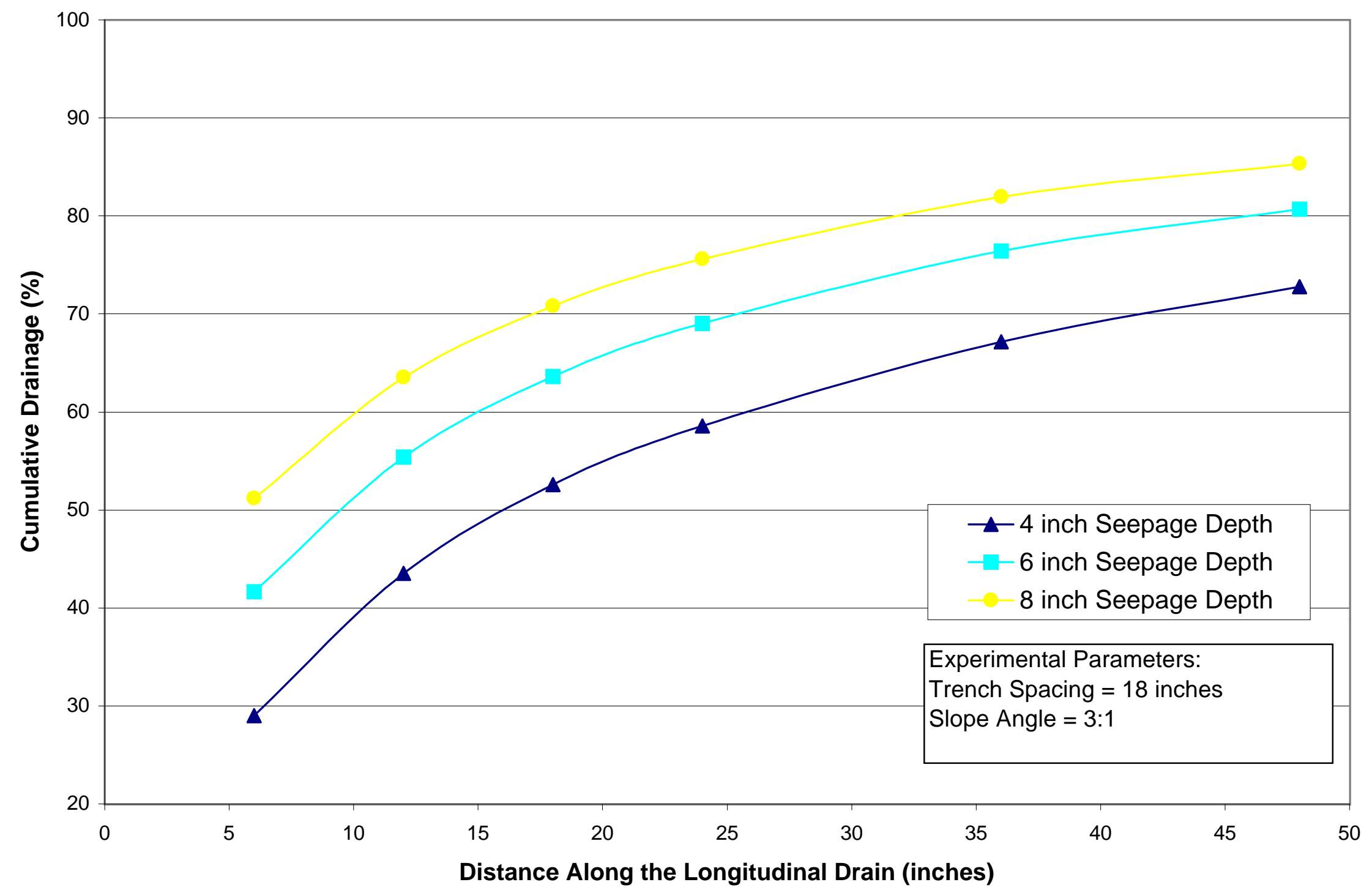

Figure 4.7: Influence of Seepage Depth on Drainge Volume. 


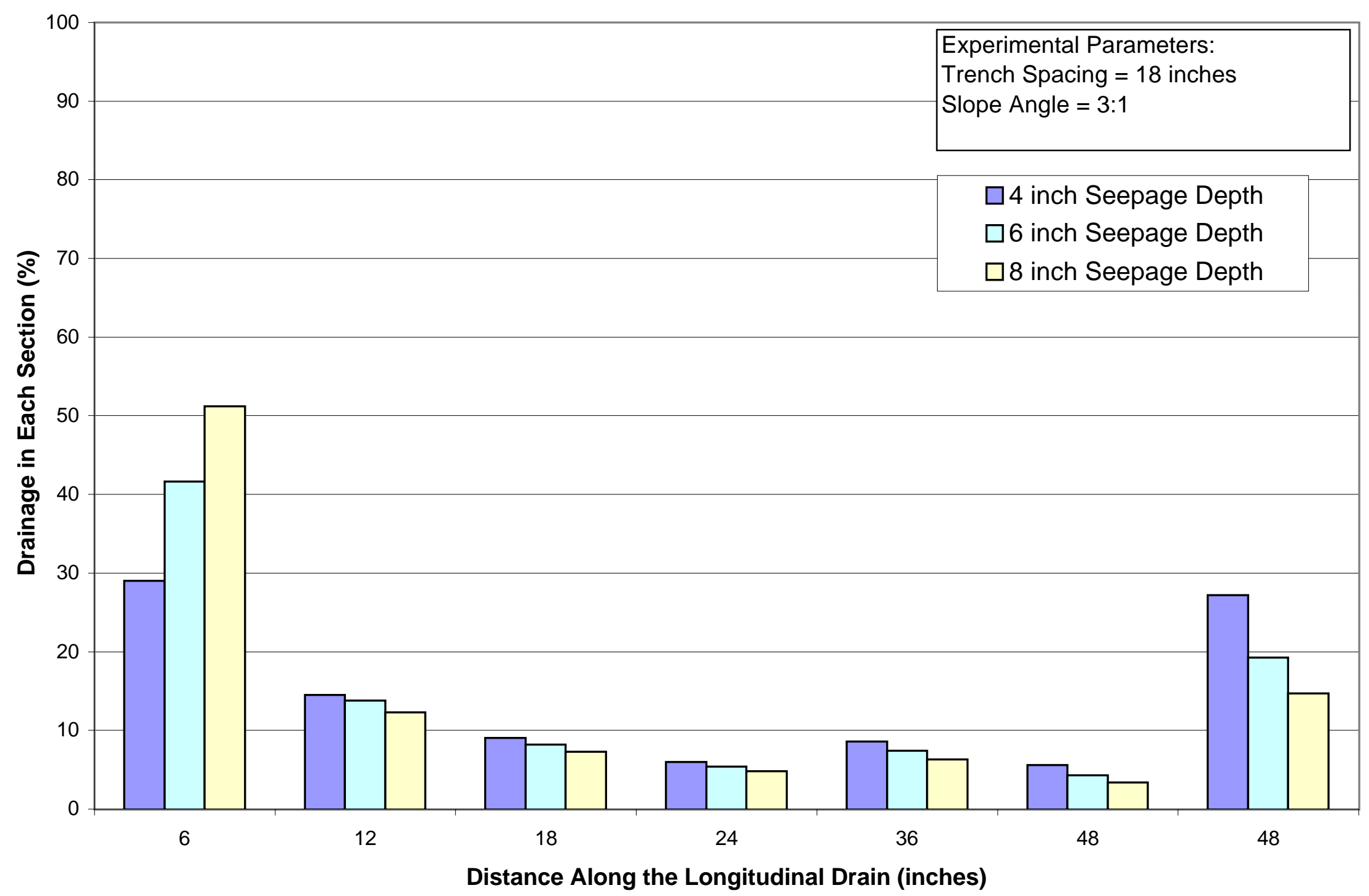

Figure 4.8: Influence of Seepage Depth on Drainage Volume in Each Section. 


\subsection{FLOW RATES}

The influence of slope angle $(\theta)$ on flow rate $\left(\mathrm{ft}^{3} /\right.$ day) in to each drain section is illustrated in Figures 4.9, 4.10, and 4.11. By examining these figures it is seen that the flow rate into each section, for a given trench spacing (w) and seepage depth (h), remains constant as the slope angle is varied. This is contrary to the decreasing relationship seen in the removal rate data (Figure 4.3 and 4.4). The source of this discrepancy lies with the flow rates from the end of the apparatus. As the slope angle is increased more seepage moves through the soil mass, which can be seen by the increasing flow rate for the entire specimen (labeled "Total" on the figures.) Given this increase in total flow rate, the reason for the decrease in removal rates becomes apparent. An increase in total flow rate through the specimen, with constant removal from each section would result in decreasing removal rates (i.e. percentages).

Figure 4.12 demonstrates the relation between seepage depth and flow rate. As the seepage depth increases the flow rate in each of the sections also increases regardless of the slope angle or trench spacing. Figure 4.13 shows the relation between flow rate for the first chamber and the seepage depth for all combinations tested. The increasing flow rate would be expected, given the increase in gradient from the soil to the drain.

Looking at the relation between flow rates and trench spacing, several different patterns emerge (Figure 4.14). The flow rate into the trench drain did not change as the trench spacing was increased for a given seepage depth and slope angle. However, the flow rate at the downstream end and the total flow rate increased with the trench spacing. 
This trend is similar to the one seen for slope angle. From these two tends it is clear that the influence of trench spacing and slope angle on the flow rates into the drain are not significant. The primary factor influencing flow rate is the seepage depth. While the volume of water collected by the drain remains the same, the volume of water not collected by the drain does increase with slope angle and trench spacing. 


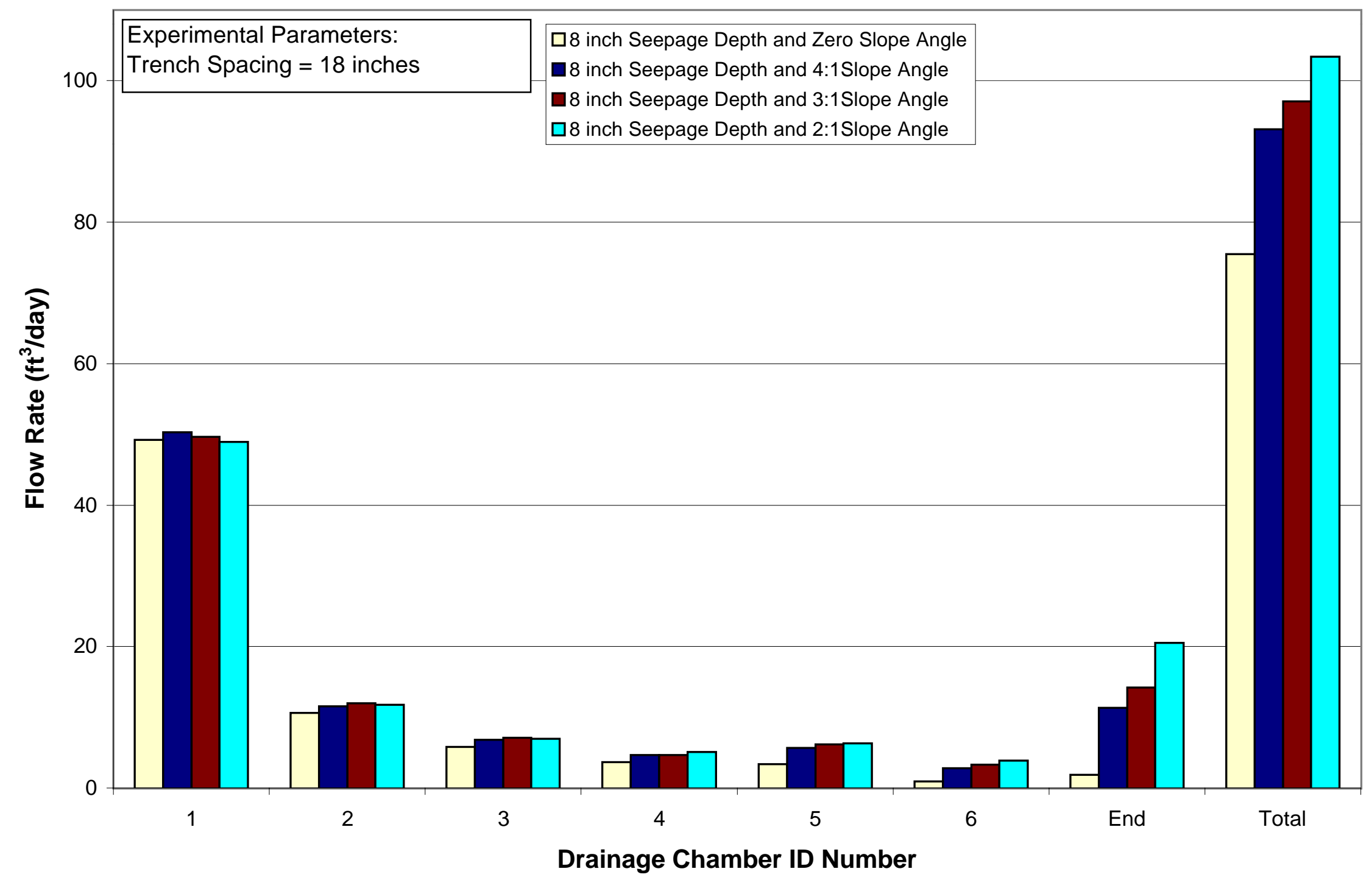

Figure 4.9: Influence of Slope Angle on Flow Rate with 18 inch Trench Spacing. 


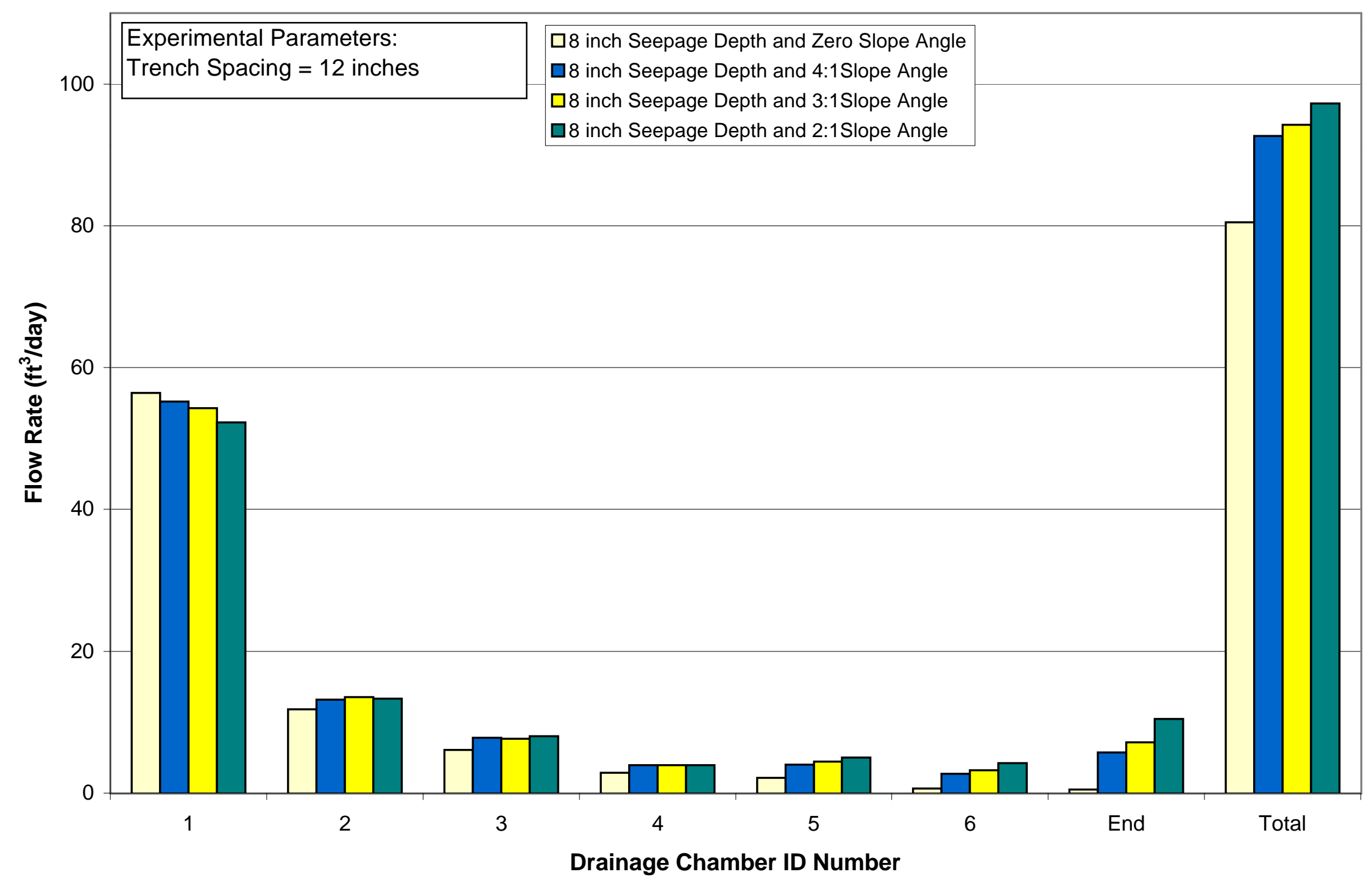

Figure 4.10: Influence of Slope Angle on Flow Rate with 12 inch Trench Spacing. 


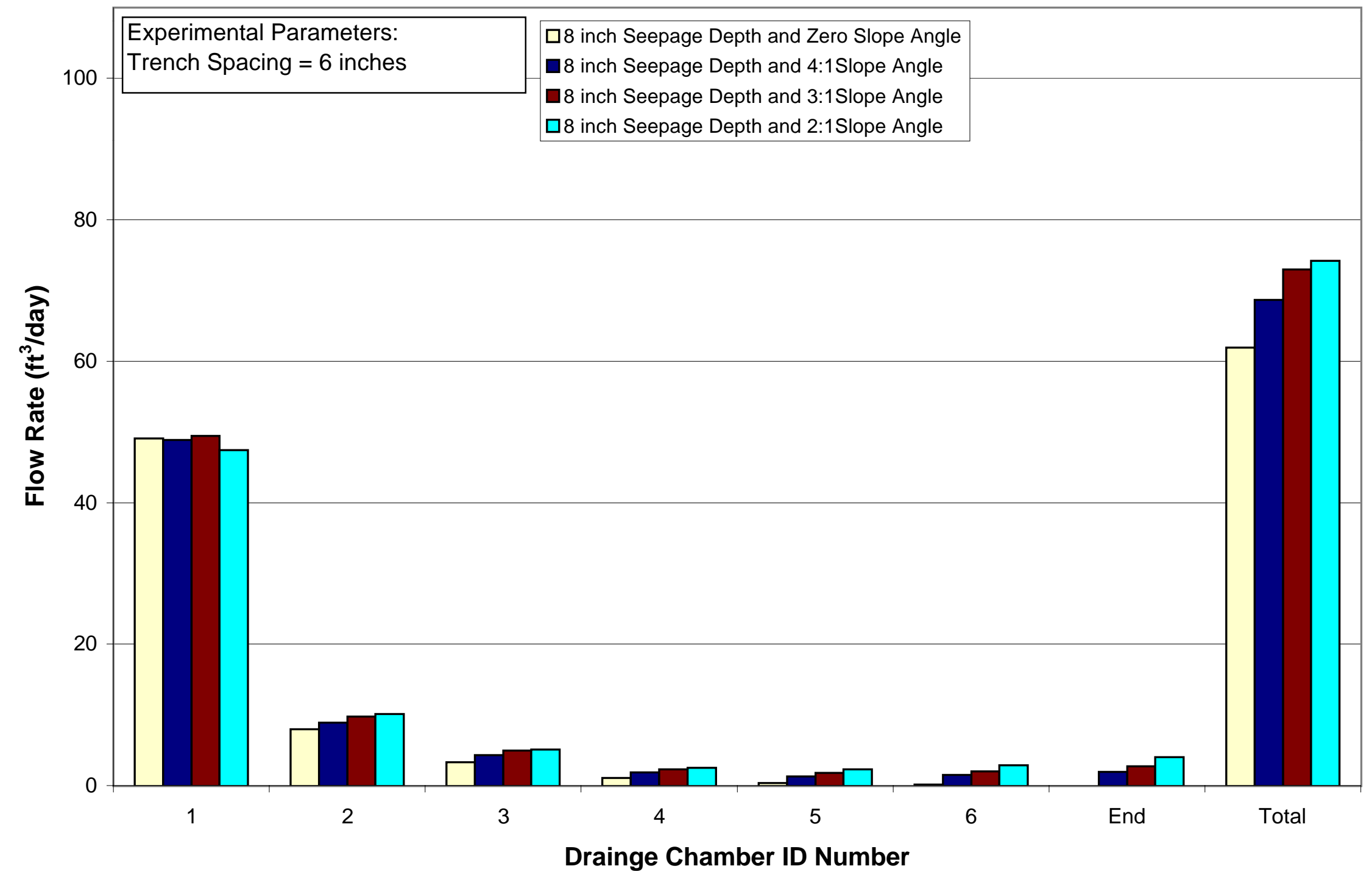

Figure 4.11: Influence of Slope Angle on Flow Rate with 6 inch Trench Spacing. 


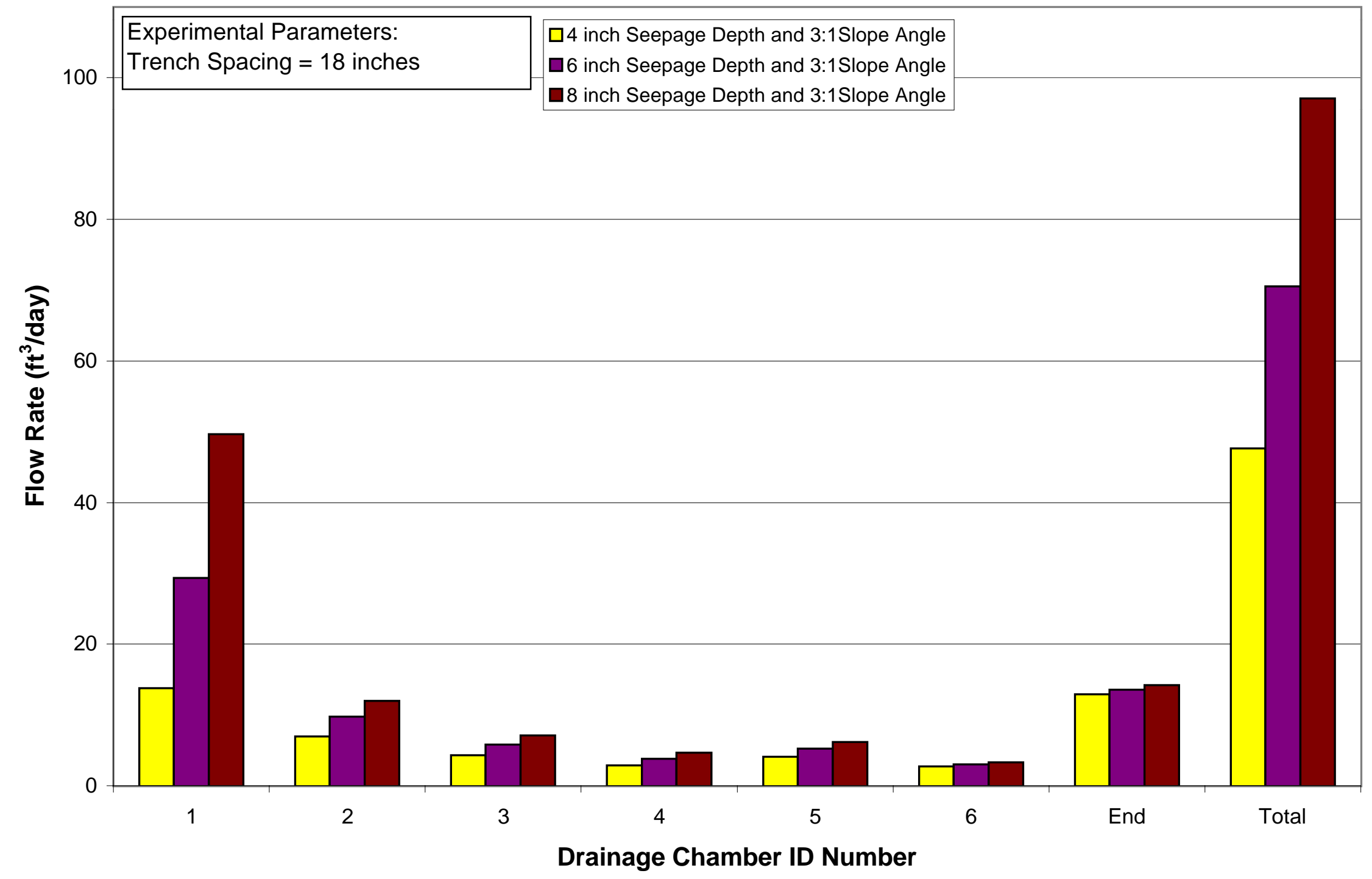

Figure 4.12: Influence of Seepage Depth on Flow Rate with 18 inch Trench Spacing and 3:1 Slope Angle. 


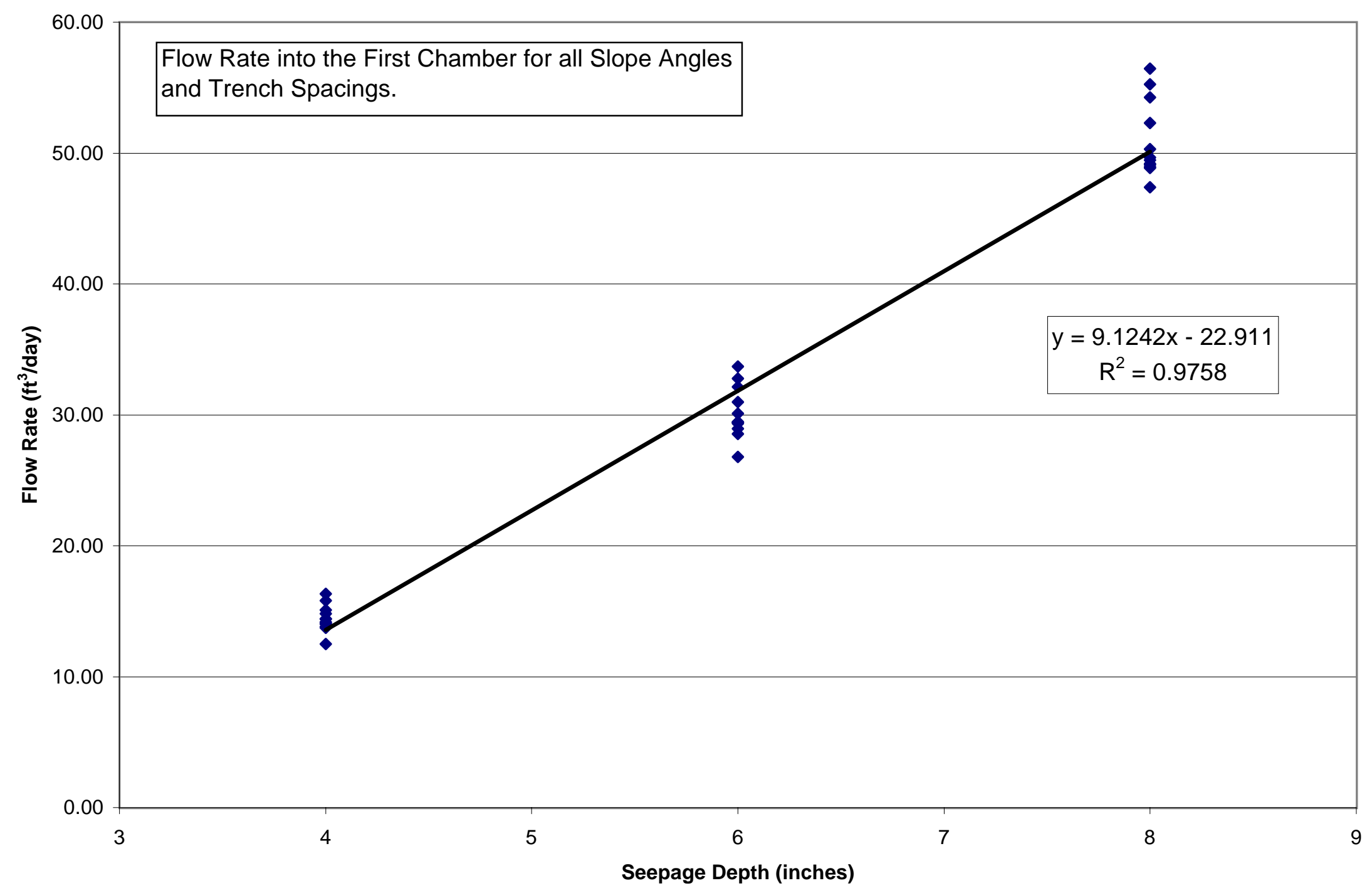

Figure 4.13 Variation in the Flow Rate to the First Chamber 


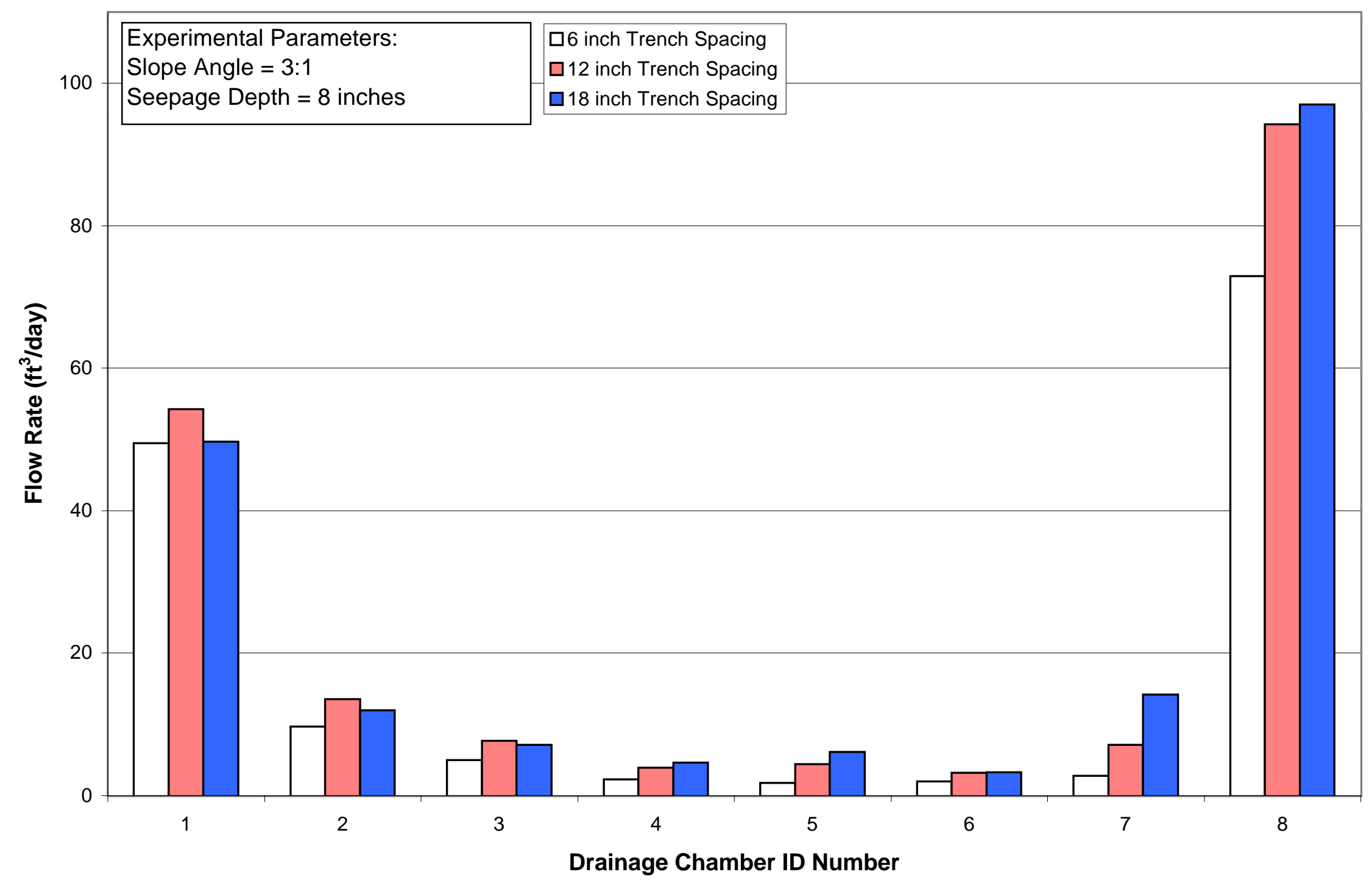

Figure 4.14: Influence of Trench Spacing on Flow Rate with 8 inch Seepage Depth and 3:1 Slope Angle. 


\subsection{PIEZOMETRIC DATA}

The piezometric data provides insight into the flow patterns present in the soil mass (Appendix E). Plots of the piezometric head along the line A-A' (Figure 3.1) are shown in Figures 4.15 to 4.17. Plots of the piezometric levels at cross sections perpendicular to the longitudinal drain are shown in Figures 4.18-4.20. Figure 4.15 and 4.18 show the influence of slope angle for 8 inches $(20 \mathrm{~cm})$ of seepage depth $(\mathrm{h})$. As the slope angle $(\theta)$ increases for a given trench spacing $(\mathrm{w})$ and seepage depth, the piezometric levels also rise. The average change due to the slope angle $(\theta)$ is less than 0.5 inches $(1.3 \mathrm{~cm})$. When the trench spacing (w) is 6 inches $(15 \mathrm{~cm})$, there is little change in piezometric levels in response to slope angle in the first 6-12 inches $(15-30 \mathrm{~cm})$ of drain length $(\mathrm{x})$. After this point the change is greater but still less than that corresponding to half-widths (w) of 12 and 18 inches (30 and $46 \mathrm{~cm}$ ).

Figures 4.16 and 4.19 show the influence of trench spacing on piezometric head. The plots show that with increasing trench spacing, there is a corresponding increase in the piezometric levels at all points not bounded by constant head (i.e. the supply tank and the terminus drain.) There is a significant change in piezometric levels when the trench spacing is increased from 6 inches $(15 \mathrm{~cm})$ to 12 inches $(30 \mathrm{~cm})$ with a maximum piezometric difference of 2.5 inches $(6 \mathrm{~cm})$. However, the difference between the 12 inch $(30 \mathrm{~cm})$ and 18 inch $(46 \mathrm{~cm})$ trench spacing is less than that of the previous case, with a maximum difference of 1 inch $(2.5 \mathrm{~cm})$. Looking at any curve for the 6 inch (15 $\mathrm{cm}$ ) trench spacing where the drain effectively removes $99 \%$ of the flow, a parabolic shape can be seen in the piezometric curve. 
For wider trench spacing the piezometric surface extends from the constant head source to the down-stream end with little or no curvature. It is possible that with significant drain length (x) the shape of the curves for all values of (w) would be similar to the shape of the curve corresponding to 6 inch $(15 \mathrm{~cm})$ drain spacing. In addition, the curves for half-widths $(w)$ of 6 inches $(15 \mathrm{~cm})$ also show a sudden drop after 24 inches $(60 \mathrm{~cm})$ of drain length.

Figures 4.17 and 4.20 show the influence of seepage depth on the piezometric surface. As the seepage depth decreases the piezometric surface also decreases. This finding helps explain the influence of seepage depth on the flow rates. With increased seepage depth the piezometric surface is higher, thus the gradient between the soil and the drain is larger. This would lead to a greater volume of seepage into the drain.

In summary, as the slope angle $(\theta)$ and trench spacing $(w)$ increase, the piezometric levels also rise. The drain lowered the piezometric levels by $99 \%$ at a drain length of 35 inches $(88 \mathrm{~cm})$ when the trench spacing was 6 inches $(15 \mathrm{~cm})$. However, for the other two cases of trench spacing $(12$ inch $(30 \mathrm{~cm})$ and 18 inch $(46 \mathrm{~cm}))$, the piezometric levels gradually drop over the entire length of the drain. 


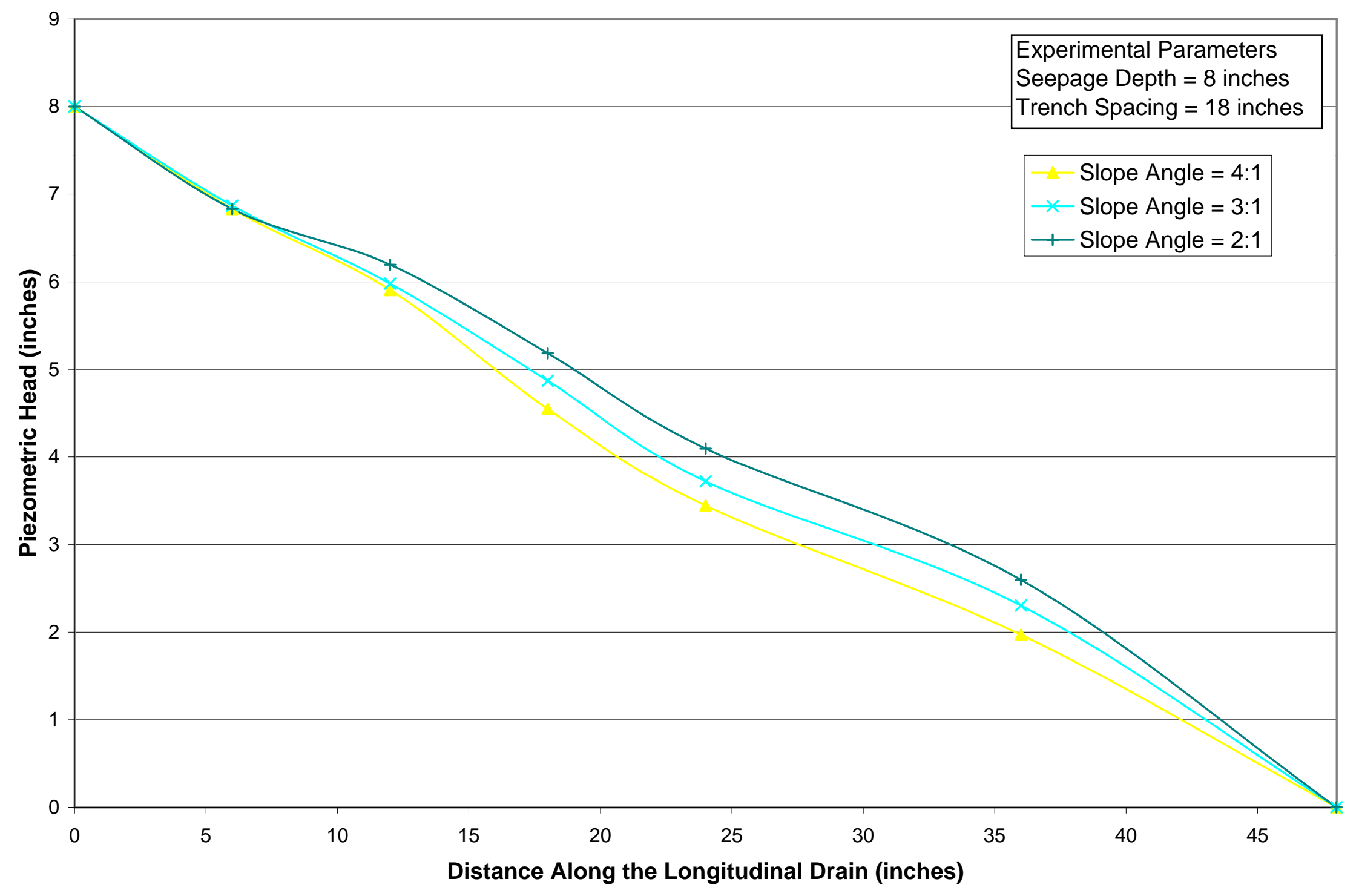

Figure 4.15: Influence of Slope Angle on Piezometric Head at the Centerline Between Drains. 


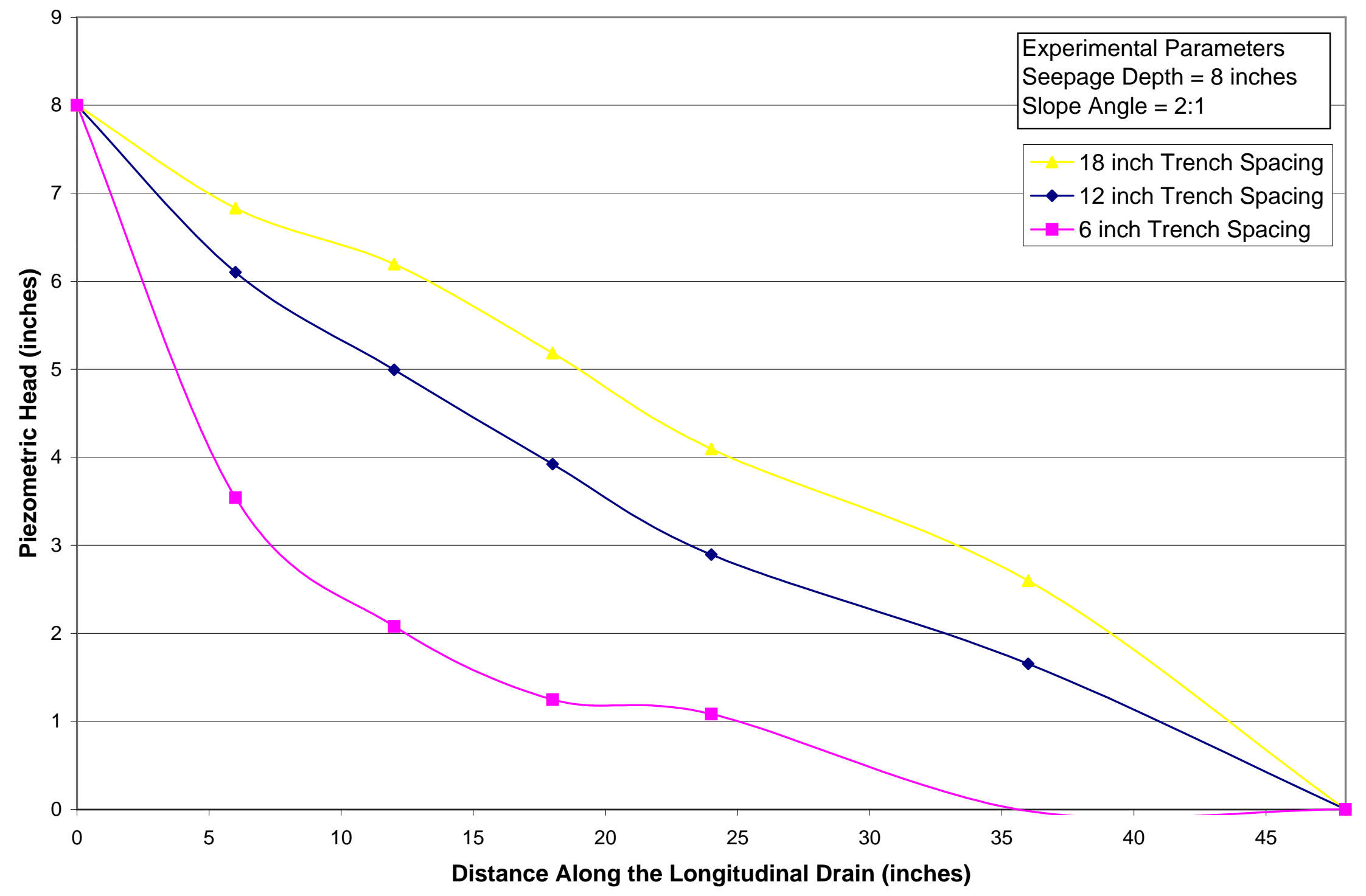

Figure. 4.16: Influence of Trench Spacing on Piezometric Head at the Centerline Between Drains. 


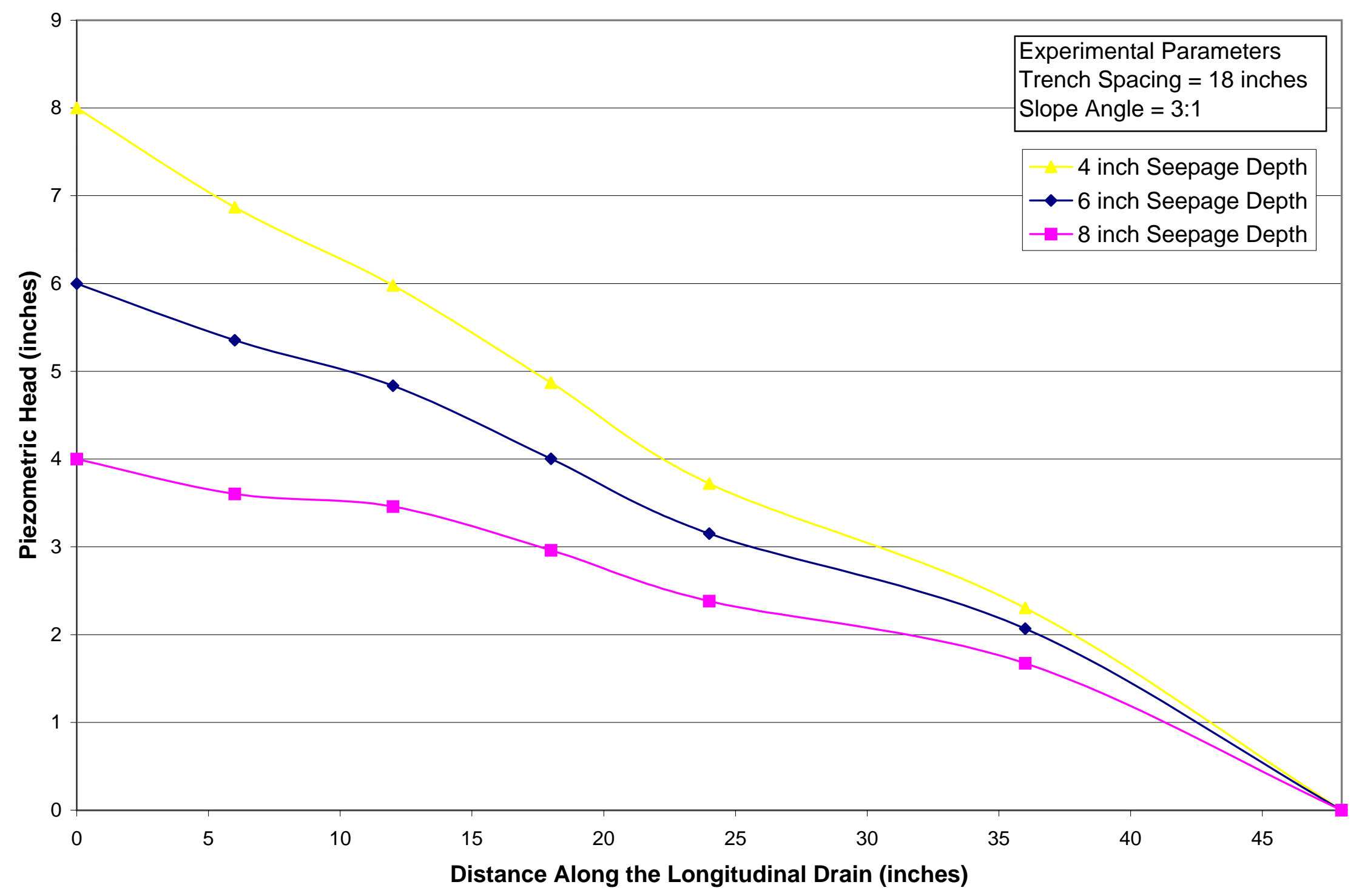

Figure 4.17: Influence of Seepage Depth on Piezometric Head at the Centerline Between Drains. 


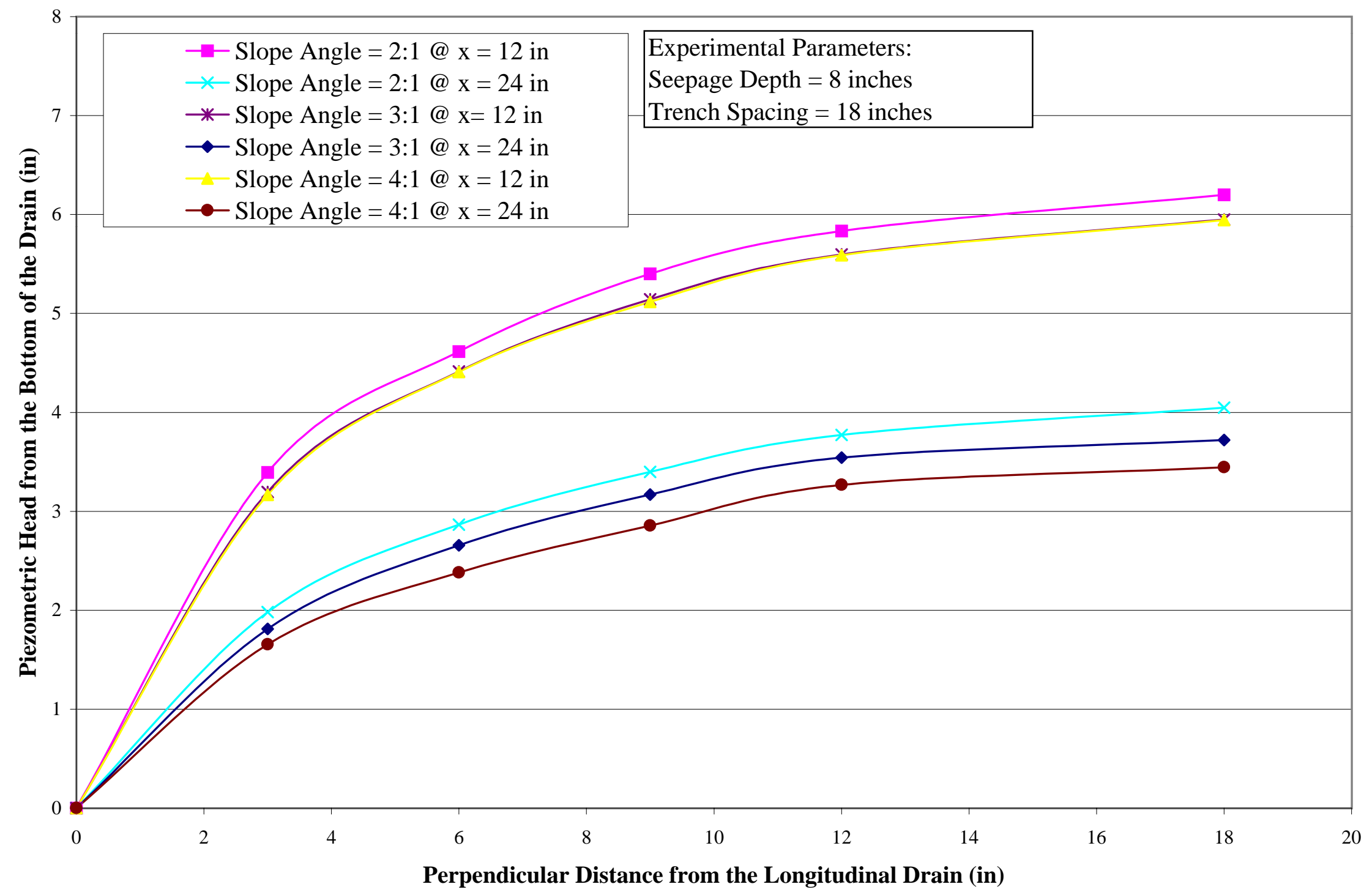

Figure 4.18 Influence of Slope Angle on the Piezometric Surface at Cross Sections Perpendicular to the Longitudinal Drain. 


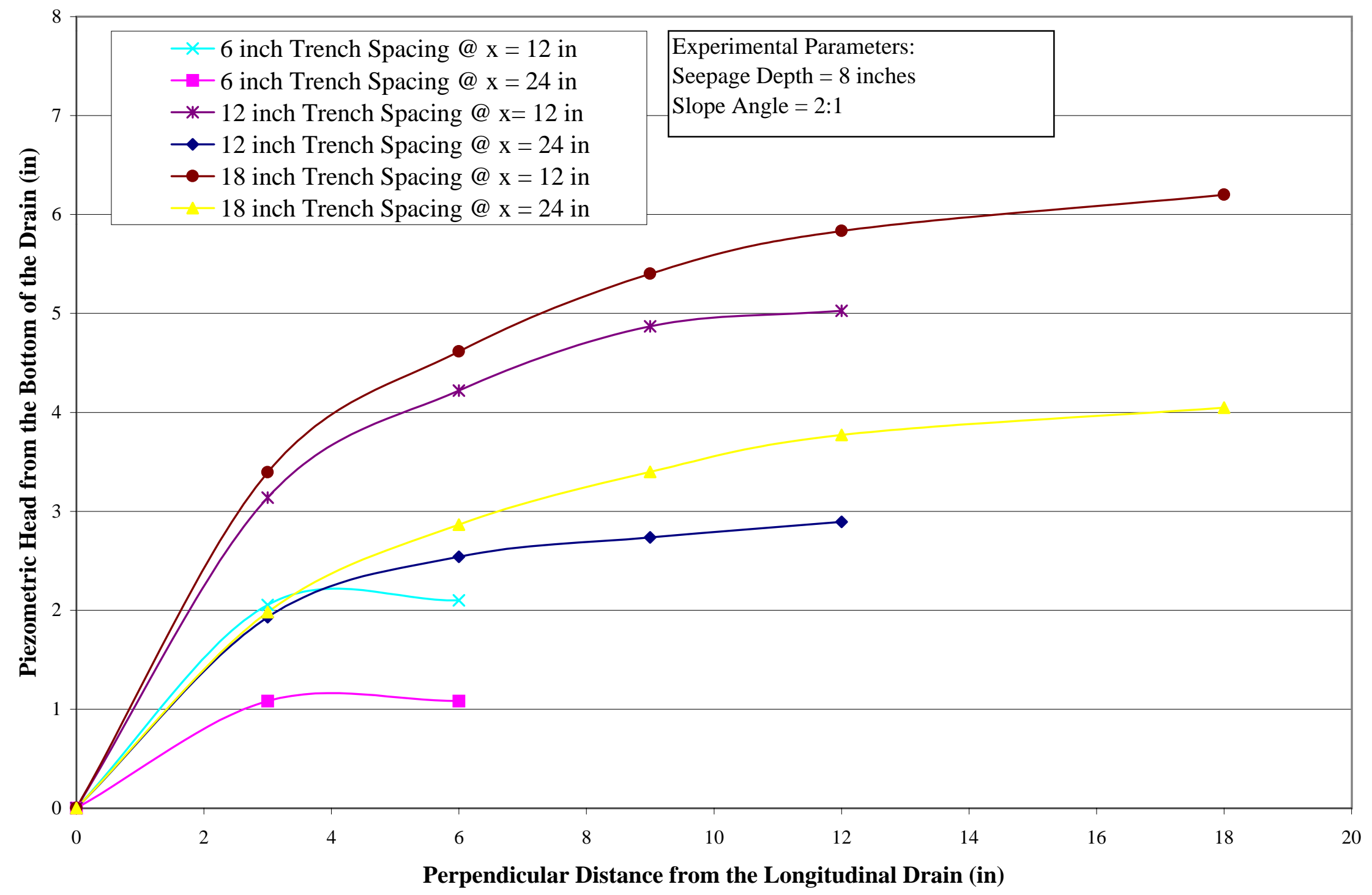

Figure 4.19 Influence of Trench Spacing on the Piezometric Surface at Cross Sections Perpendicular to the Longitudinal Drain. 


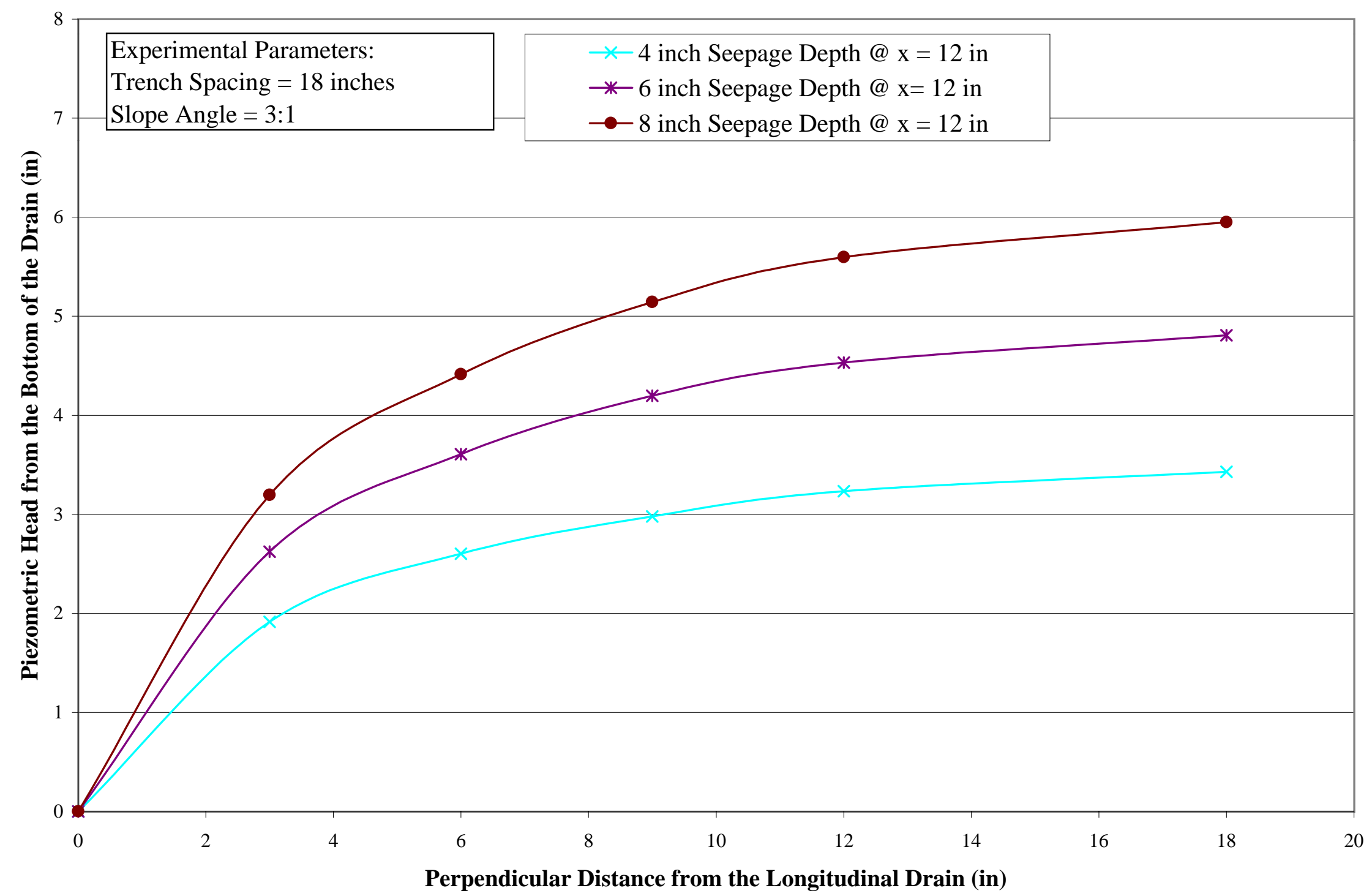

Figure 4.20 Influence of Seepage Depth on the Piezometric Surface at Cross Sections Perpendicular to the Longitudinal Drain. 


\section{CHAPTER 5}

\section{CONCLUSIONS AND RECOMMENDATIONS}

\subsection{CONCLUSIONS}

The major trends seen in the experimental data are shown below:

1. An increase in trench spacing results in decreased total removal from the slope.

2. Deeper seepage depths reduce the overall removal rate of the system.

3. Steeper slope angles allow more seepage to pass through the system without being collected.

The use of a longitudinal trench drain is an effective means to remove seepage from soil slopes if the trench spacing is adequate. The experimental test results show that if the drain spacing is 6 inches $(15 \mathrm{~cm})$, a trench drain of 48 inches $(122 \mathrm{~cm})$ in length will remove $90 \%$ of the seepage. The influence of slope angle $(\theta)$ and seepage depth (h) at this trench spacing does not significantly decrease the removal rate. However, a trench spacing larger than 6 inches $(15 \mathrm{~cm})$ the drain does not remove all of the seepage. Due to the length of the apparatus, determination of the length necessary for $90 \%$ removal of the seepage volume was not determined for most of the combinations.

The flow rate into the drain under constant trench spacing (w) is not influenced by the slope angle. The flow rate is influenced by the seepage depth (h). Flow rates for each of the drain segments decreases with increasing drainage length (x).

\subsection{RECOMMENDATIONS}

This study provided insight into the effectiveness of a trench drain to remove seepage from a soil slope under steady state conditions for one soil type. Future studies should focus on the influence of soil type on the removal rates of the longitudinal drain. 
When applying longitudinal drains as a corrective measure to a failing slope, the time it takes for the drain to take effect is important. For this reason the study should also focus on the transient condition to determine the time required to reach steady state conditions.

Only one drain length was used during this study. The current study could be expanded by including other drain lengths to better determine the necessary length (x) required for proper drainage.

The data collected in this study could be used to calibrate a numerical model of the longitudinal drain. Such a model would aid in the application of the longitudinal drain to real slope stability problems. 


\section{REFERENCES}

Abtamson, Lee W. et al. Slope Stability and Stabilization Methods. NY: Wiley, 1996.

Barua,, Gautam, and K.N. Tiwari. "Ditch Drainage Theories for Homogeneous

Anisotropic Soil." Journal of Irrigation and Drainage Engineering. 122 (1996) : 276285.

Cedergren, Harry R. Seepage, Drainage, and Flow Nets. NY: Wiley, 1977.

Choi, Edmund C. C.. "Seepage Around Horizontal Drains in Hill Slopes." Journal of Hydraulic Engineering. 109 (1983) : 1363-8.

Das, B.M. Principles of Geotechnical Engineering $3^{\text {rd }}$. Boston: PWS, 1993.

David, F.W. and Nolle, H. Experimental Modeling in Engineering. Boston:

Butterworths, 1982.

Domenico, P. A. Concepts and Models in Groundwater Hydrology. NY: McGraw-Hill, 1972

Holtz, R.D. and Kovacs, W.D. An Introduction to Geotechnical Engineering. New Jersey: Prentice Hall, 1981.

Luthin, James N. Drainage Engineering. Huntingtion, N.Y.: Krieger, 1973.

United States. Dept. of the Interior. Drainage from Sloping Land Using Oblique Drains. Washington: GPO, 1990.

Schuring, Dieterich J. Scale Models In Engineering, Fundamentals and Applications. NY: Pergamon, 1977.

Stanic, B. "Influence of Drainage Trenches on Slope Stability." Journal of Geotechnical Engineering. 110:11(1984): 1624-36

Stello, Michael W.. "Seepage Charts for Homogeneous and Zoned Embankments." Journal of Geotechnical Engineering. 113 (1987) : 996-1012.

Stephenson, D and Meadows, M.E. Kinematic Hydrology and Modeling. NY: Elsevier, 1986 
Appendix A

Drainage Volumes Collected for Each Section. 


\begin{tabular}{|c|c|c|c|c|c|c|c|c|c|c|c|c|c|c|}
\hline & \multicolumn{14}{|c|}{ Seepage Depth $=8$ inches } \\
\hline & \multicolumn{2}{|c|}{$Q_{1}$} & \multicolumn{2}{|c|}{$Q_{2}$} & \multicolumn{2}{|c|}{$Q_{3}$} & \multicolumn{2}{|c|}{$Q_{4}$} & \multicolumn{2}{|c|}{$Q_{5}$} & \multicolumn{2}{|c|}{$Q_{6}$} & \multicolumn{2}{|c|}{$Q_{7}$} \\
\hline & $\operatorname{Exp} 1$ & Exp 2 & Exp 1 & $\operatorname{Exp} 2$ & Exp 1 & $\operatorname{Exp} 2$ & Exp 1 & $\operatorname{Exp} 2$ & Exp 1 & Exp 2 & Exp 1 & $\operatorname{Exp} 2$ & Exp 1 & $\overline{E x p} 2$ \\
\hline \multicolumn{15}{|l|}{$\begin{array}{c}\text { Slope Angle = } \\
\text { Zero }\end{array}$} \\
\hline$w=6$ inches & 9710 & 9605 & 1520 & 1625 & 625 & 665 & 230 & 180 & 85 & 60 & 18 & 30 & 2 & 0 \\
\hline$w=12$ inches & 10240 & 11965 & 2145 & 2500 & 1170 & 1215 & 515 & 620 & 430 & 420 & 145 & 110 & 115 & 70 \\
\hline$w=18$ inches & 9995 & 9350 & 2370 & 1800 & 1240 & 1055 & 735 & 695 & 715 & 615 & 210 & 165 & 350 & 380 \\
\hline \multicolumn{15}{|l|}{$\begin{array}{c}\text { Slope Angle }= \\
4: 1\end{array}$} \\
\hline$w=6$ inches & 9545 & 9670 & 1665 & 1835 & 790 & 890 & 390 & 335 & 260 & 250 & 320 & 285 & 410 & 355 \\
\hline$w=12$ inches & 9930 & 11795 & 2350 & 2840 & 1540 & 1525 & 635 & 900 & 775 & 815 & 525 & 555 & 1180 & 1085 \\
\hline$w=18$ inches & 10135 & 9640 & 2535 & 2000 & 1470 & 1220 & 950 & 880 & 1220 & 1020 & 625 & 475 & 2195 & 2275 \\
\hline \multicolumn{15}{|l|}{$\begin{array}{c}\text { Slope Angle }= \\
3: 1\end{array}$} \\
\hline$w=6$ inches & 10030 & 9425 & 1880 & 1945 & 980 & 975 & 495 & 395 & 370 & 325 & 430 & 360 & 615 & 470 \\
\hline$w=12$ inches & 9715 & 11625 & 2510 & 2820 & 1475 & 1545 & 605 & 945 & 800 & 940 & 610 & 660 & 1425 & 1390 \\
\hline$w=18$ inches & 10345 & 9190 & 2600 & 2115 & 1500 & 1290 & 965 & 860 & 1310 & 1105 & 750 & 550 & 2800 & 2790 \\
\hline \multicolumn{15}{|l|}{$\begin{array}{c}\text { Slope Angle }= \\
2: 1\end{array}$} \\
\hline$w=6$ inches & 9730 & 8910 & 1930 & 2040 & 1000 & 1005 & 540 & 440 & 470 & 420 & 600 & 530 & 870 & 700 \\
\hline$w=12$ inches & 9845 & 10720 & 2440 & 2795 & 1560 & 1600 & 590 & 965 & 895 & 1070 & 785 & 870 & 2055 & 2060 \\
\hline$w=18$ inches & 9570 & 9680 & 2440 & 2185 & 1435 & 1305 & 1035 & 970 & 1310 & 1160 & 875 & 640 & 3880 & 4185 \\
\hline
\end{tabular}

Table A.1 Volume of Seepage Collected in Each Drain Segment for 8 inch Seepage Depth. (ml/10 min) 


\begin{tabular}{|c|c|c|c|c|c|c|c|c|c|c|c|c|c|c|}
\hline & \multicolumn{14}{|c|}{ Seepage Depth $=6$ inches } \\
\hline & \multicolumn{2}{|c|}{$Q_{1}$} & \multicolumn{2}{|c|}{$Q_{2}$} & \multicolumn{2}{|c|}{$Q_{3}$} & \multicolumn{2}{|c|}{$Q_{4}$} & \multicolumn{2}{|c|}{$Q_{5}$} & \multicolumn{2}{|c|}{$Q_{6}$} & \multicolumn{2}{|c|}{$Q_{7}$} \\
\hline & Exp 1 & Exp 2 & Exp 1 & Exp 2 & Exp 1 & Exp 2 & Exp 1 & Exp 2 & $\operatorname{Exp} 1$ & Exp 2 & Exp 1 & $\operatorname{Exp} 2$ & Exp 1 & Exp 2 \\
\hline $\begin{array}{c}\text { Slope Angle = } \\
\text { Zero }\end{array}$ & & & & & & & & & & & & & & \\
\hline$w=6$ inches & 5895 & 5680 & 1165 & 1280 & 475 & 500 & 180 & 135 & 55 & 40 & 16 & 35 & 1 & 0 \\
\hline$w=12$ inches & 6205 & 7045 & 1615 & 1850 & 900 & 915 & 390 & 450 & 320 & 300 & 110 & 85 & 85 & 30 \\
\hline$w=18$ inches & 5895 & 5690 & 1805 & 1390 & 930 & 810 & 540 & 520 & 510 & 450 & 165 & 125 & 265 & 285 \\
\hline $\begin{array}{c}\text { Slope Angle }= \\
4: 1\end{array}$ & & & & & & & & & & & & & & \\
\hline$w=6$ inches & 6120 & 5725 & 1545 & 1555 & 765 & 730 & 375 & 290 & 280 & 225 & 340 & 275 & 460 & 350 \\
\hline$w=12$ inches & 5930 & 6955 & 1840 & 2205 & 1240 & 1240 & 520 & 735 & 665 & 690 & 490 & 520 & 1125 & 1060 \\
\hline$w=18$ inches & 5990 & 5585 & 2035 & 1585 & 1185 & 970 & 765 & 675 & 1020 & 845 & 570 & 405 & 2095 & 2030 \\
\hline $\begin{array}{c}\text { Slope Angle }= \\
3: 1\end{array}$ & & & & & & & & & & & & & & \\
\hline$w=6$ inches & 6020 & 5370 & 1560 & 1635 & 820 & 810 & 425 & 345 & 335 & 300 & 435 & 355 & 595 & 470 \\
\hline$w=12$ inches & 5790 & 6845 & 1970 & 2230 & 1235 & 1290 & 505 & 800 & 700 & 820 & 575 & 625 & 1375 & 1355 \\
\hline$w=18$ inches & 5990 & 5545 & 2100 & 1730 & 1230 & 1050 & 800 & 705 & 1115 & 940 & 690 & 500 & 2675 & 2660 \\
\hline $\begin{array}{c}\text { Slope Angle }= \\
2: 1\end{array}$ & & & & & & & & & & & & & & \\
\hline$w=6$ inches & 5660 & 4870 & 1600 & 1745 & 845 & 860 & 475 & 390 & 440 & 395 & 590 & 520 & 865 & 695 \\
\hline$w=12$ inches & 5480 & 6710 & 1870 & 2240 & 1320 & 1370 & 490 & 835 & 785 & 950 & 745 & 840 & 2020 & 2025 \\
\hline$w=18$ inches & 5565 & 5660 & 1945 & 1740 & 1175 & 1020 & 885 & 820 & 1130 & 990 & 815 & 585 & 2740 & 4015 \\
\hline
\end{tabular}

Table A.2 Volume of Seepage Collected in Each Drain Segment for 6 inch Seepage Depth. (ml/10 min) 


\begin{tabular}{|c|c|c|c|c|c|c|c|c|c|c|c|c|c|c|}
\hline & \multicolumn{14}{|c|}{ Seepage Depth $=4$ inches } \\
\hline & \multicolumn{2}{|c|}{$Q_{1}$} & \multicolumn{2}{|c|}{$Q_{2}$} & \multicolumn{2}{|c|}{$Q_{3}$} & \multicolumn{2}{|c|}{$Q_{4}$} & \multicolumn{2}{|c|}{$Q_{5}$} & \multicolumn{2}{|c|}{$Q_{6}$} & \multicolumn{2}{|c|}{$Q_{7}$} \\
\hline & Exp 1 & Exp 2 & Exp 1 & $\operatorname{Exp} 2$ & Exp 1 & $\operatorname{Exp} 2$ & Exp 1 & $\operatorname{Exp} 2$ & Exp 1 & $\operatorname{Exp} 2$ & Exp 1 & $\operatorname{Exp} 2$ & Exp 1 & $\operatorname{Exp} 2$ \\
\hline $\begin{array}{c}\text { Slope Angle = } \\
\text { Zero }\end{array}$ & & & & & & & & & & & & & & \\
\hline$w=6$ inches & 3035 & 2795 & 710 & 825 & 290 & 310 & 100 & 75 & 25 & 25 & 14 & 20 & 1 & 0 \\
\hline$w=12$ inches & 3020 & 3405 & 990 & 1125 & 555 & 560 & 240 & 270 & 185 & 160 & 75 & 55 & 50 & 40 \\
\hline$w=18$ inches & 2895 & 2775 & 1180 & 890 & 590 & 495 & 340 & 315 & 305 & 265 & 110 & 80 & 160 & 190 \\
\hline $\begin{array}{c}\text { Slope Angle = } \\
4: 1\end{array}$ & & & & & & & & & & & & & & \\
\hline$w=6$ inches & 3175 & 2500 & 1010 & 1120 & 535 & 520 & 285 & 230 & 235 & 195 & 330 & 265 & 460 & 345 \\
\hline$w=12$ inches & 2890 & 3330 & 1220 & 1475 & 910 & 890 & 385 & 540 & 520 & 530 & 450 & 470 & 1070 & 1015 \\
\hline$w=18$ inches & 2830 & 2685 & 1440 & 1110 & 870 & 690 & 560 & 480 & 785 & 635 & 500 & 350 & 1970 & 1870 \\
\hline $\begin{array}{c}\text { Slope Angle }= \\
3: 1\end{array}$ & & & & & & & & & & & & & & \\
\hline$w=6$ inches & 3090 & 2305 & 1060 & 1190 & 590 & 590 & 330 & 275 & 290 & 265 & 430 & 350 & 590 & 460 \\
\hline$w=12$ inches & 2770 & 3160 & 1345 & 1500 & 925 & 960 & 375 & 605 & 560 & 650 & 525 & 580 & 1310 & 1310 \\
\hline$w=18$ inches & 2780 & 2650 & 1490 & 1240 & 920 & 775 & 605 & 520 & 880 & 735 & 615 & 445 & 2535 & 2550 \\
\hline $\begin{array}{c}\text { Slope Angle }= \\
2: 1\end{array}$ & & & & & & & & & & & & & & \\
\hline$w=6$ inches & 2880 & 2030 & 1190 & 1350 & 655 & 680 & 390 & 330 & 400 & 355 & 580 & 510 & 860 & 695 \\
\hline$w=12$ inches & 2650 & 2930 & 1370 & 1495 & 1075 & 1045 & 400 & 650 & 680 & 785 & 700 & 790 & 1980 & 1995 \\
\hline$w=18$ inches & 2725 & 2820 & 1510 & 1340 & 940 & 795 & 740 & 660 & 975 & 835 & 755 & 540 & 3615 & 3865 \\
\hline
\end{tabular}

Table A.3 Volume of Seepage Collected in Each Drain Segment for 4 inch Seepage Depth. (ml/10 min) 
Appendix B

Measured Data on Hydraulic Conductivity 


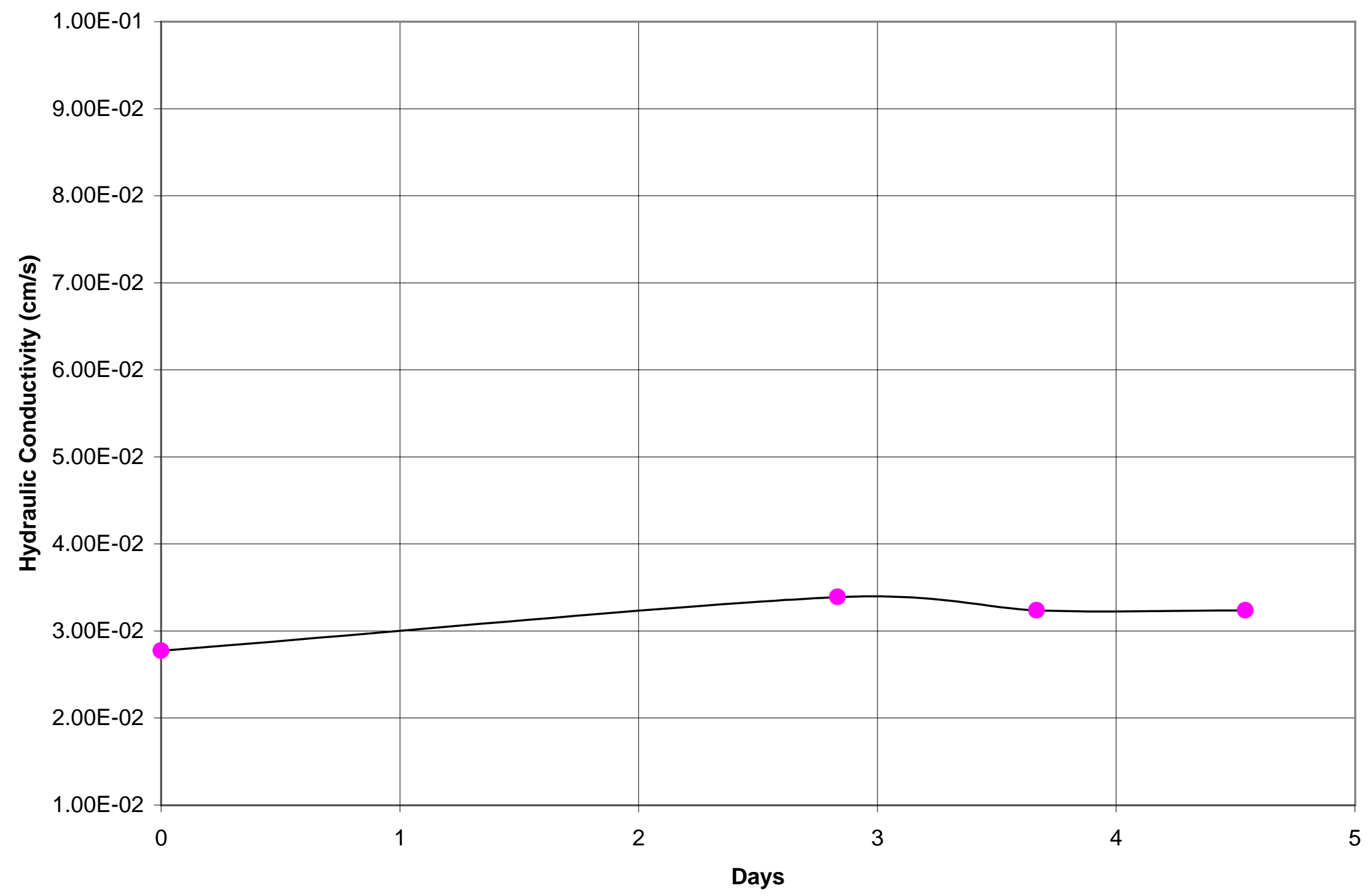

Figure B.1 Plot of Hydraulic Conductivity for 6 inch Trench Spacing, Test \# 1. 


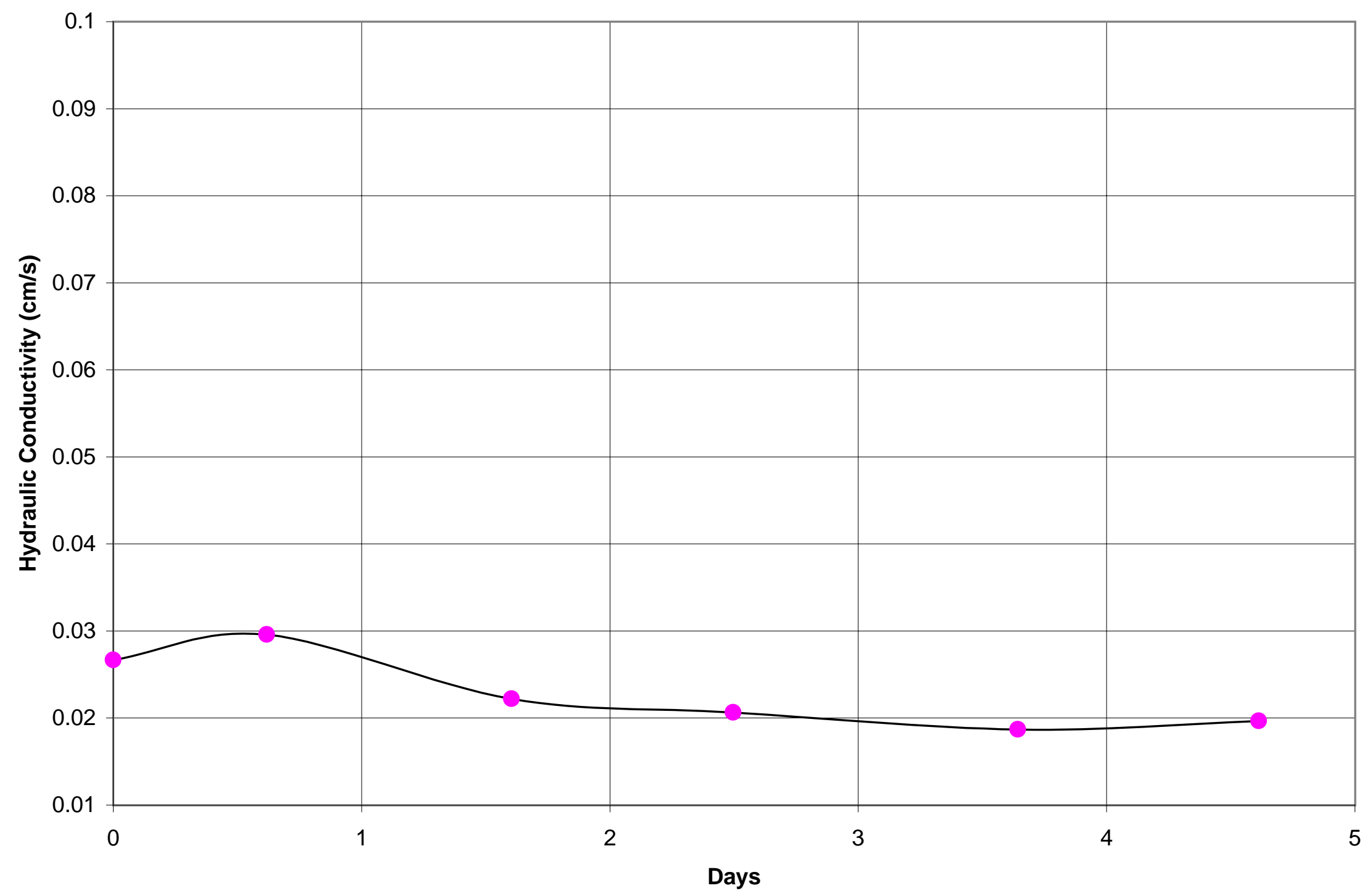

Figure B.2 Plot of Hydraulic Conductivity for 6 inch Trench Spacing, Test \# 2. 


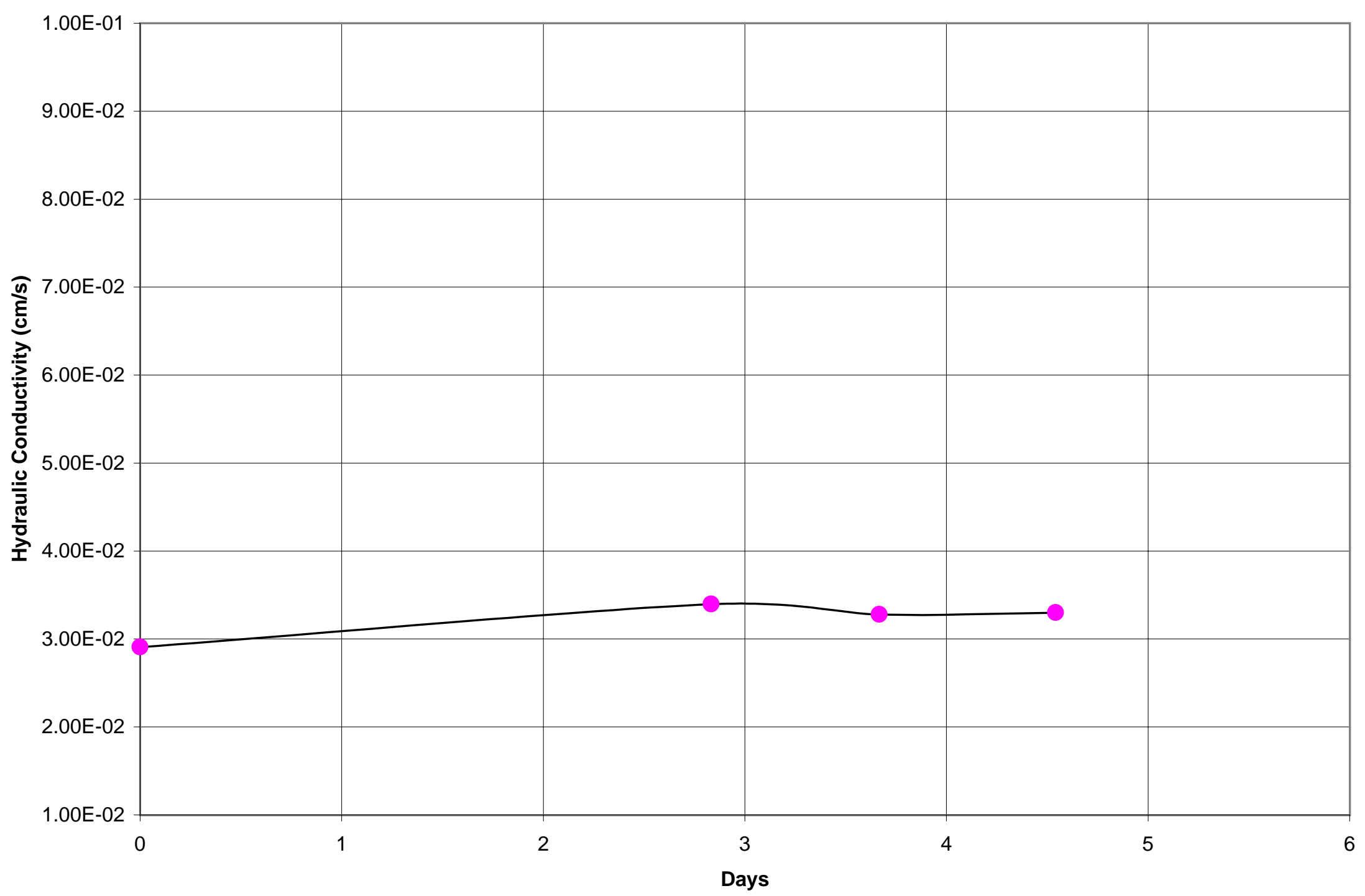

Figure B.3 Plot of Hydraulic Conductivity for 12 inch Trench Spacing \# 1 . 


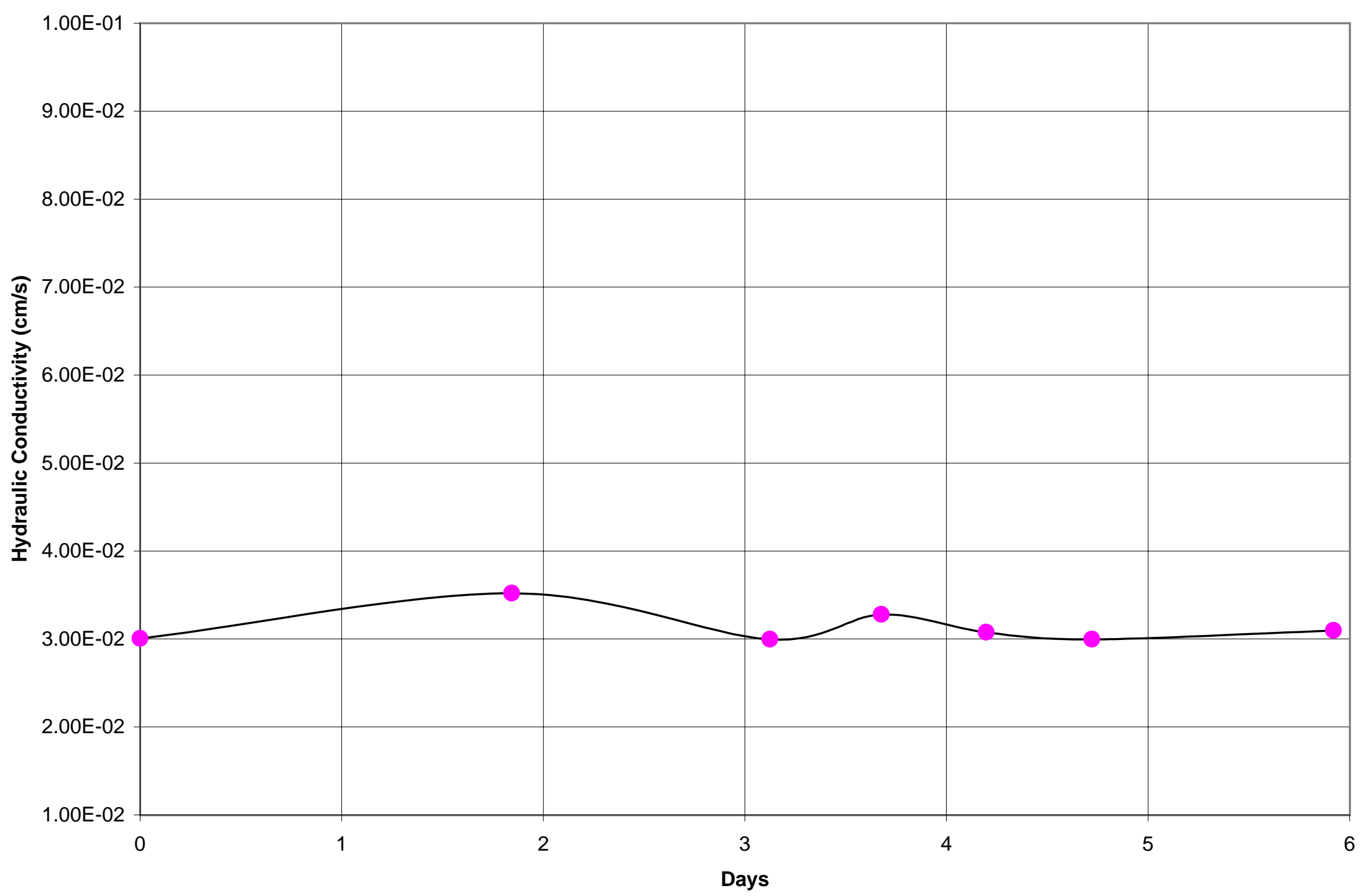

Figure B.4 Plot of Hydraulic Conductivity for 12 inch Trench Spacing, Test \# 2. 


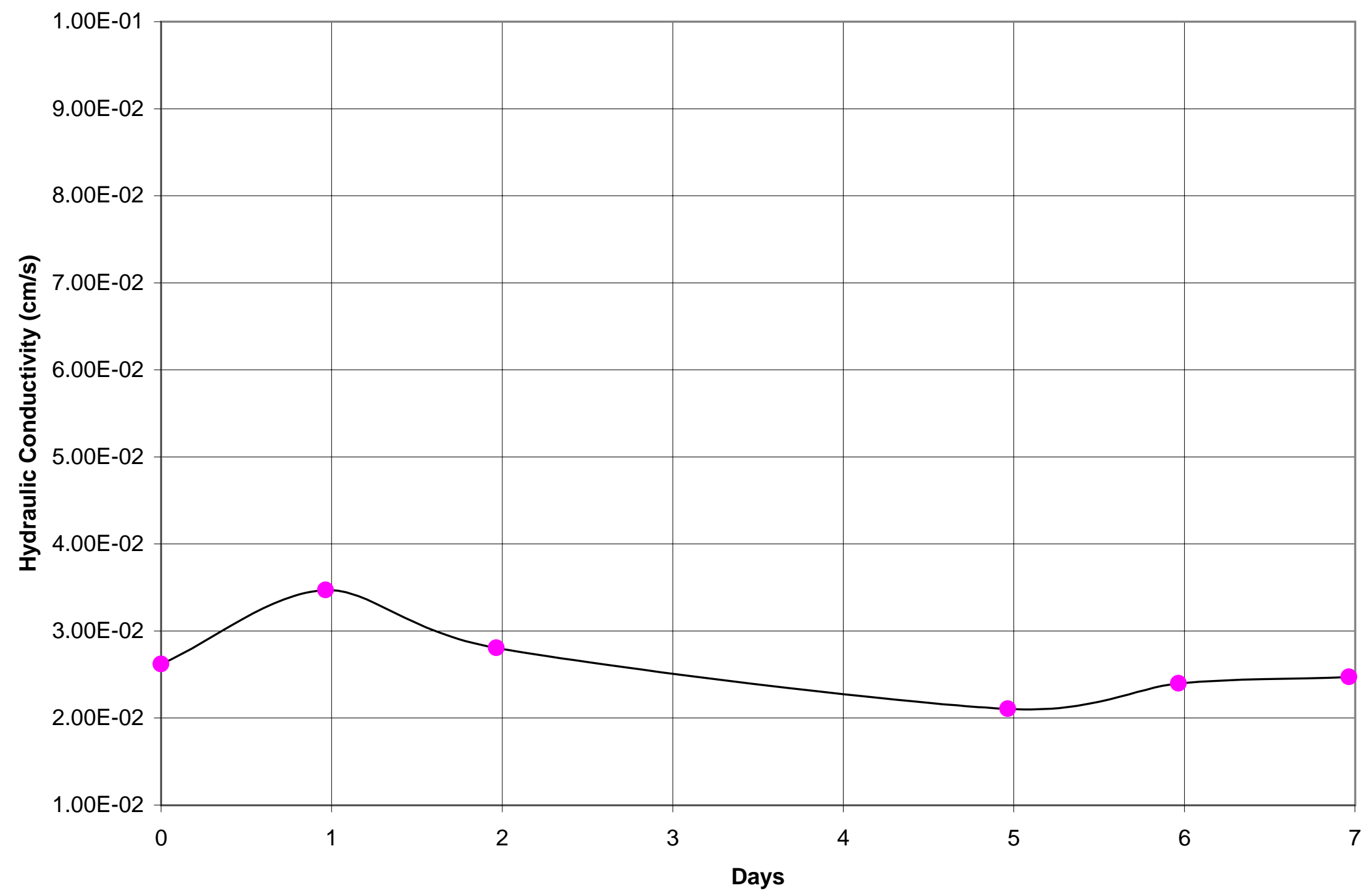

Figure B.5 Plot of Hydraulic Conductivity for 18 inch Trench Spacing, Test \# 1. 


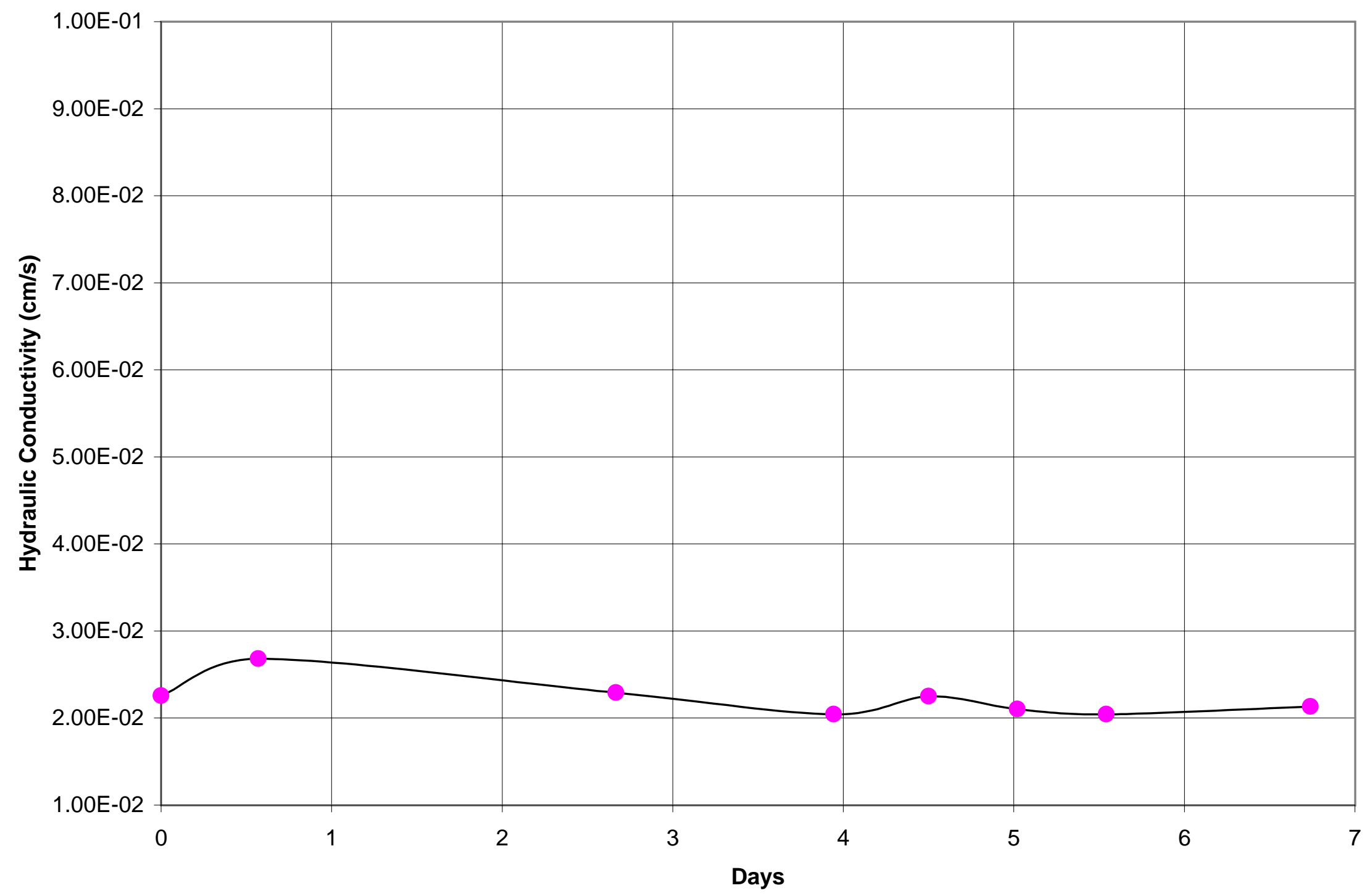

Figure B.6 Plot of Hydraulic Conductivity for 18 inch Trench Spacing, Test \# 2. 
Appendix C

Measured Data on Drainage Volumes Corresponding to

Different Experimental Parameters 


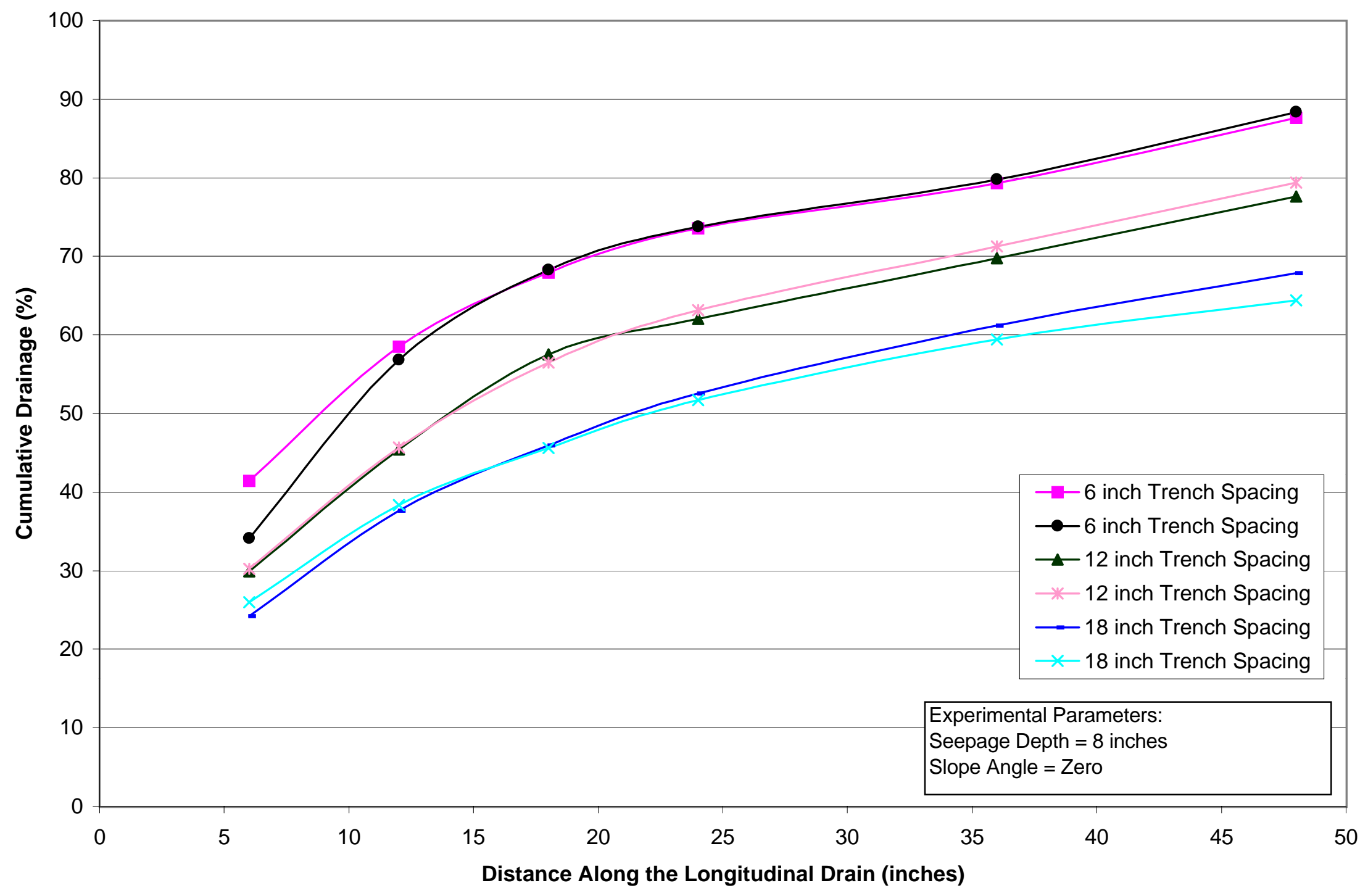

Figure C.1 Cumulative Drainage Volume for 8 inch Seepage Depth and Zero Slope Angle. 


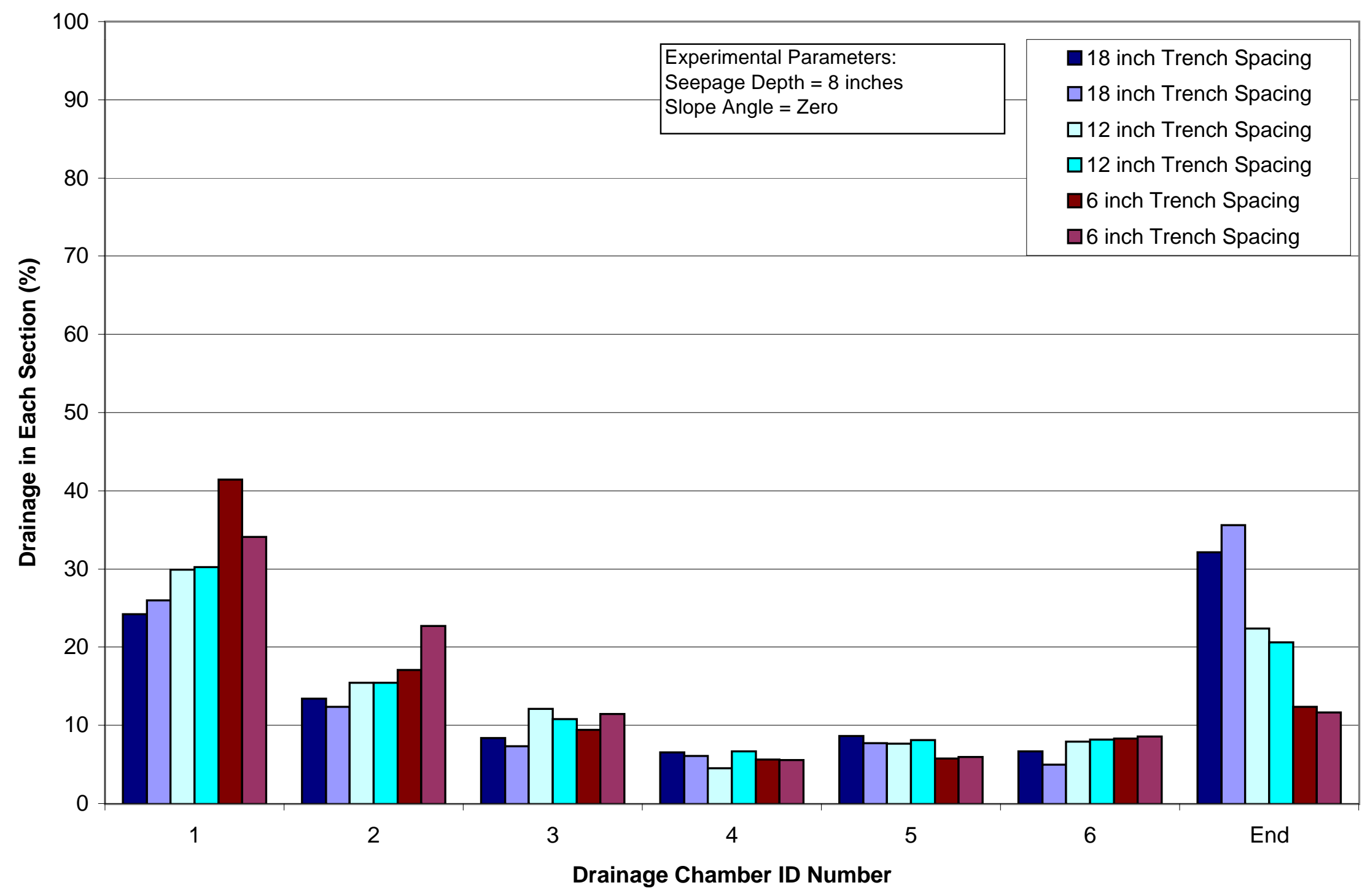

Figure C.2 Drainage Volume for Each Section for 8 inch Seepage Depth and Zero Slope Angle. 


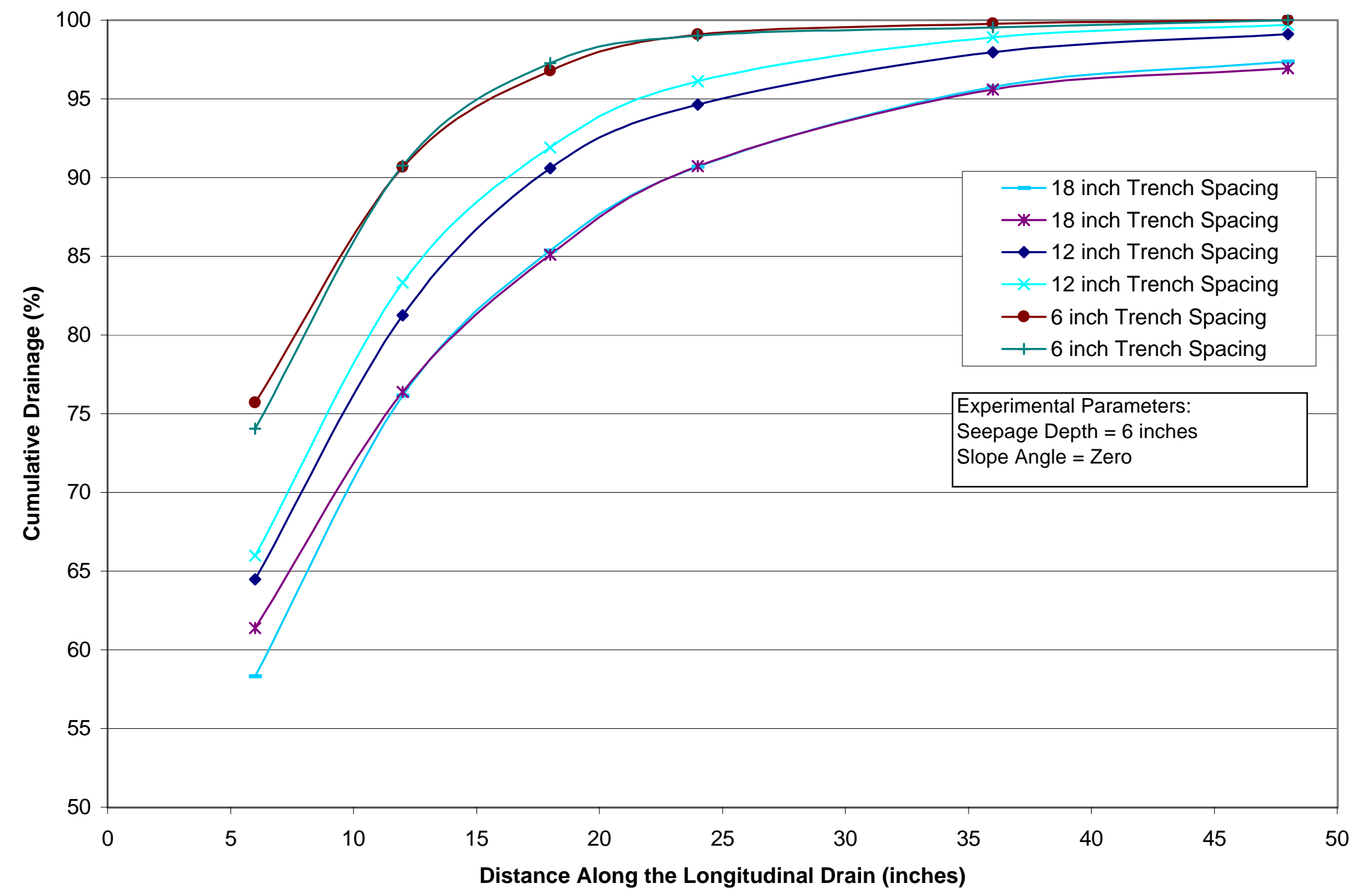

Figure C.3 Cumulative Drainage Volume for 6 inch Seepage Depth and Zero Slope Angle. 


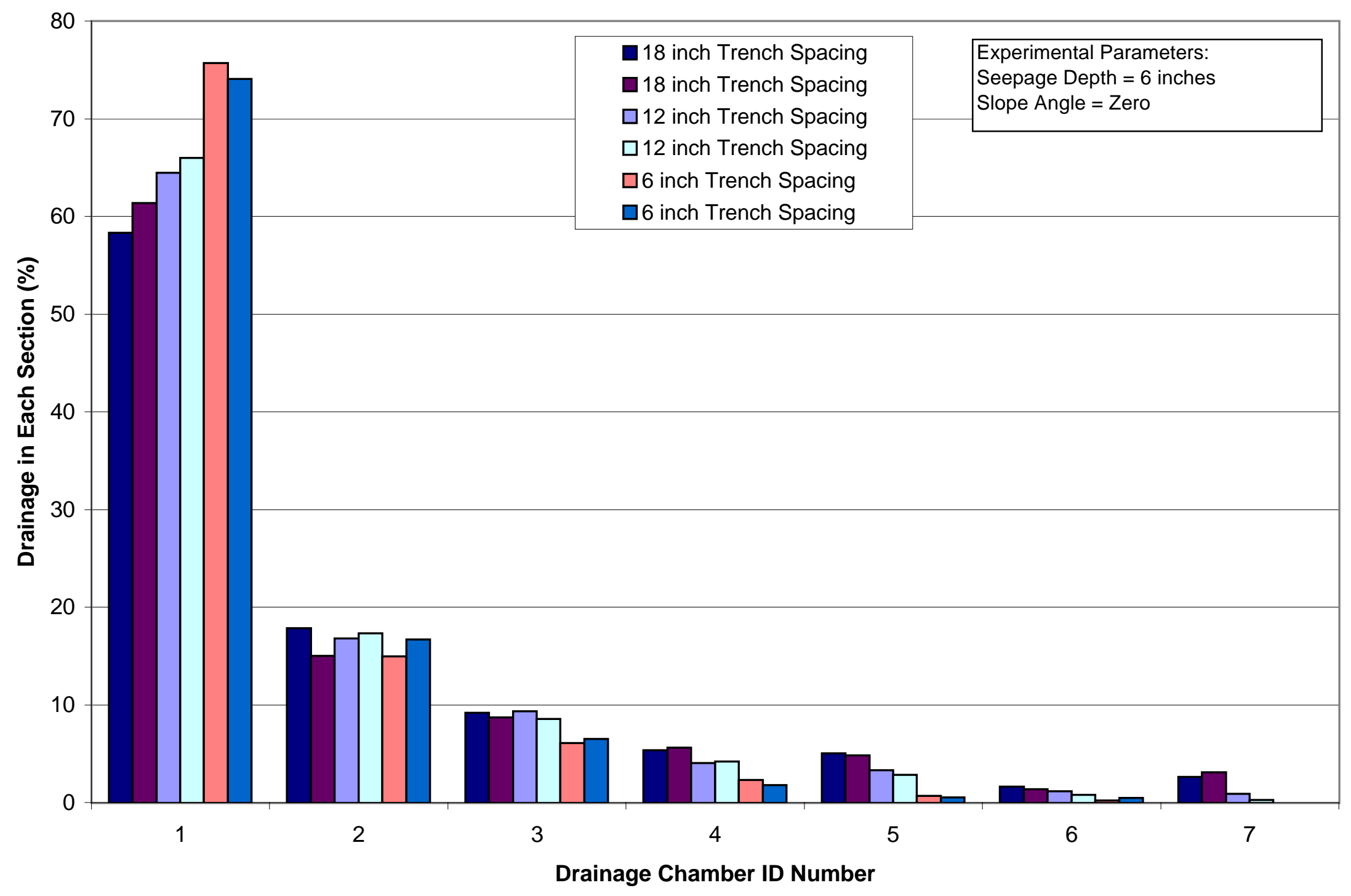

Figure C.4 Drainage Volume in Each Section for 6 inch Seepage Depth and Zero Slope Angle. 


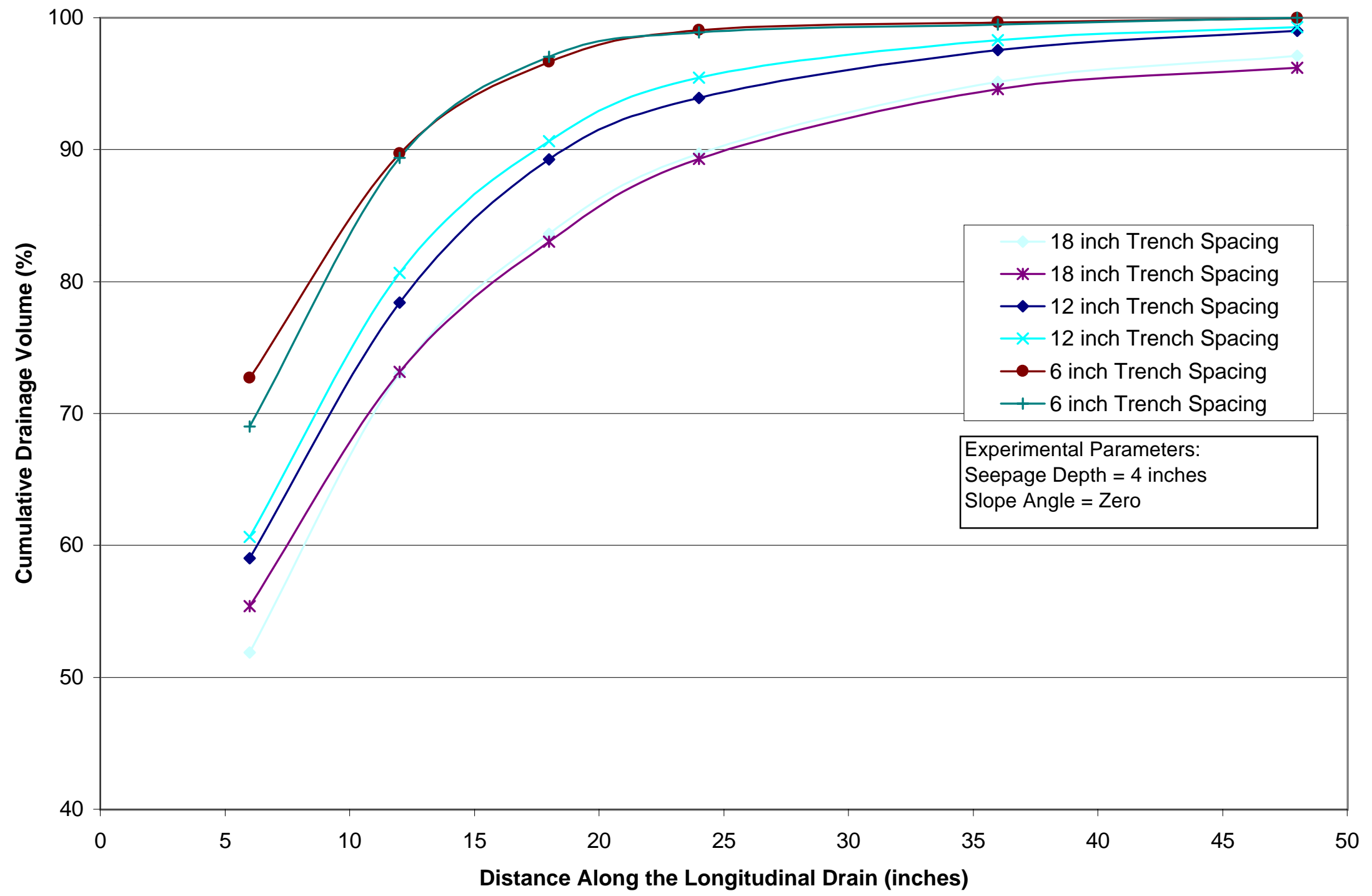

Figure C.5 Cumulative Drainage Volume for 4 inch Seepage Depth and Zero Slope Angle. 


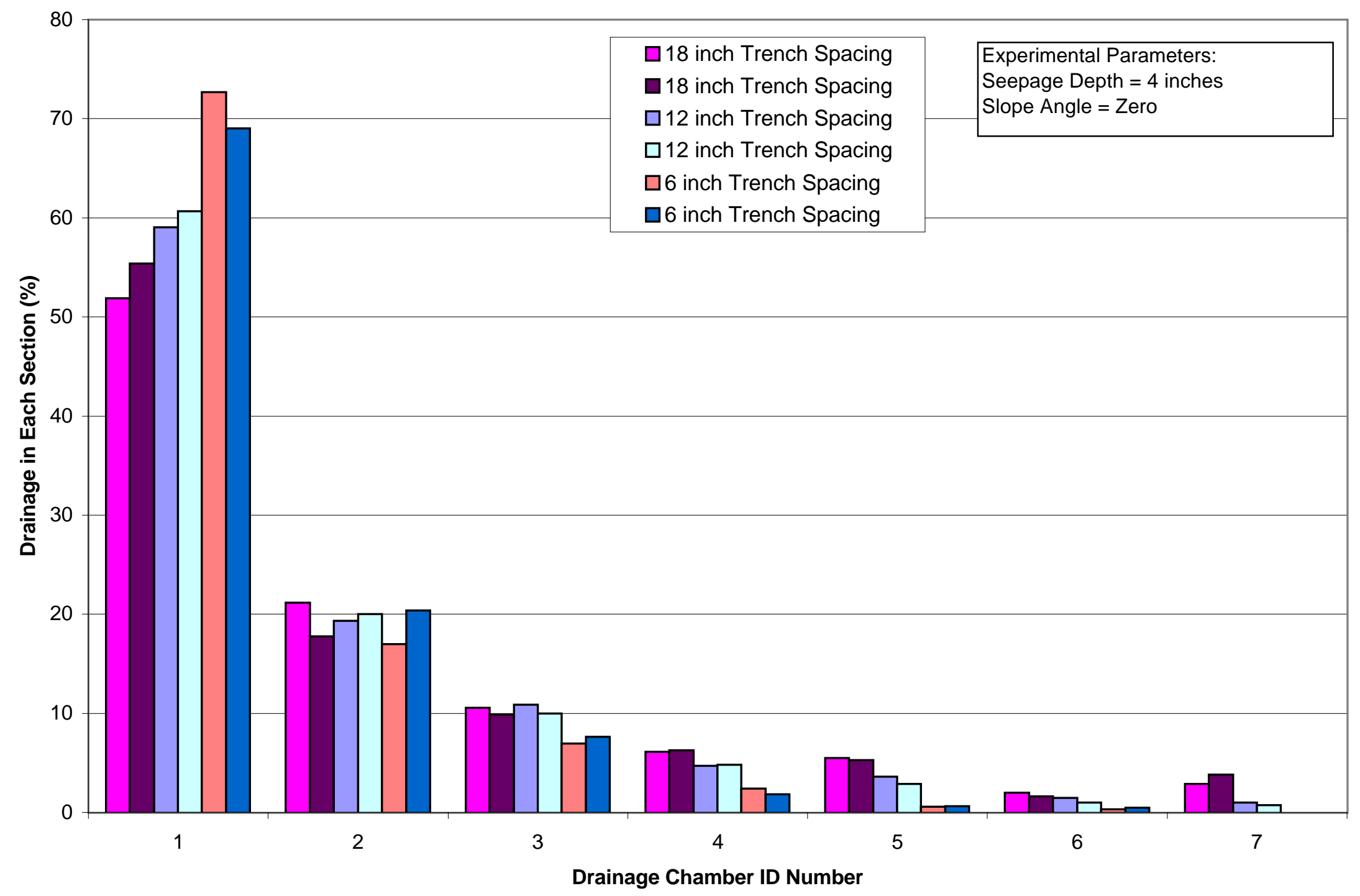

Figure C.6 Drainage Volumes for Each Segment for 4 inch Seepage Depth and Zero Slope Angle. 


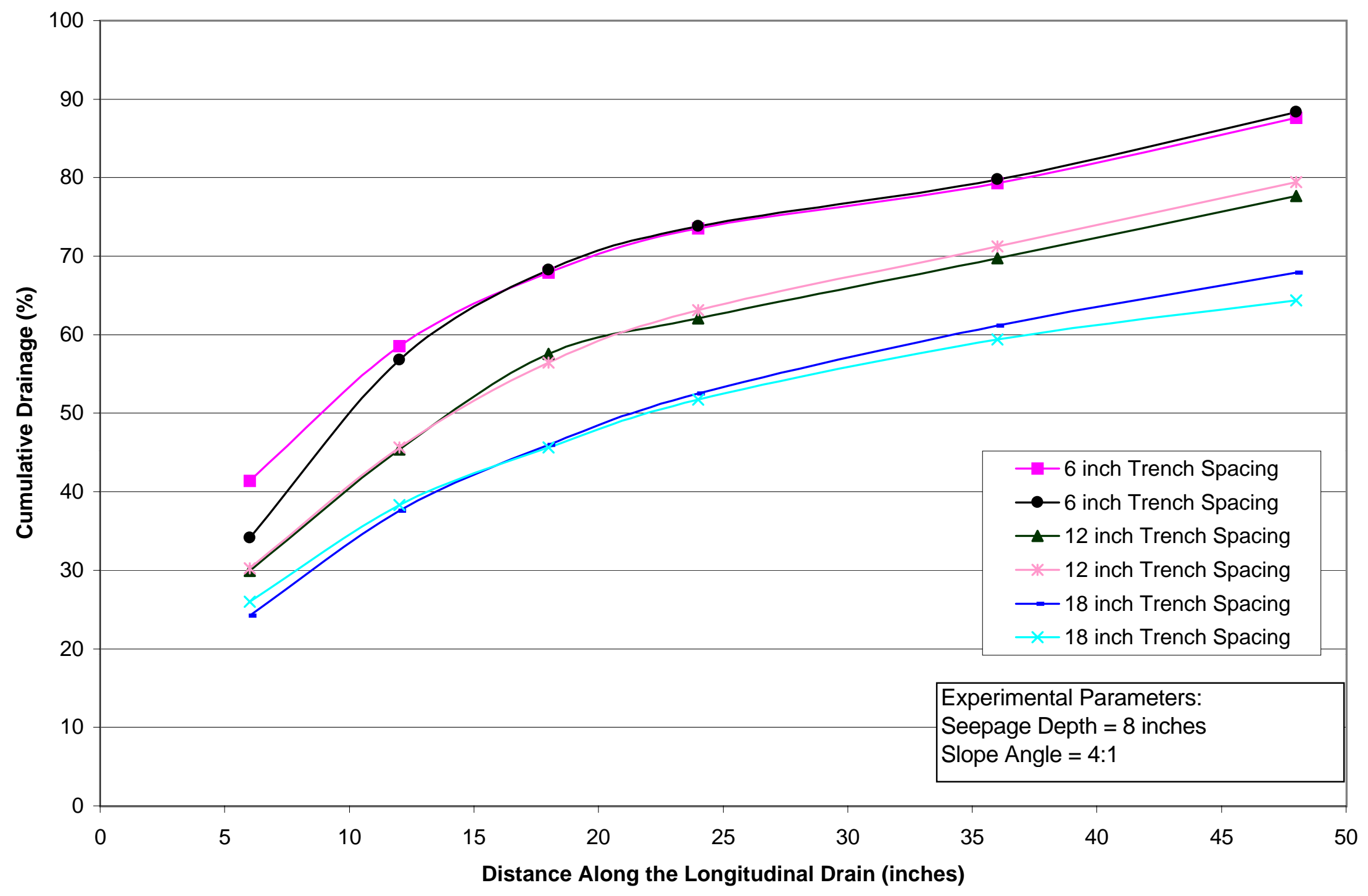

Figure C.7 Cumulative Drainage Volume for 8 inch Seepage Depth and 4:1 Slope Angle. 


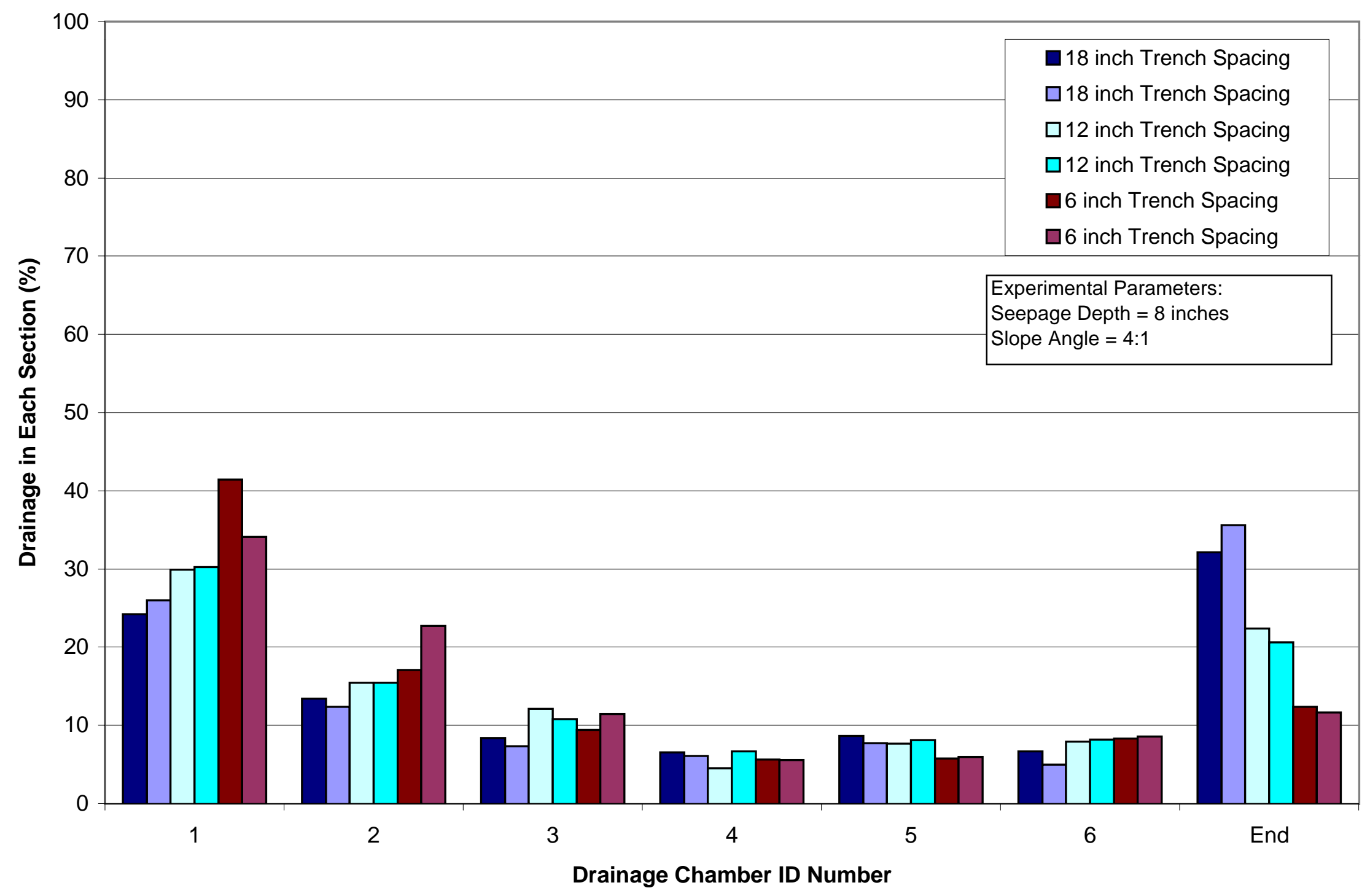

Figure C.8 Drainage Volume for Each Section for 8 inch Seepage Depth and 4:1 Slope Angle. 


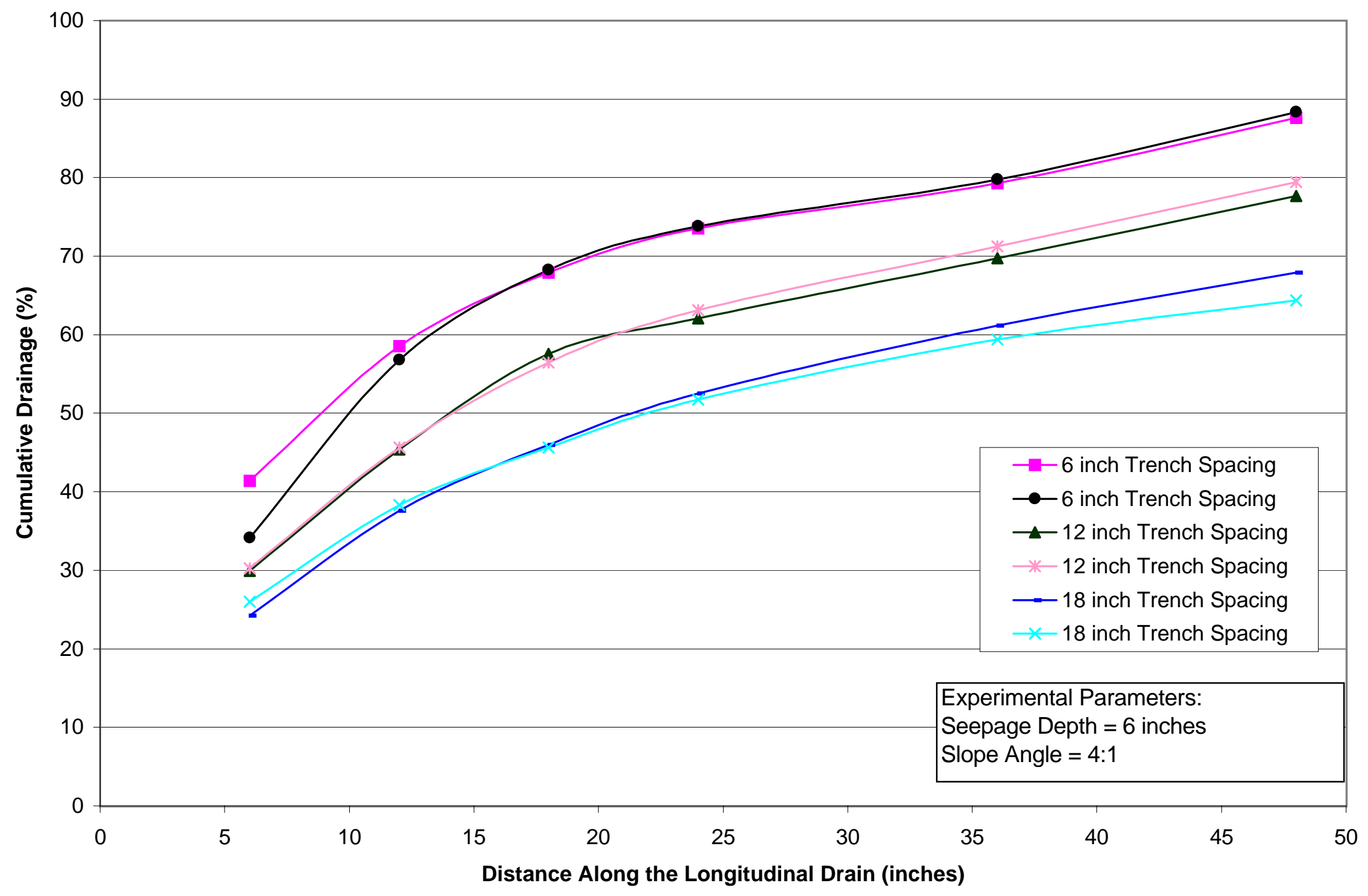

Figure C.9 Cumulative Drainage Volume for 6 inch Seepage Depth and 4:1 Slope Angle. 


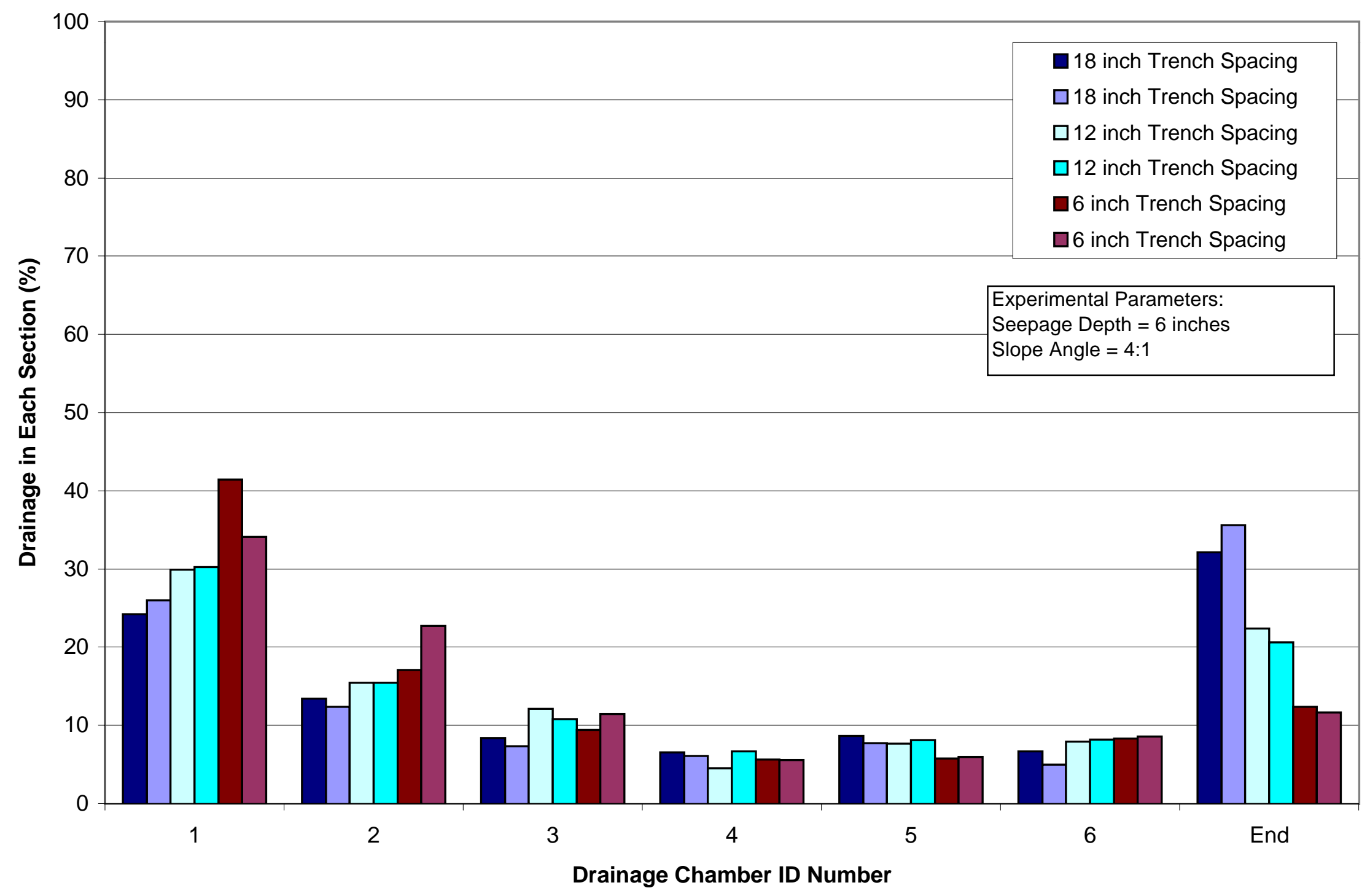

Figure C.10 Drainage Volume for Each Section for 6 inch Seepage Depth and 4:1 Slope Angle. 


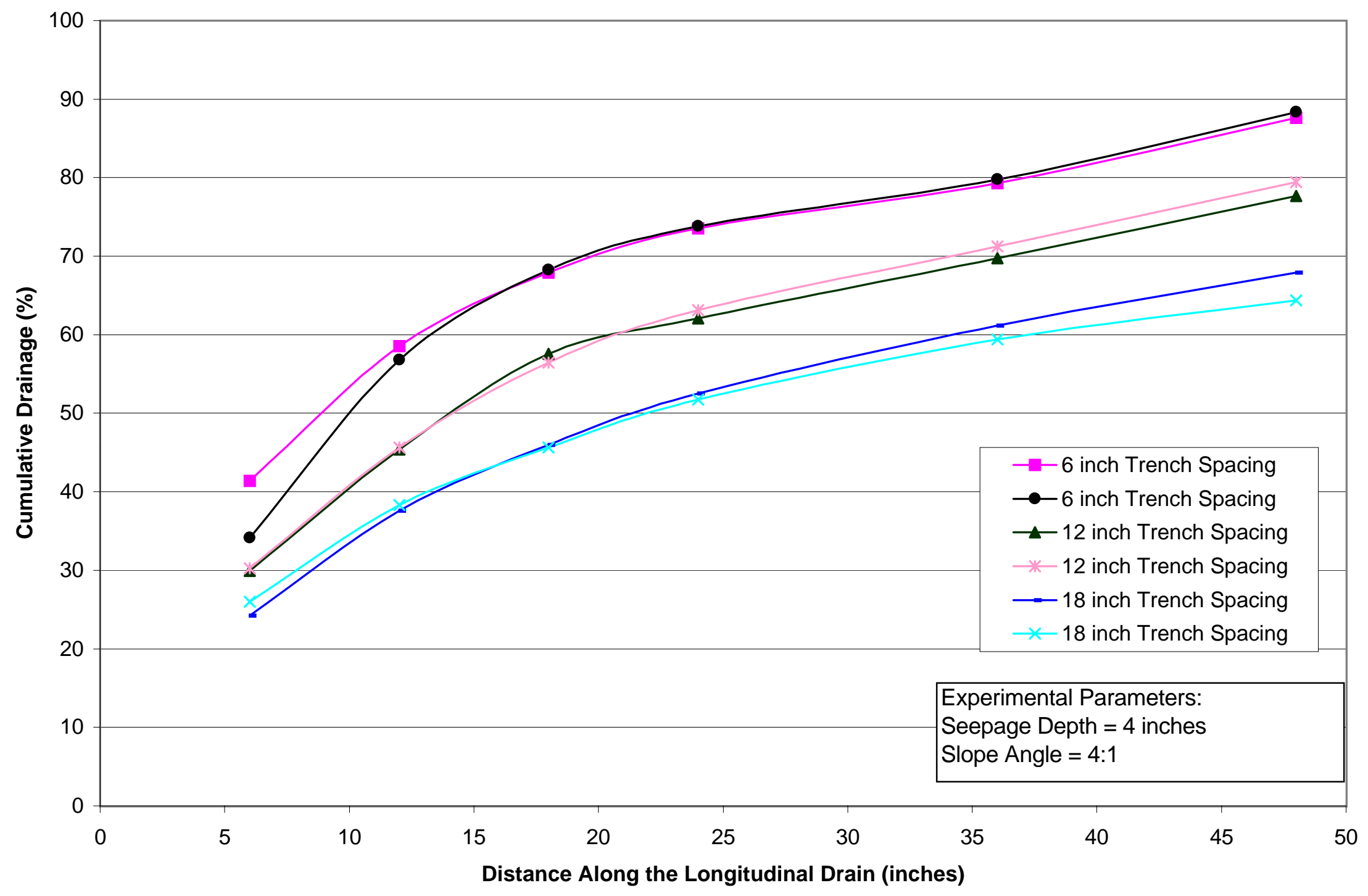

Figure C.11 Cumulative Drainage Volume for 4 inch Seepage Depth and 4:1 Slope Angle. 


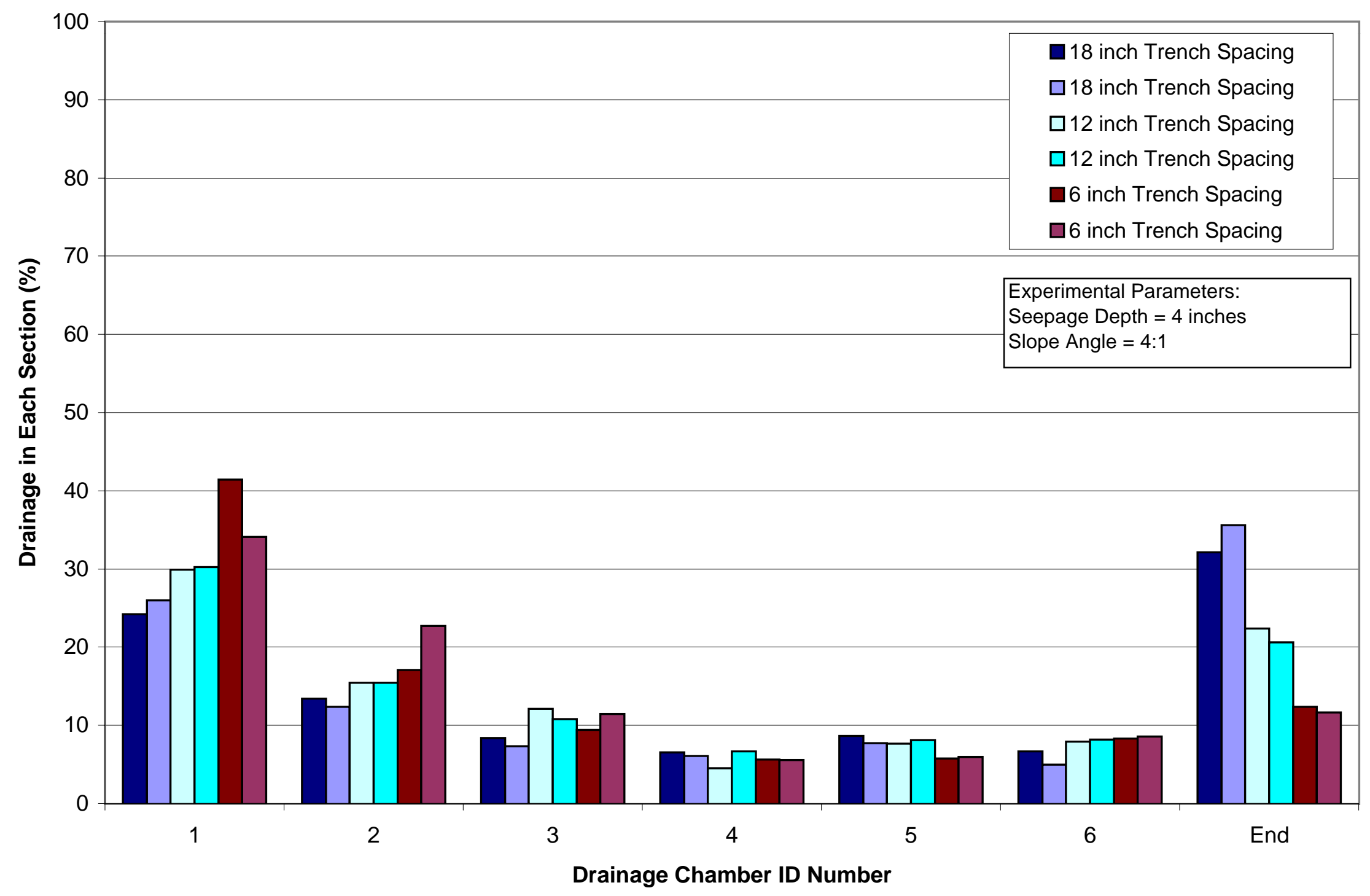

Figure C.12 Drainage Volume for Each Section for 4 inch Seepage Depth and 4:1 Slope Angle. 


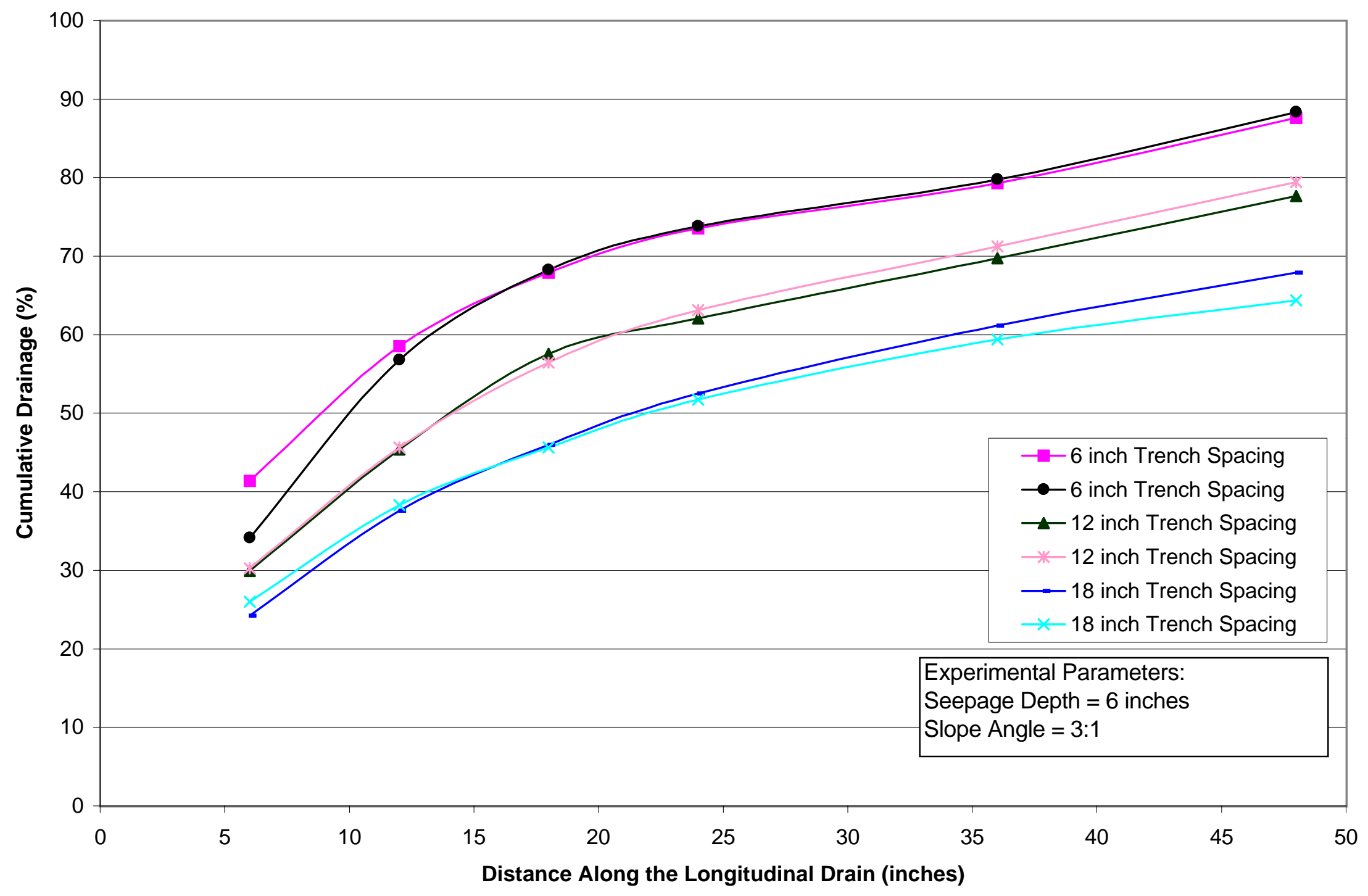

Figure C.15 Cumulative Drainage Volume for 6 inch Seepage Depth and 3:1 Slope Angle. 


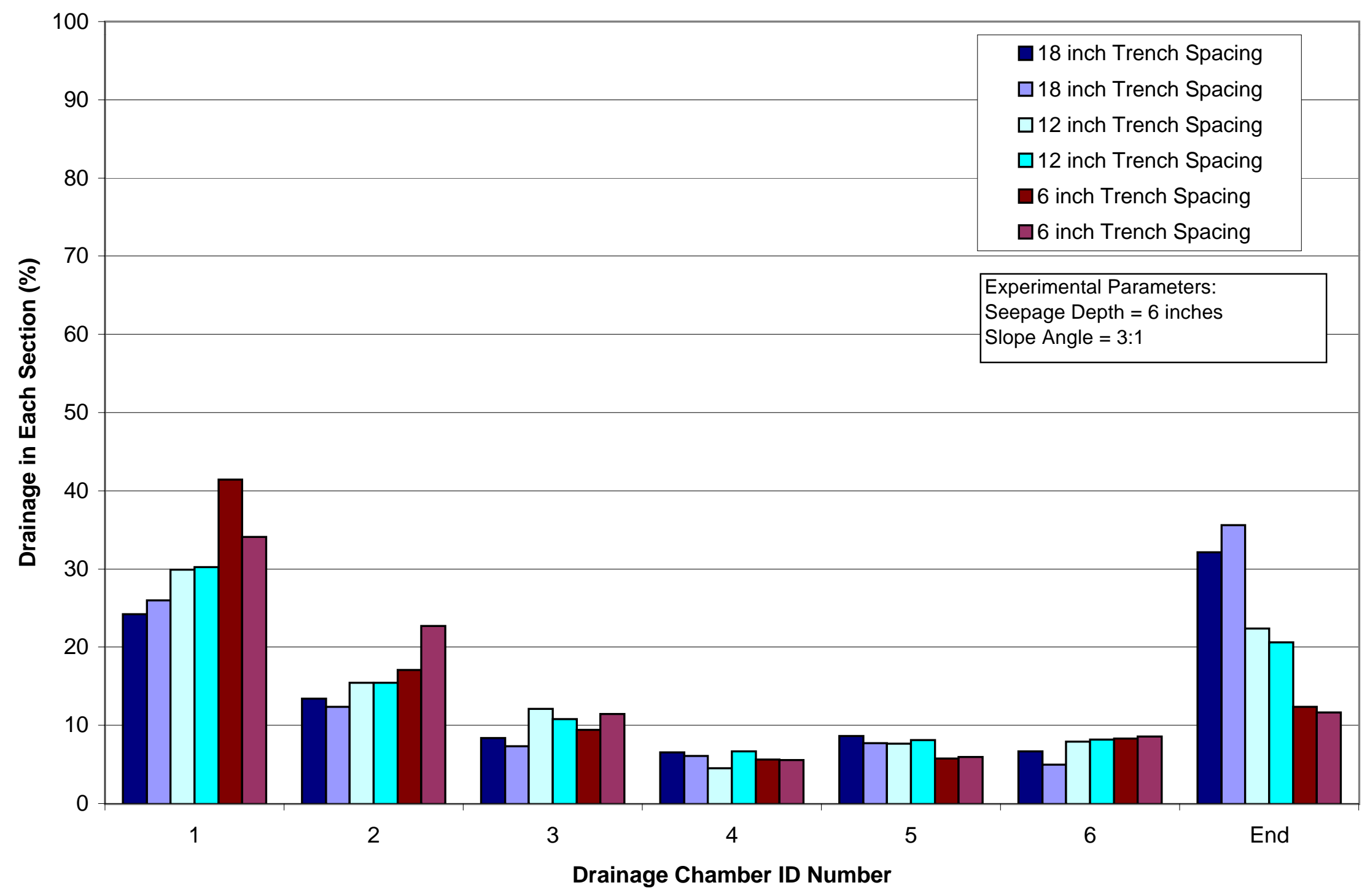

Figure C.16 Drainage Volume for Each Section for 6 inch Seepage Depth and 3:1 Slope Angle. 


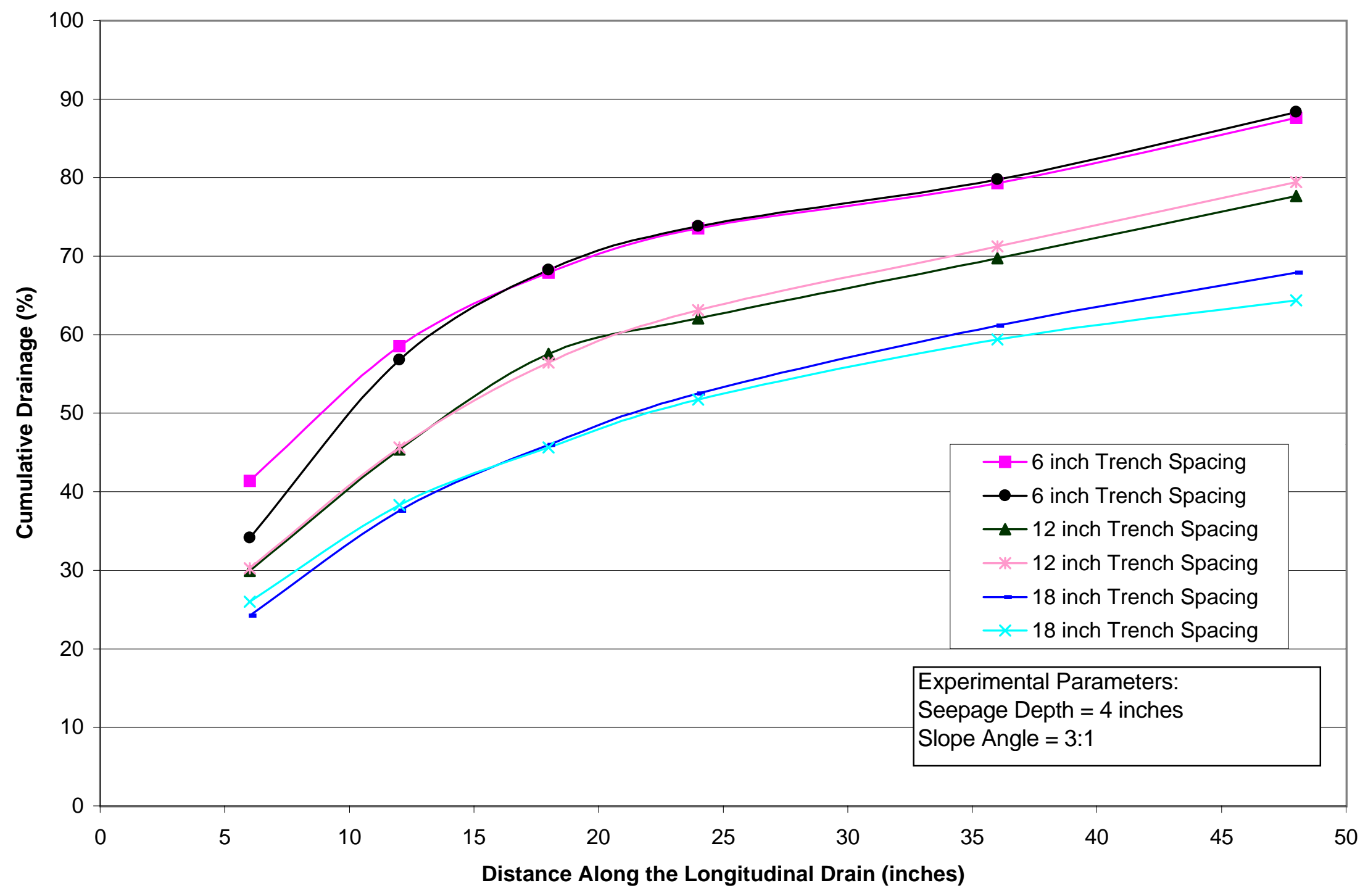

Figure C.17 Cumulative Drainage Volume for 4 inch Seepage Depth and 3:1 Slope Angle. 


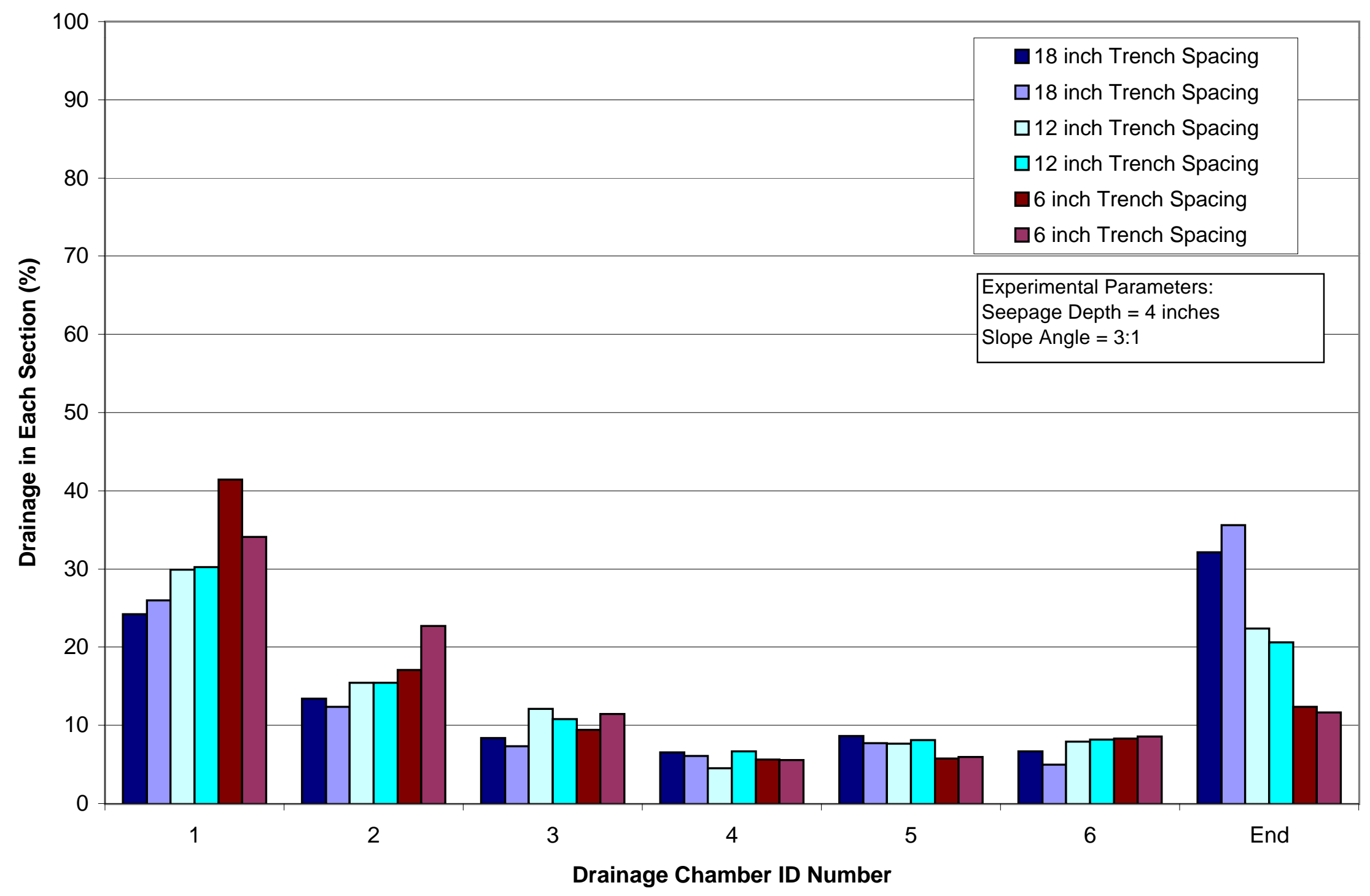

Figure C.18 Drainage Volume for Each Section for 4 inch Seepage Depth and 3:1 Slope Angle. 


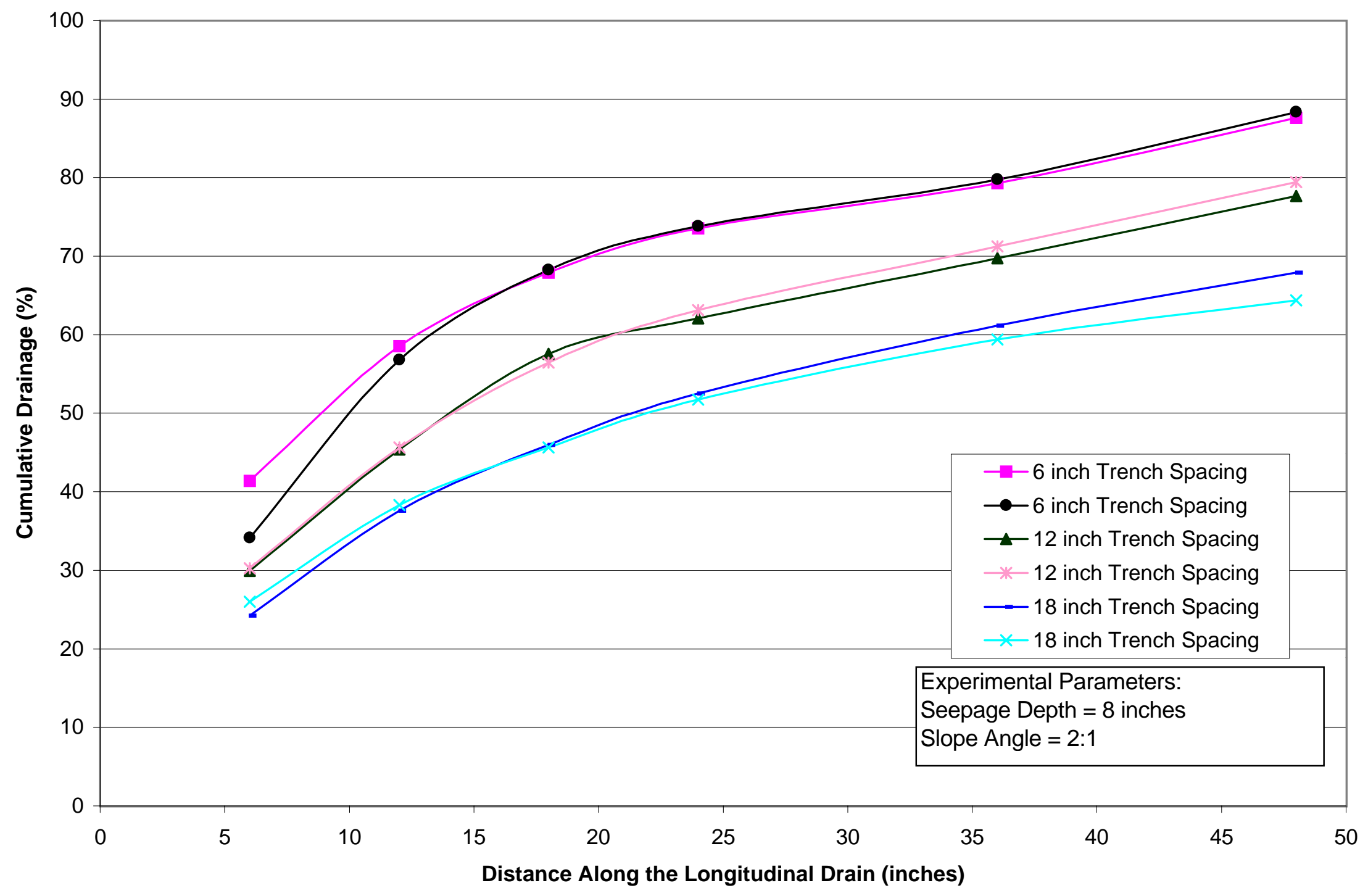

Figure C.19 Cumulative Drainage Volume for 8 inch Seepage Depth and 2:1 Slope Angle. 


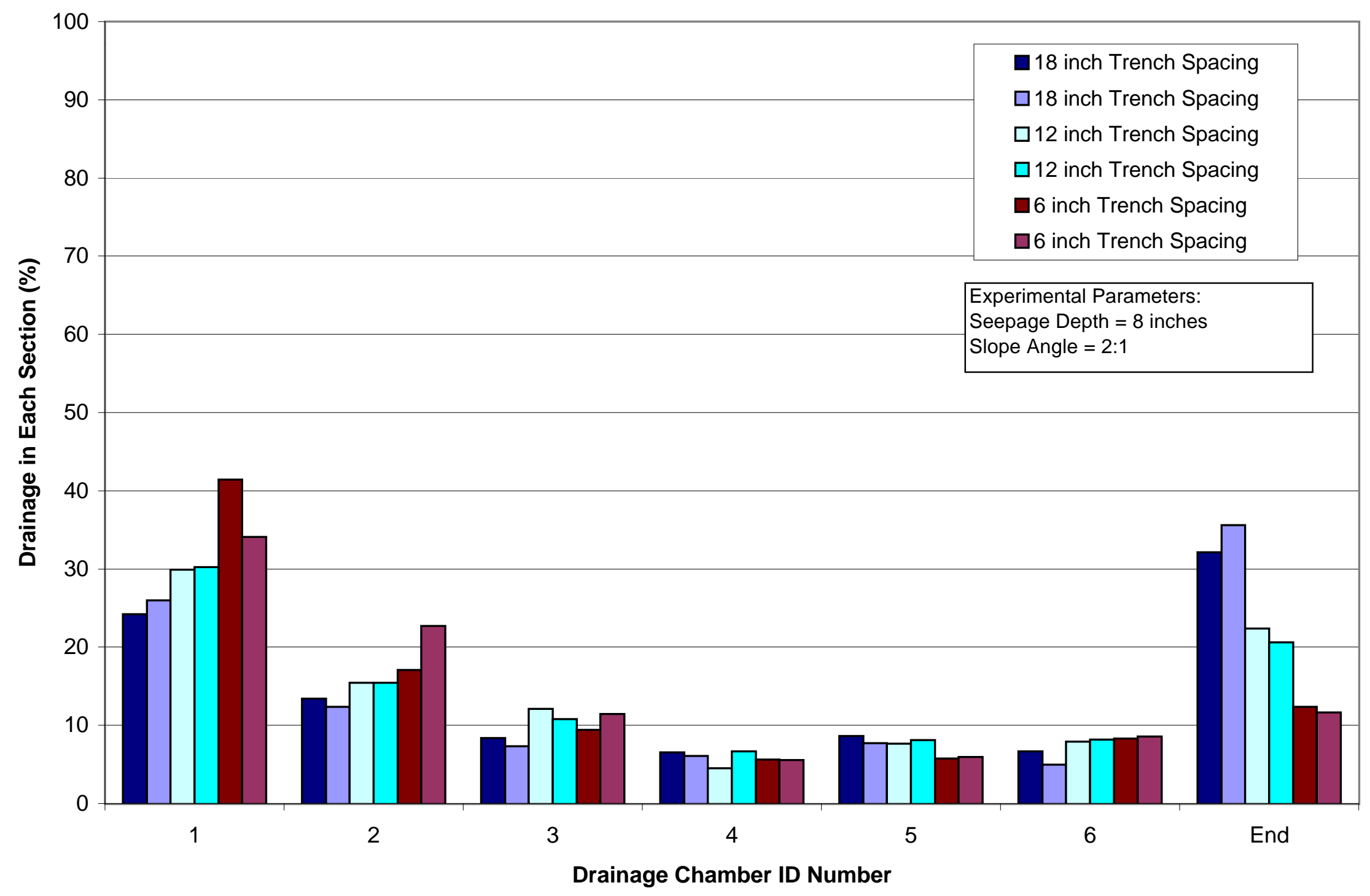

Figure C.20 Drainage Volume for Each Section for 8 inch Seepage Depth and 2:1 Slope Angle. 


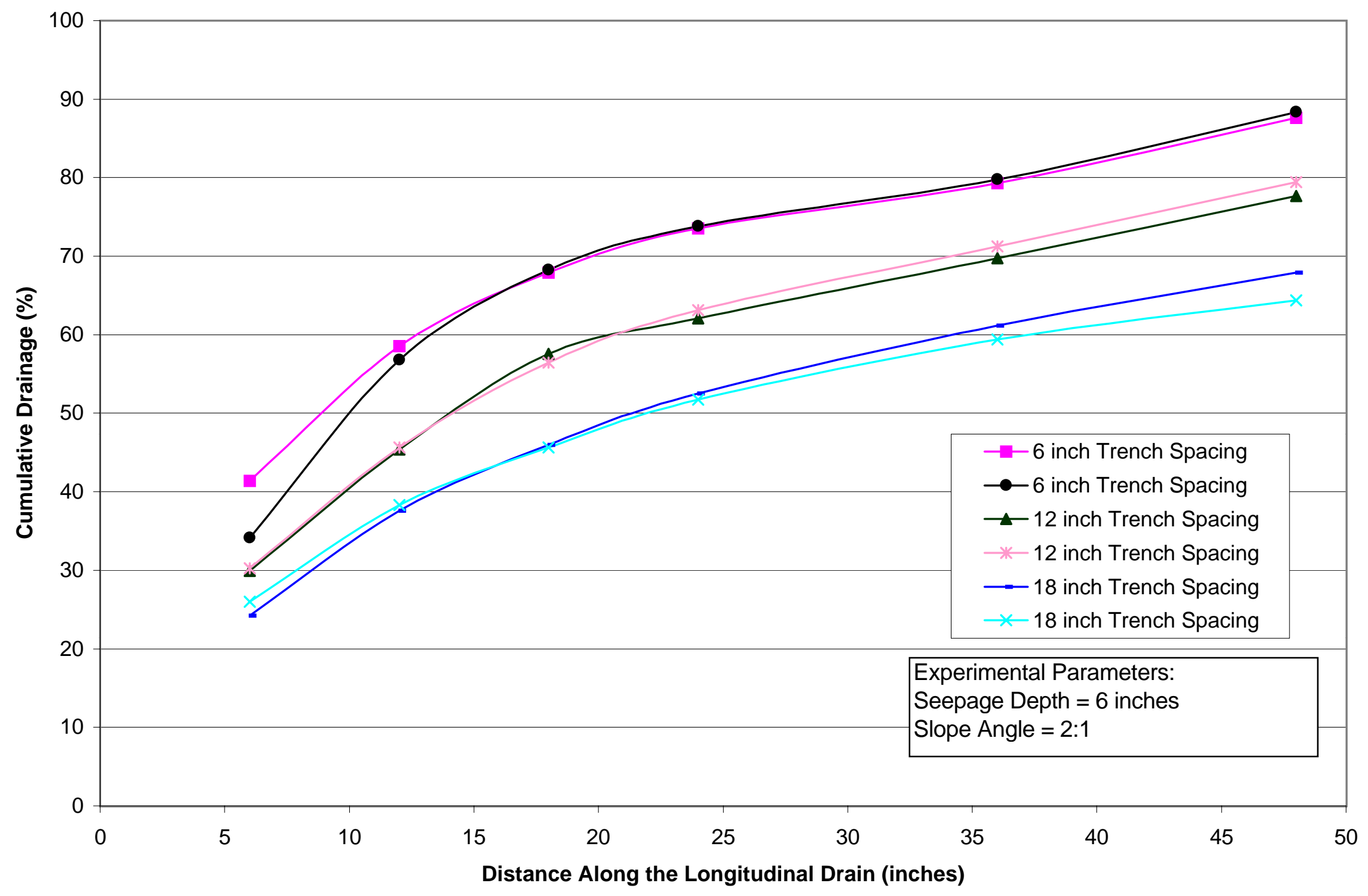

Figure C.21 Cumulative Drainage Volume for 6 inch Seepage Depth and 2:1 Slope Angle. 


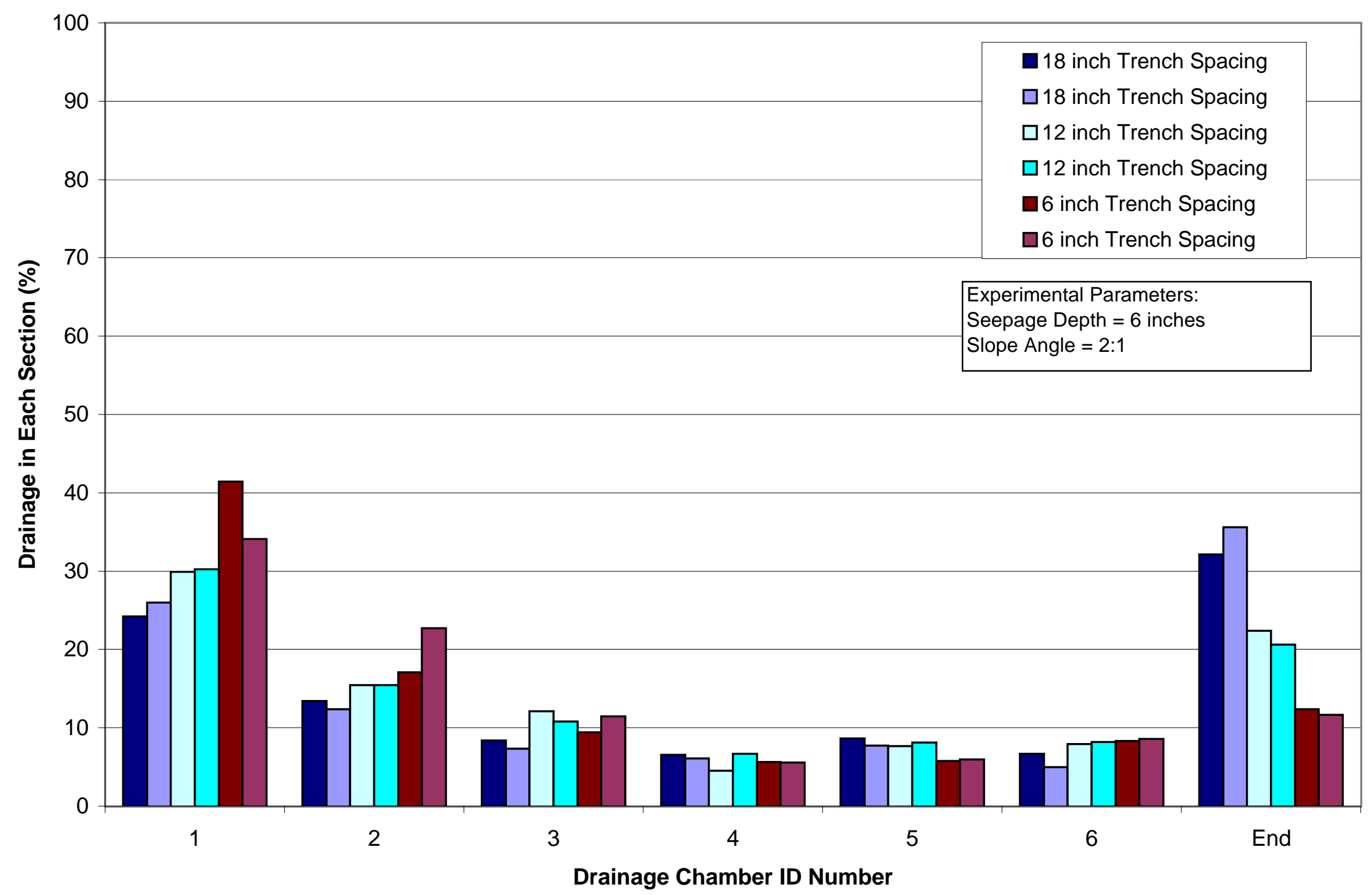

Figure C.22 Drainage Volume for Each Section for 6 inch Seepage Depth and 2:1 Slope Angle. 


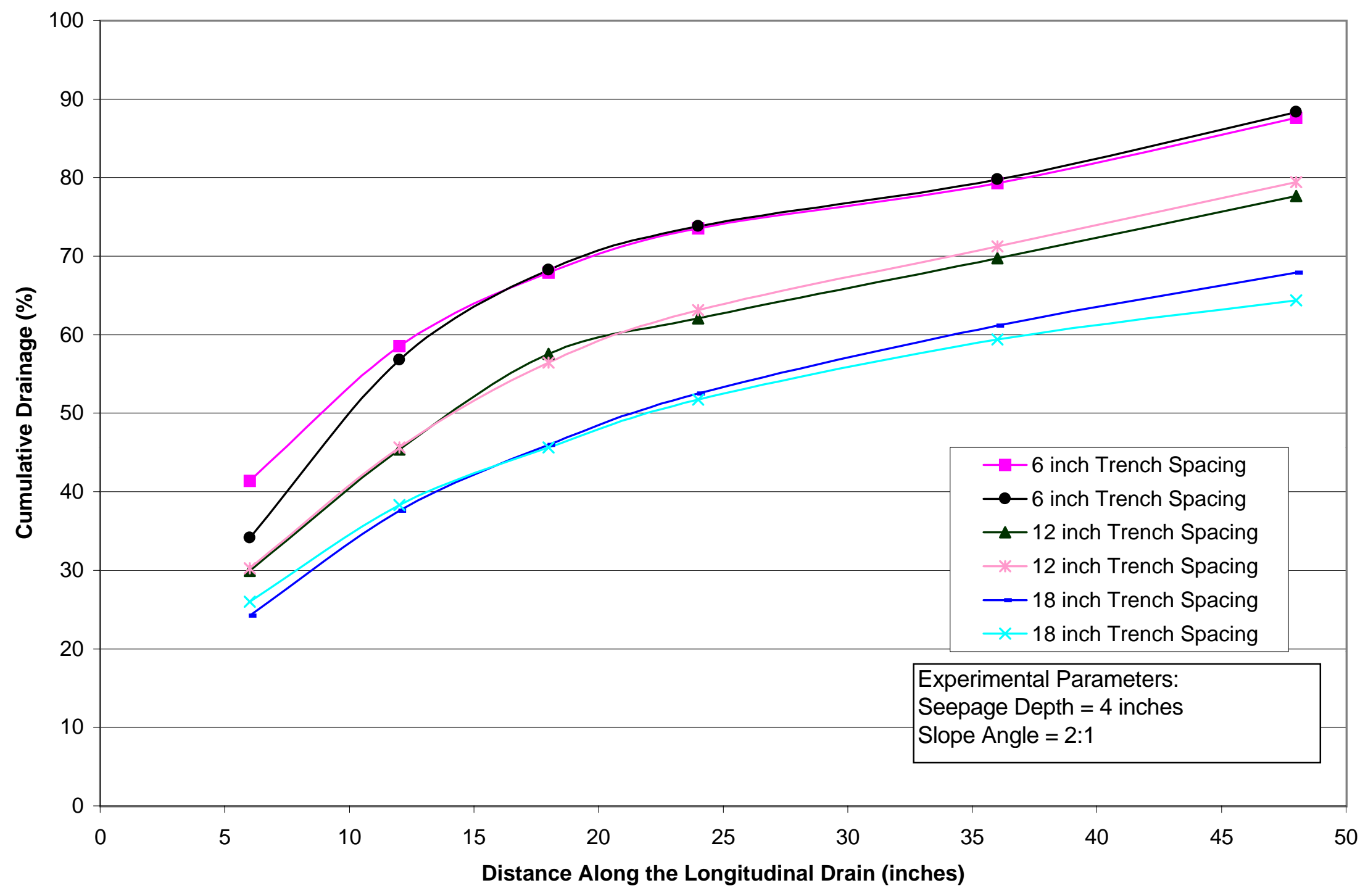

Figure C.23 Cumulative Drainage Volume for 4 inch Seepage Depth and 2:1 Slope Angle. 


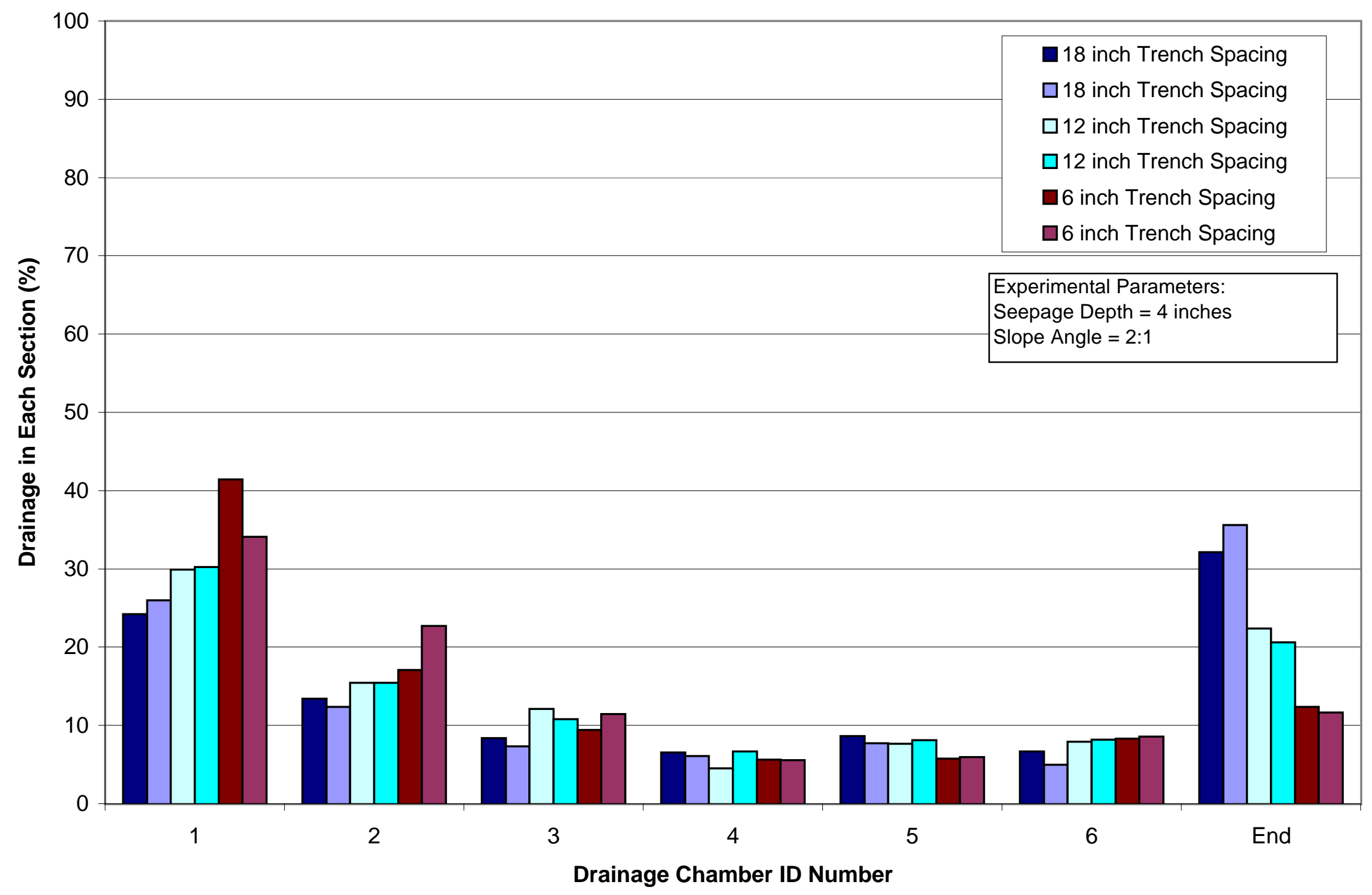

Figure C.24 Drainage Volume for Each Section for 4 inch Seepage Depth and 2:1 Slope Angle. 
Appendix D

Data on the Flow Rate in Each Drainage Chamber 


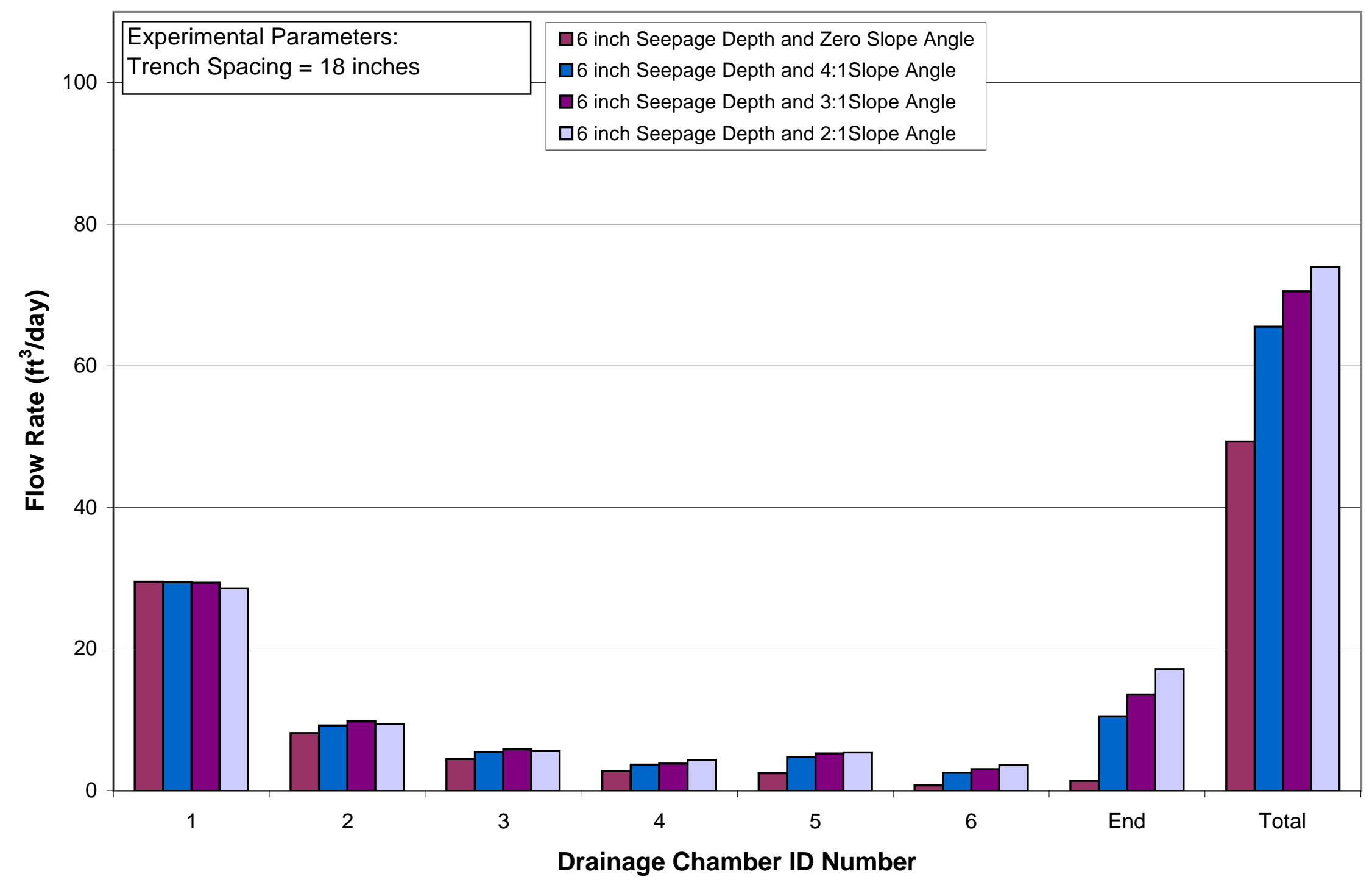

Figure D.2 Flow Rates for Each Drain Segment for 18 inch Trench Spacing and 6 inch Seepage Depth. 


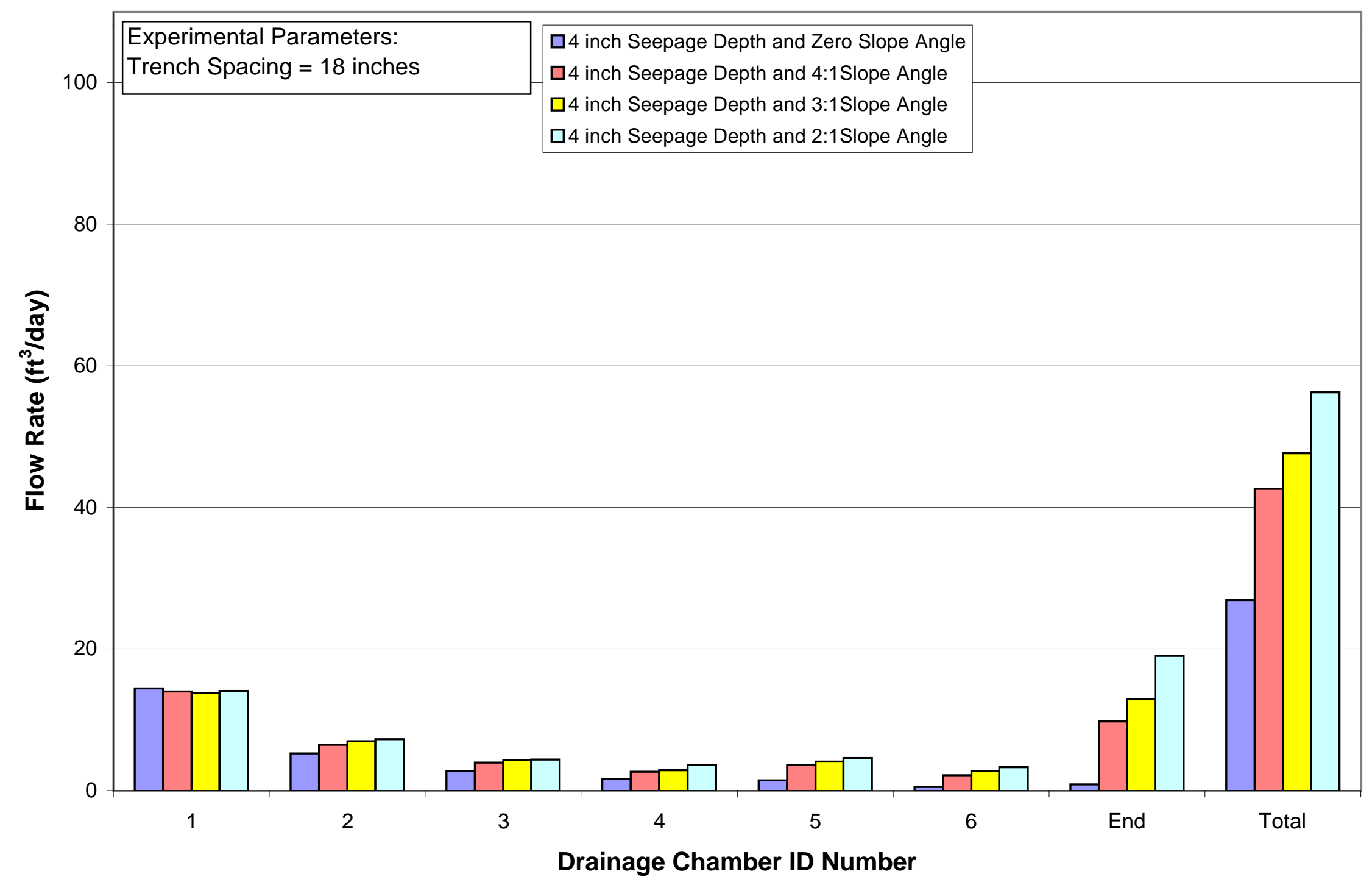

Figure D.3 Flow Rates for Each Drain Section for 18 inch Trench Spacing and 4 inch Seepage Depth. 


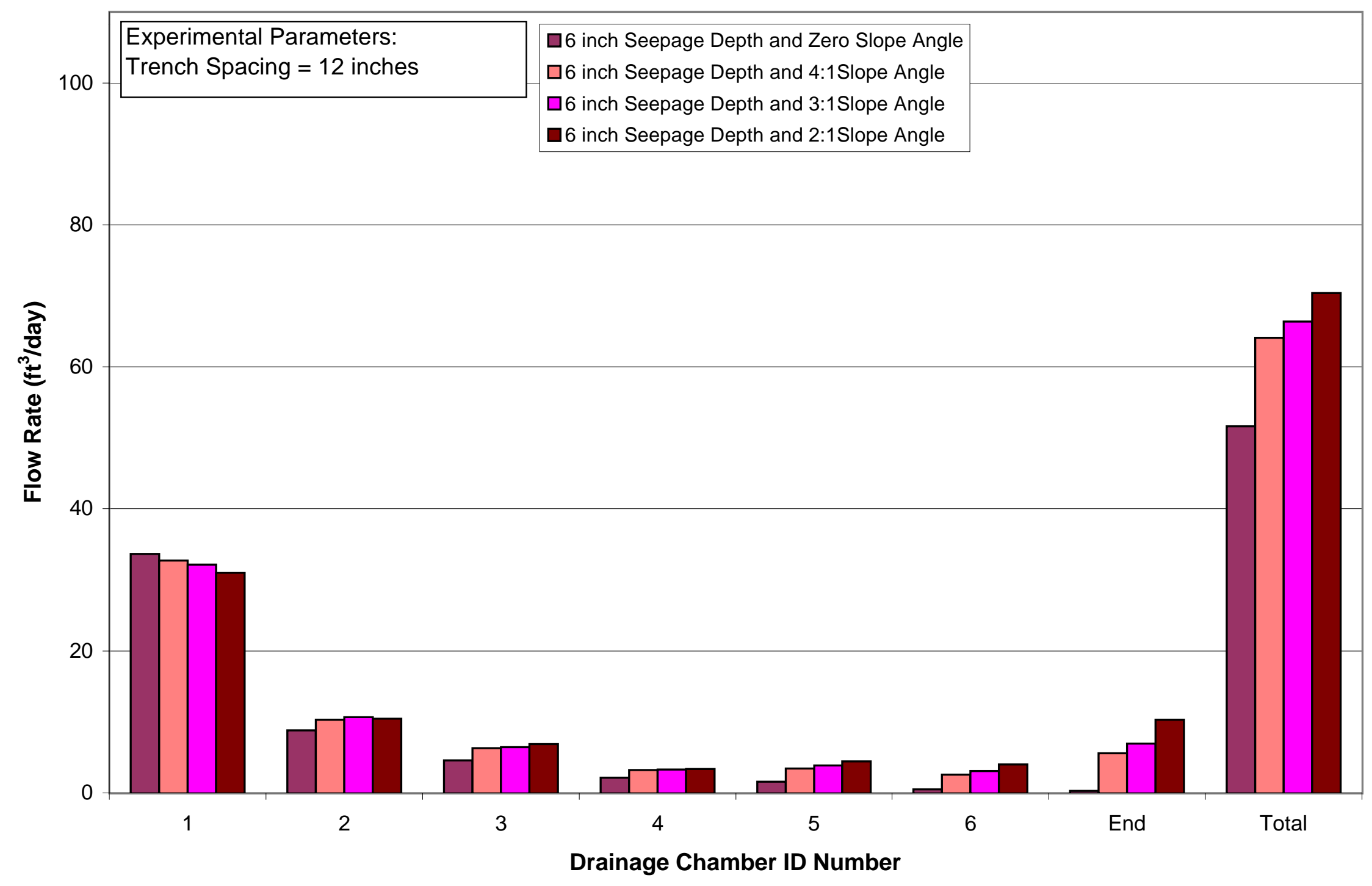

Figure D.5 Flow Rates for Each Drain Section for 12 inch Trench Spacing and 6 inch Seepage Depth. 


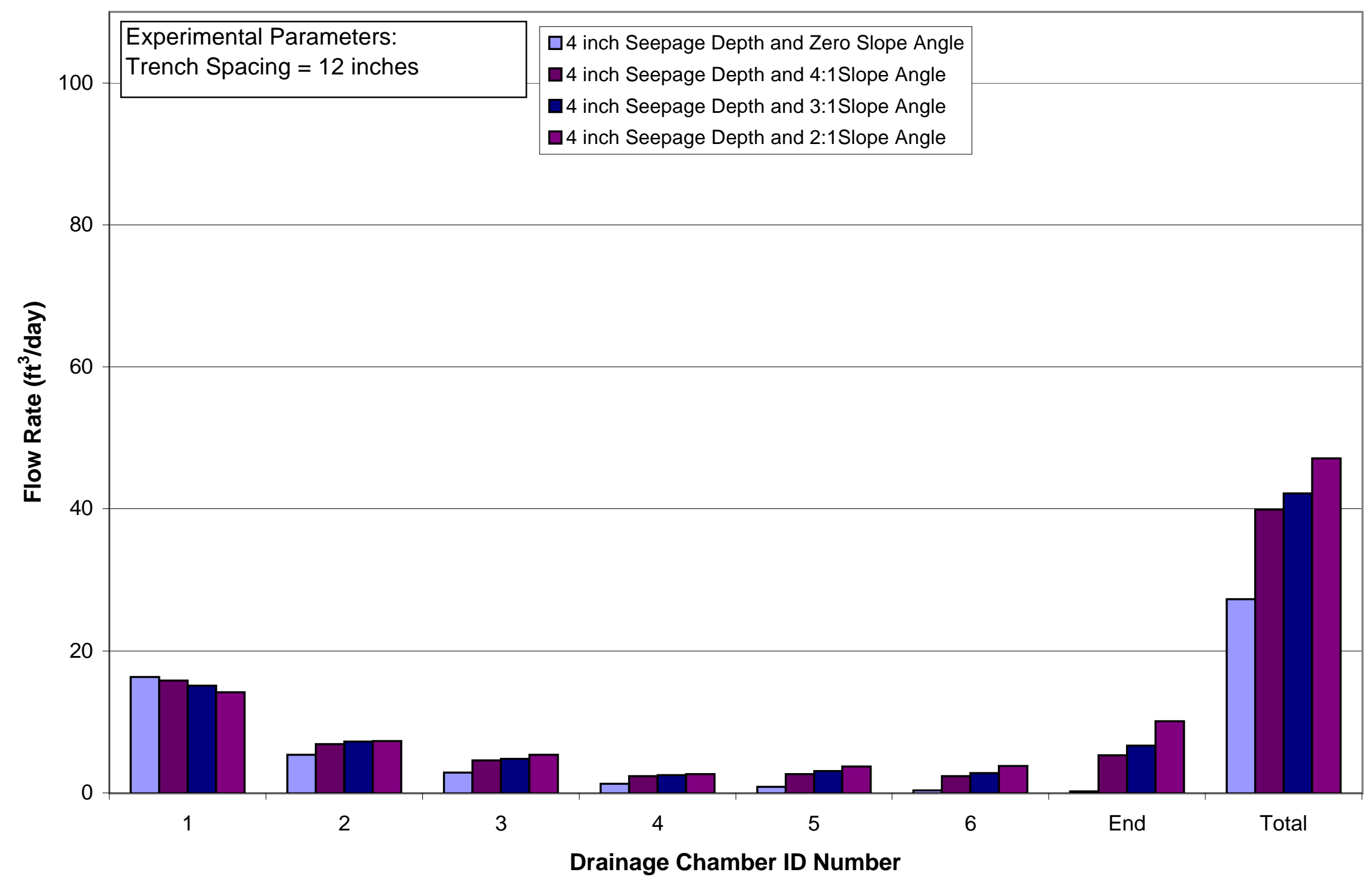

Figure D.6 Flow Rates for Each Drain Section for 12 inch Trench Spacing and 4 inch Seepage Depth. 


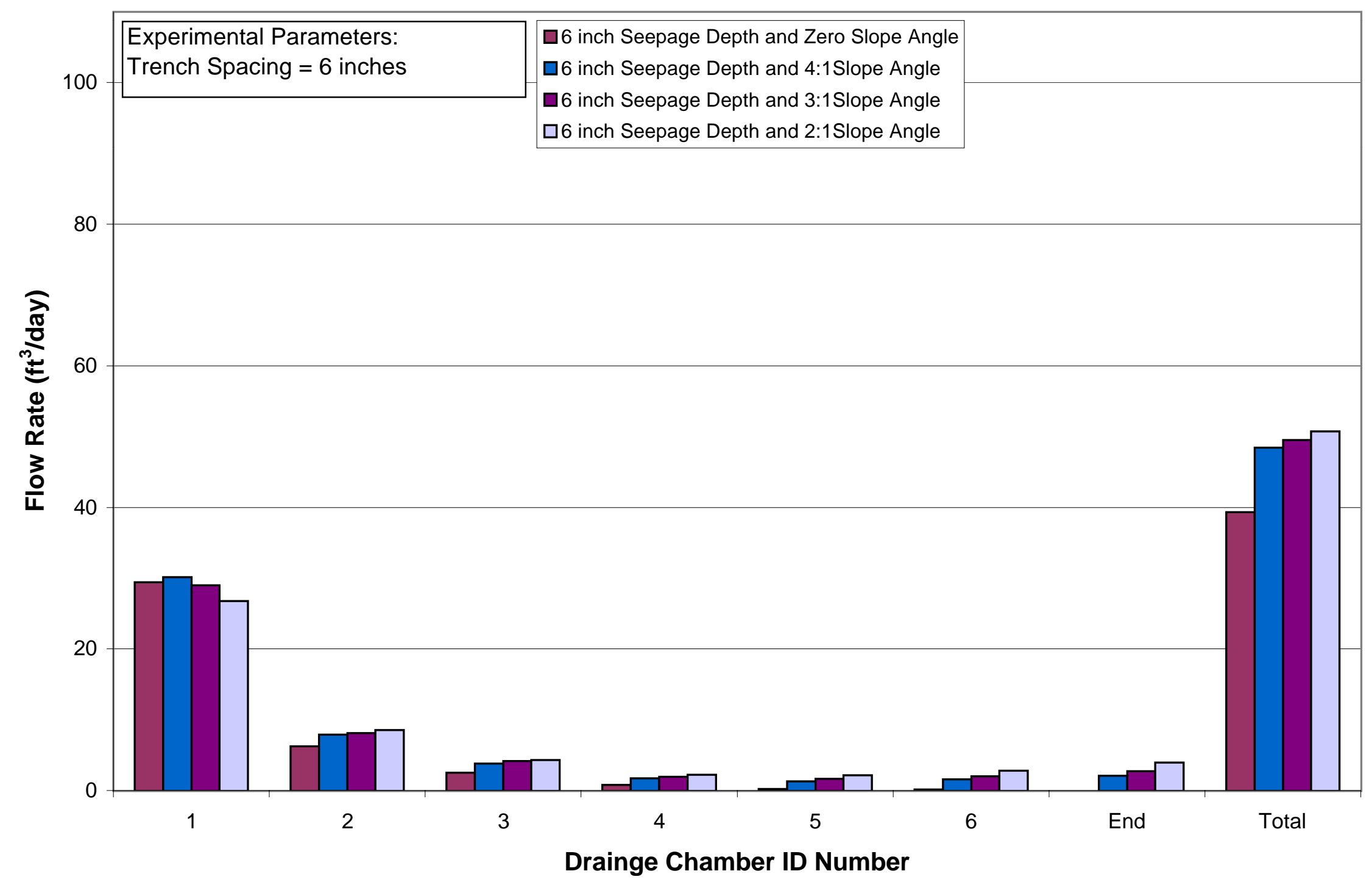

Figure D.8 Flow Rates for Each Drain Section for 6 inch Trench Spacing and 6 inch Seepage Depth. 


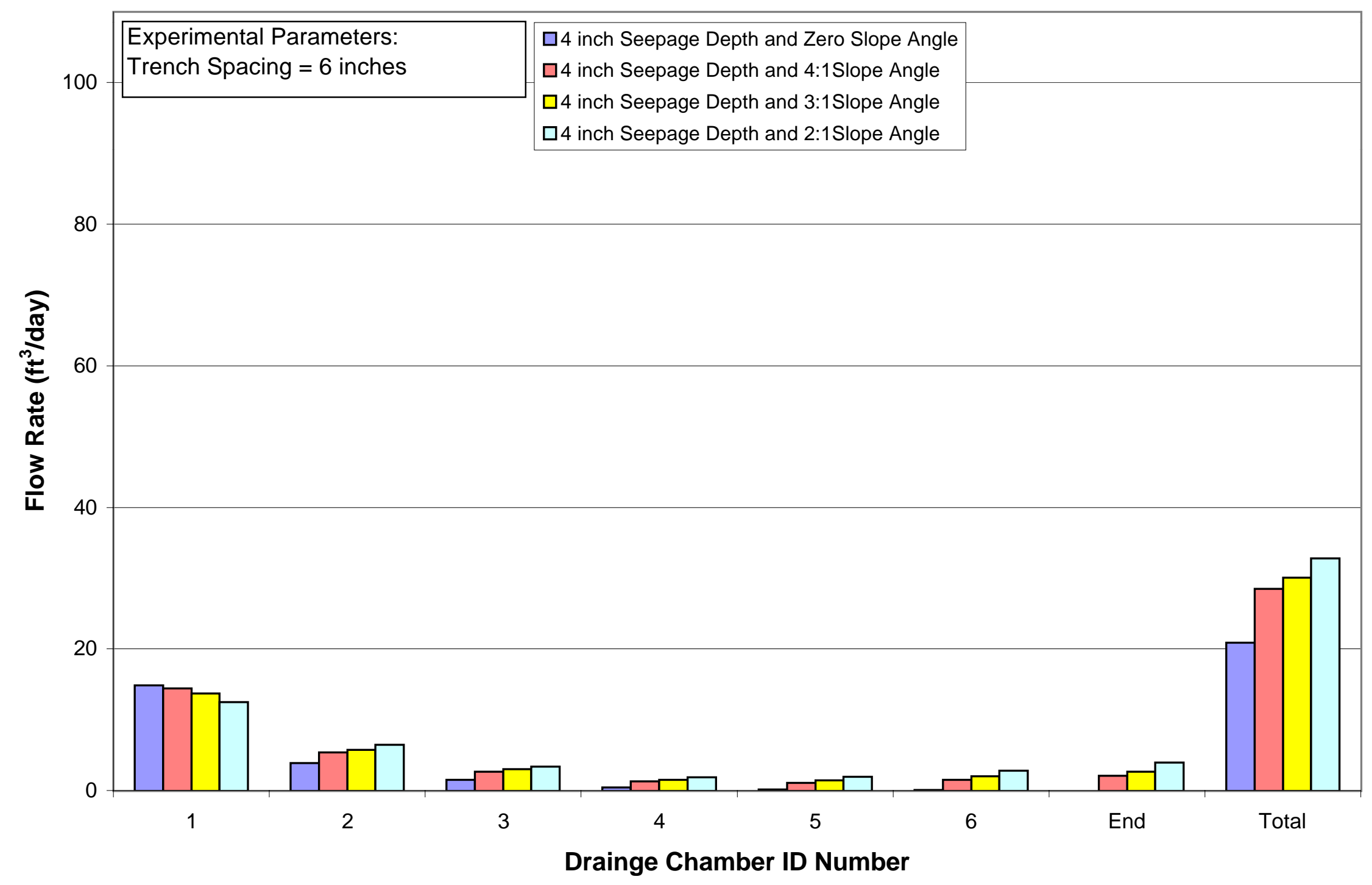

Figure D.9 Flow Rates for Each Drain Section for 6 inch Trench Spacing and 4 inch Seepage Depth. 
Appendix E

Data on Piezometric Measurements 


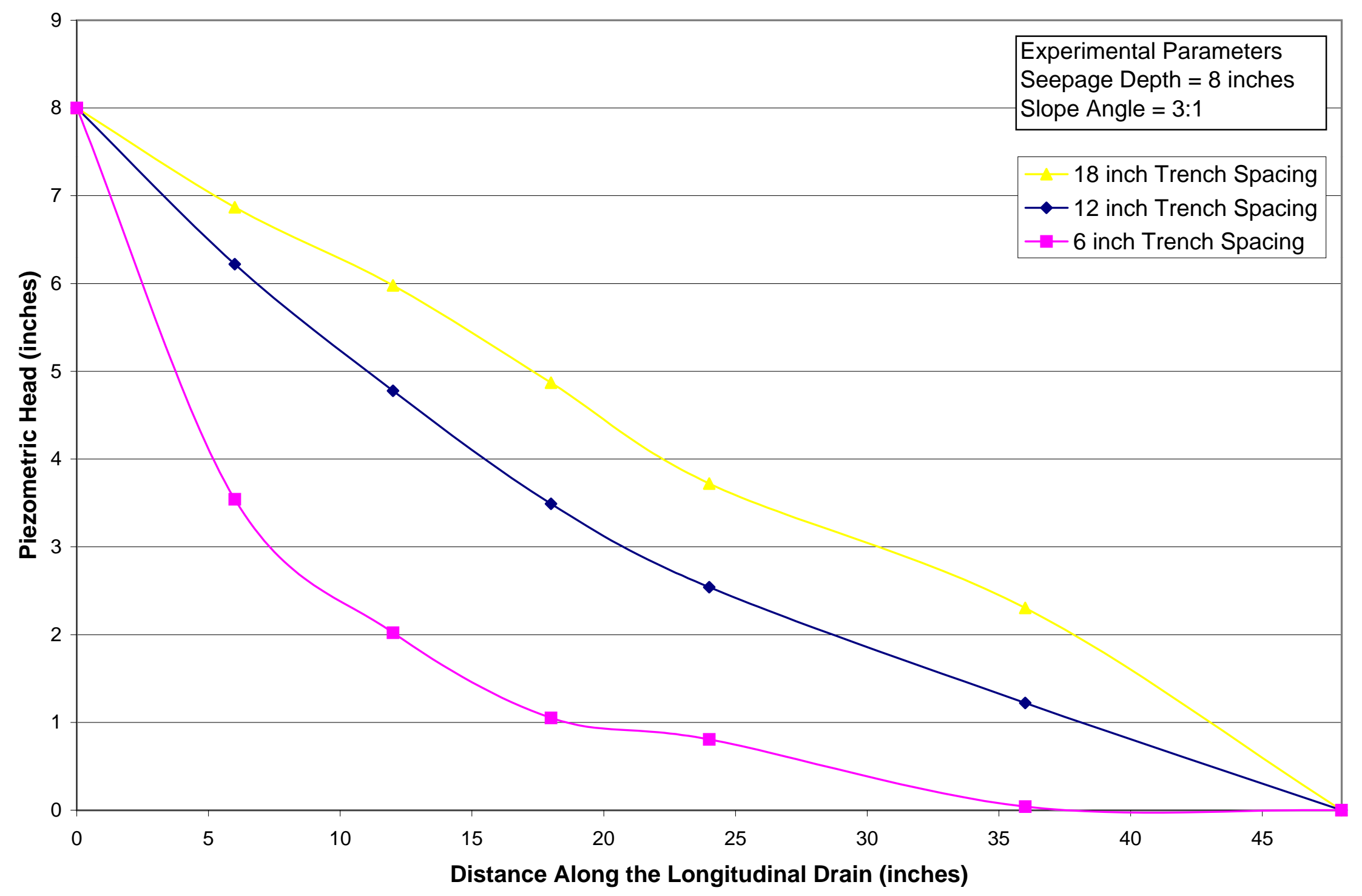

Figure E.2 Piezometric Head at the Centerline Between two Drains for 8 inch Seepage Depth and 3:1 Slope Angle. 


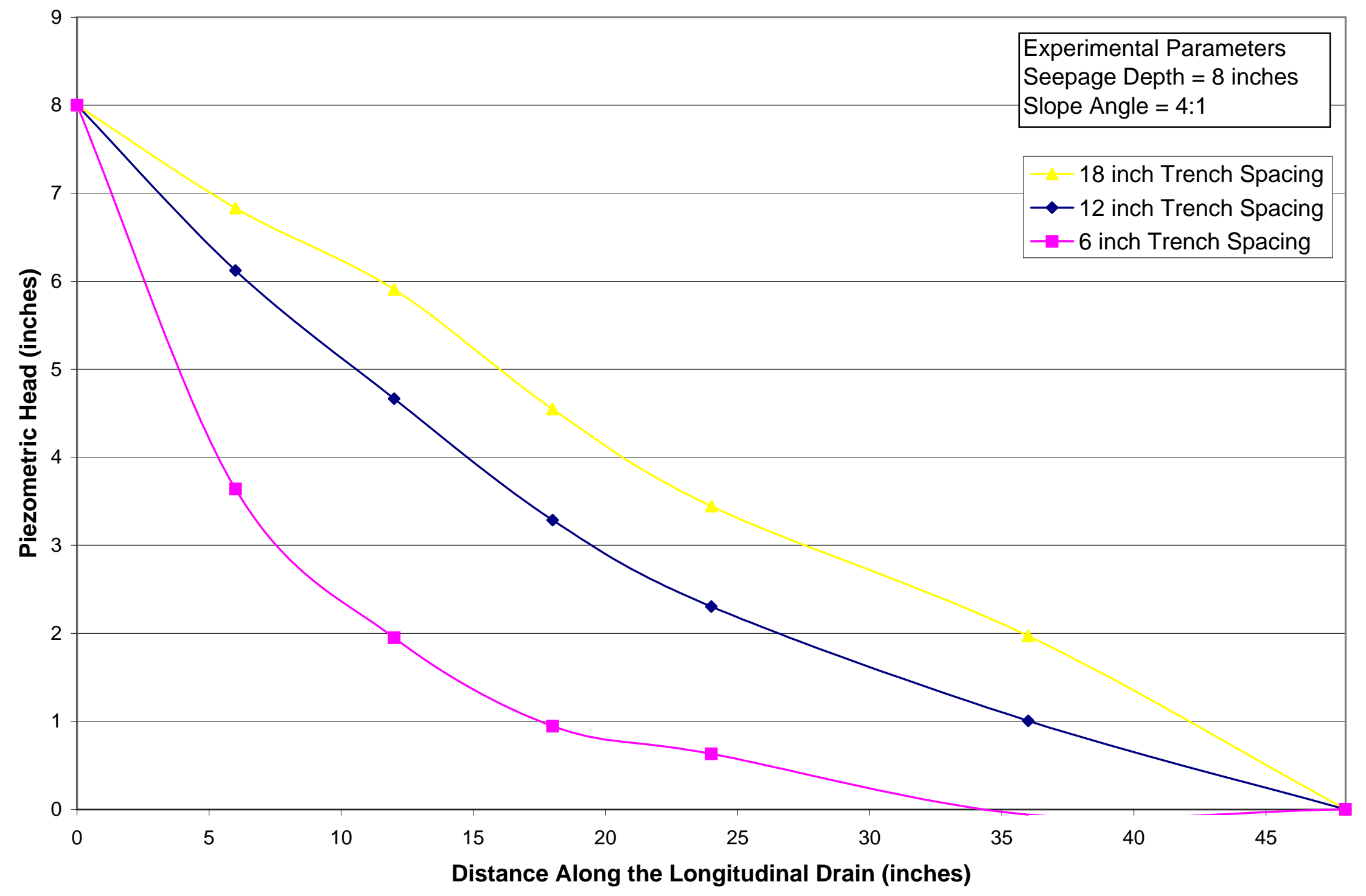

Figure E.3 Piezometric Head at the Centerline Between Drains for 8 inch Seepage Depth and 4:1 Slope Angle. 


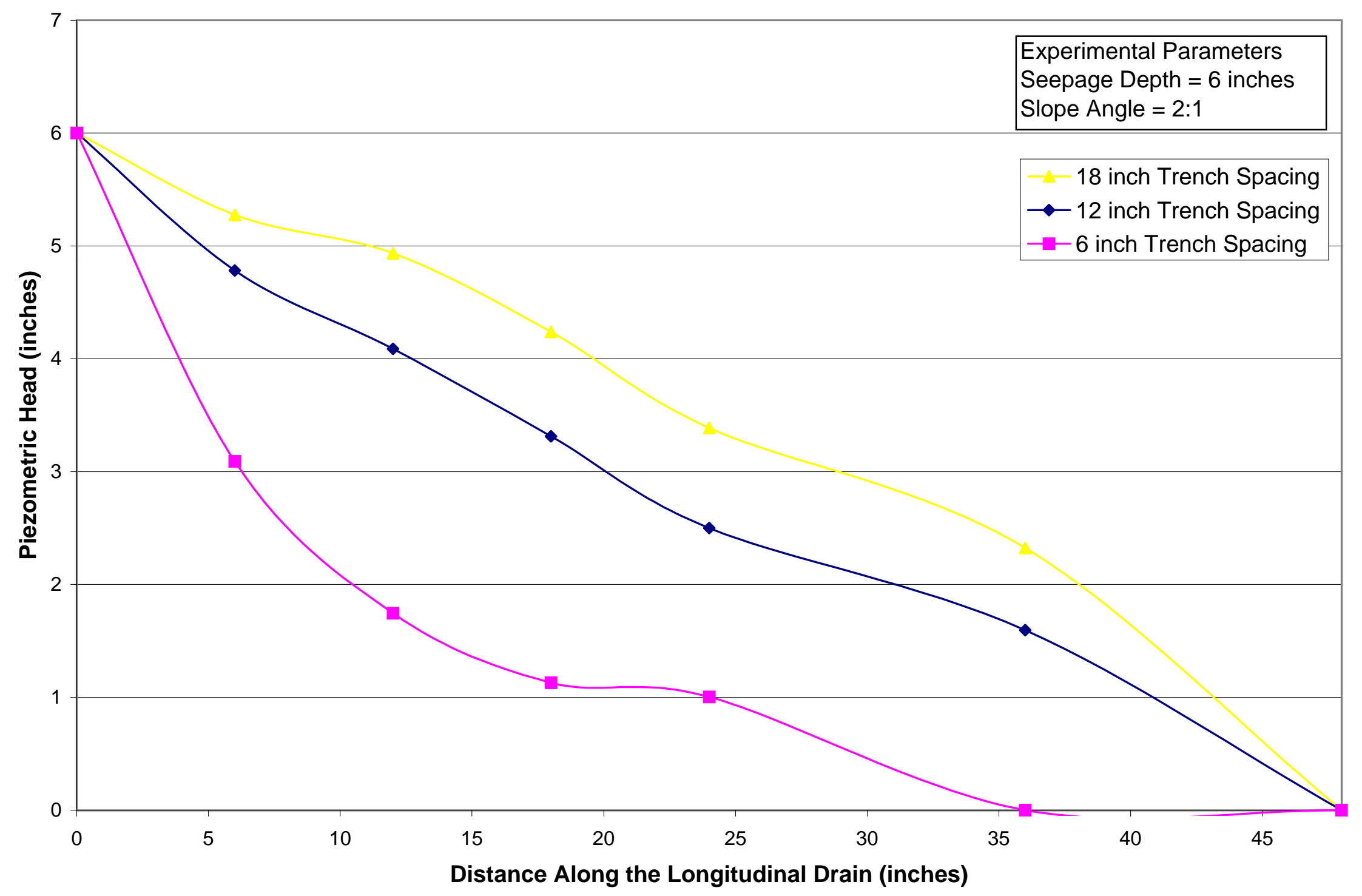

Figure E.4 Piezometric Head at the Centerline Between Drains for 6 inch Seepage Depth and 2:1 Slope Angle. 


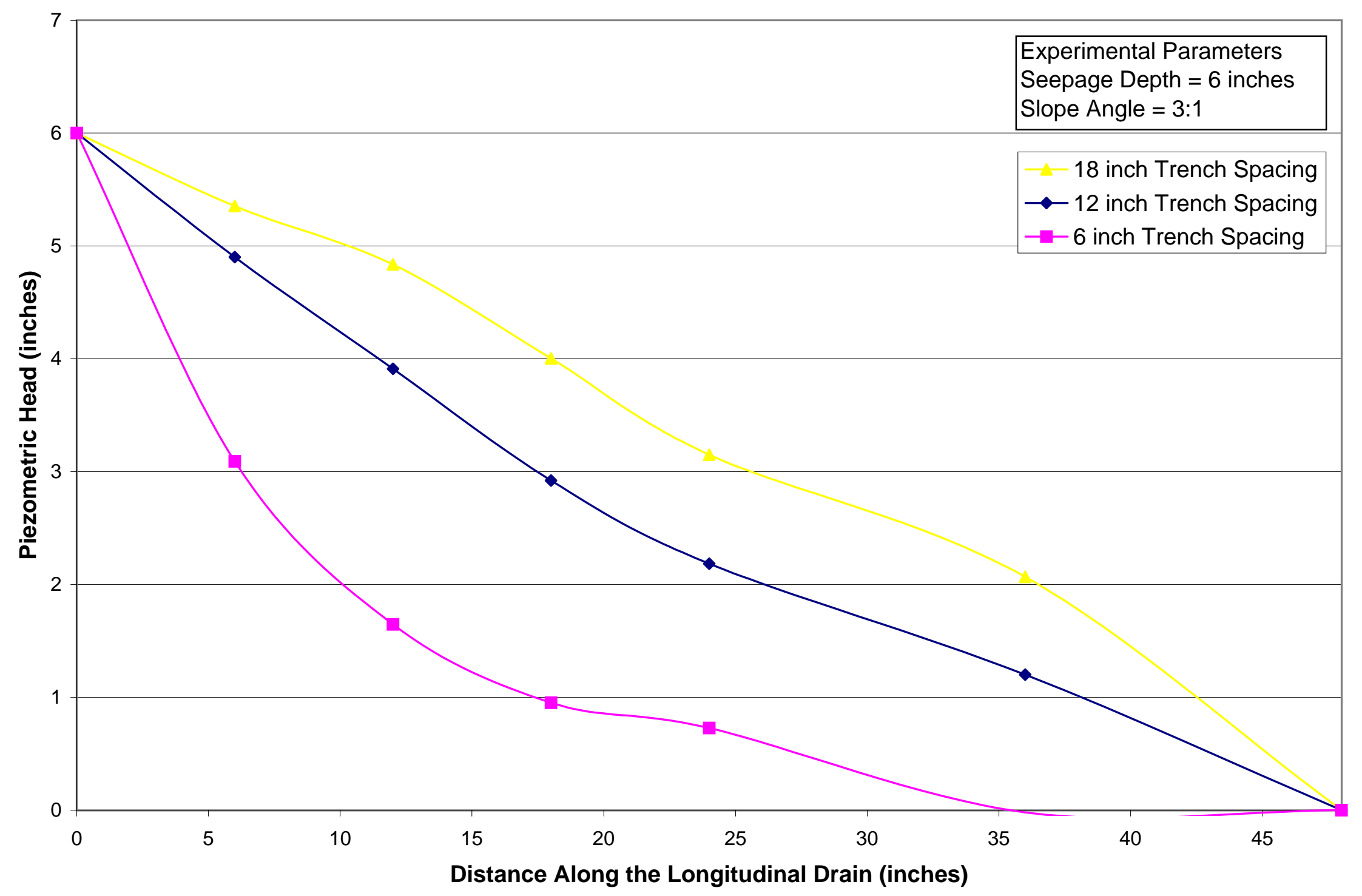

Figure E.5 Piezometric Head at the Centerline Between Drains for 6 inch Seepage Depth and 3:1 Slope Angle. 


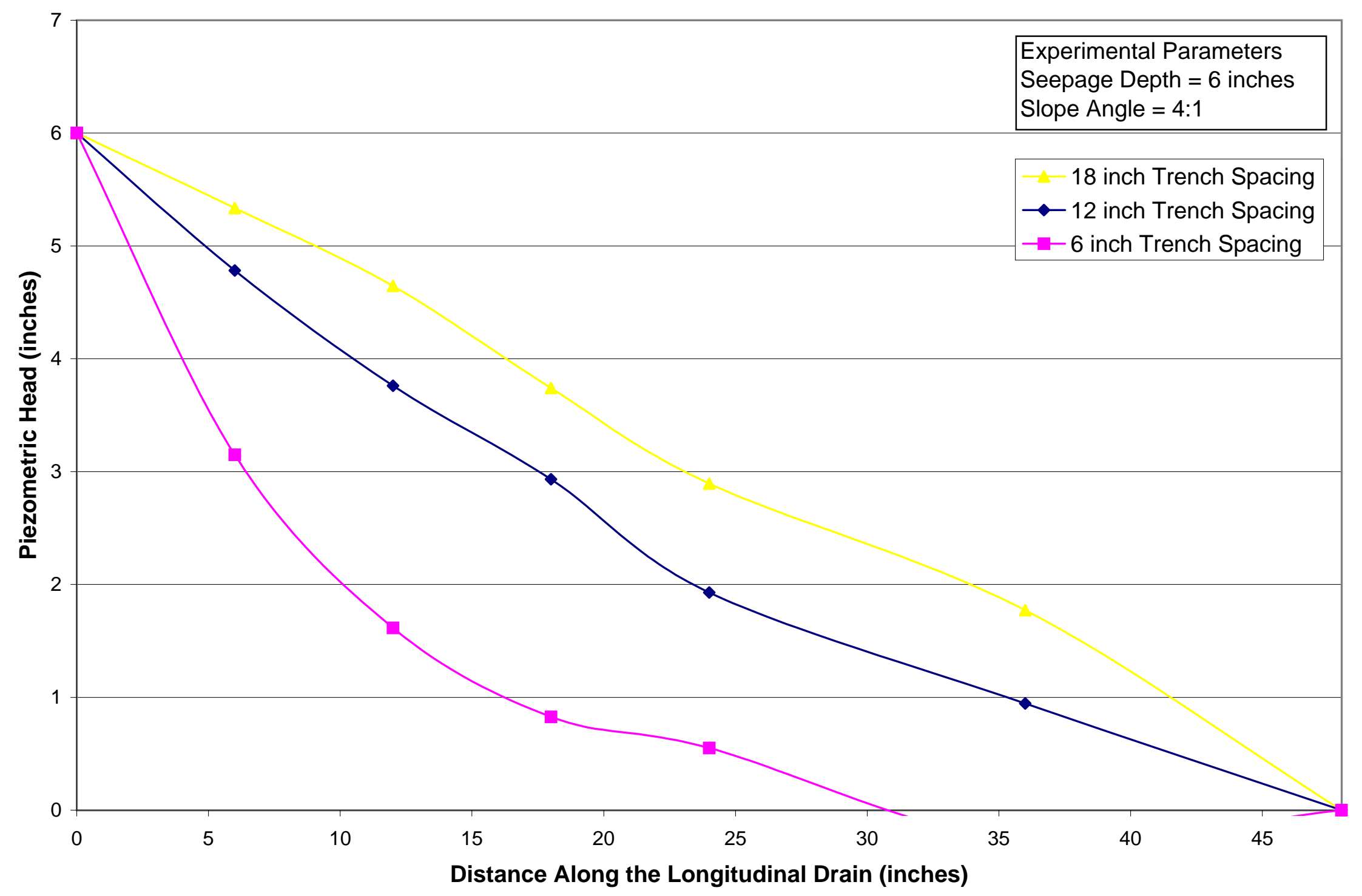

Figure E.6 Piezometric Head at the Centerline Between Drains for 6 inch Seepage Depth and 4:1 Slope Angle. 


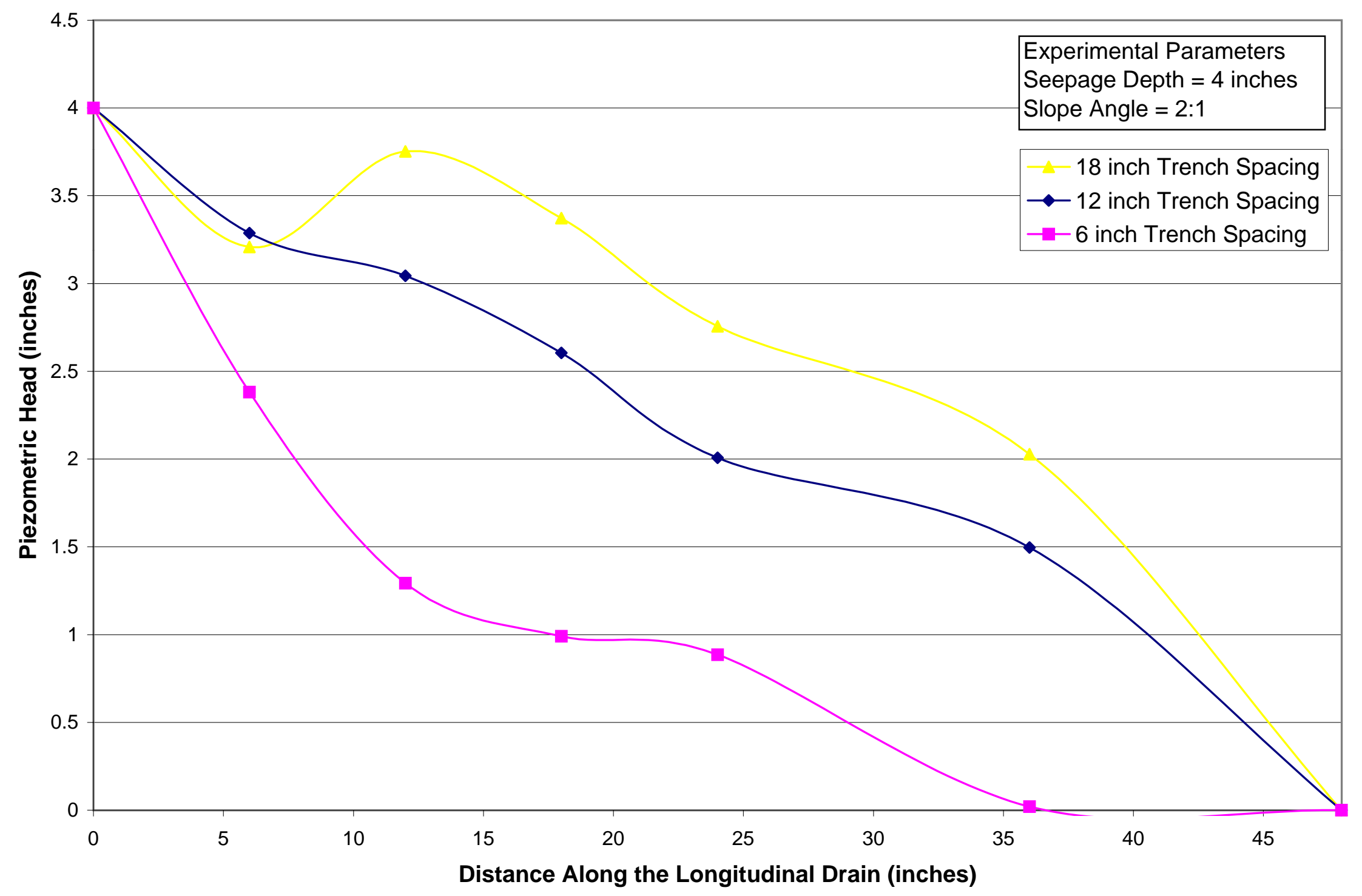

Figure E.7 Piezometric Head at the Centerline Between Drains for 4 inch Seepage Depth and 2:1 Slope Angle. 


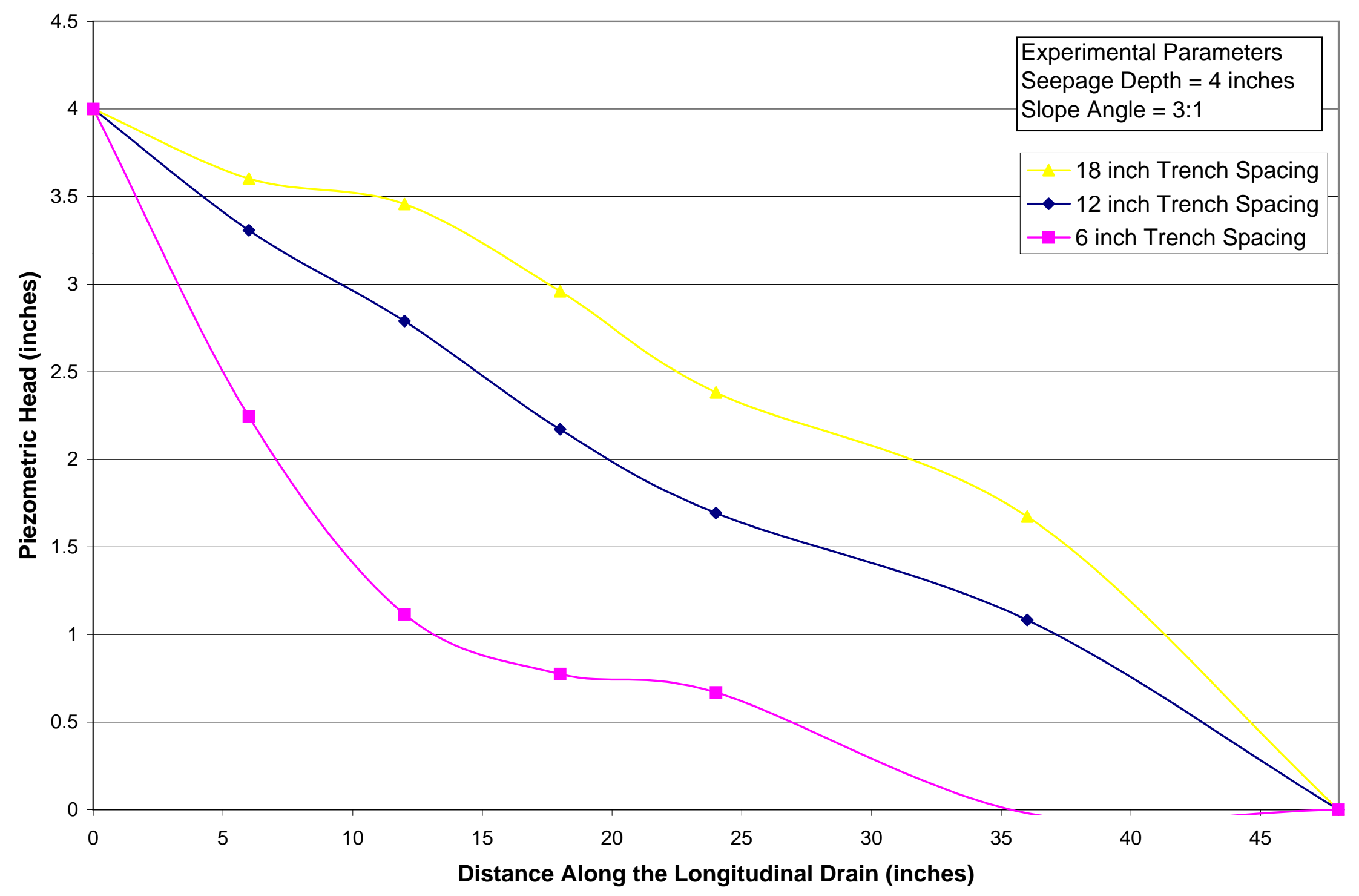

Figure E.8 Piezometric Head at the Centerline Between Drains for 4 inch Seepage Depth and 3:1 Slope Angle. 


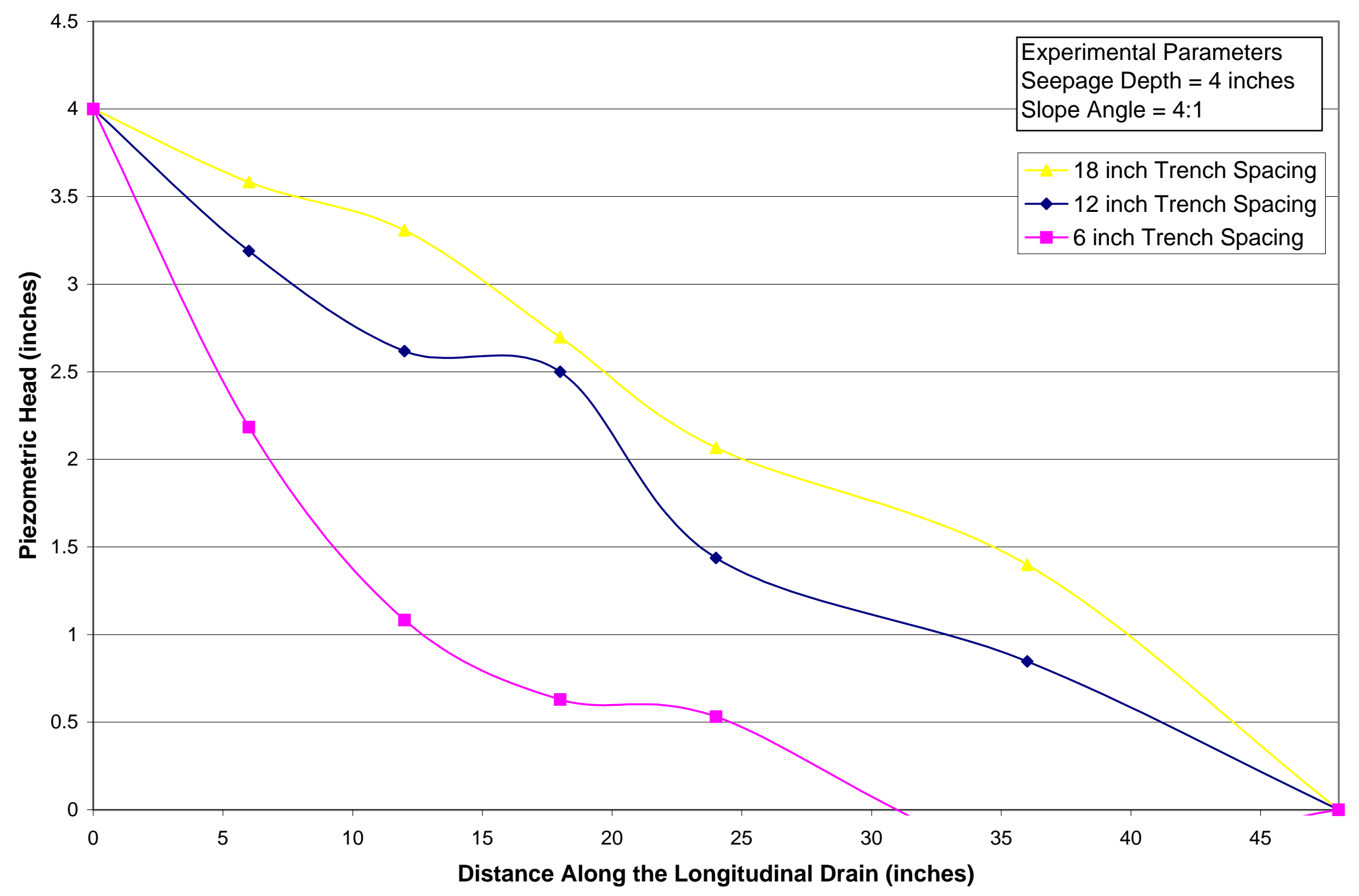

Figure E.9 Piezometric Head at the Centerline Between Drains for 4 inch Seepage Depth and 4:1 Slope Angle. 


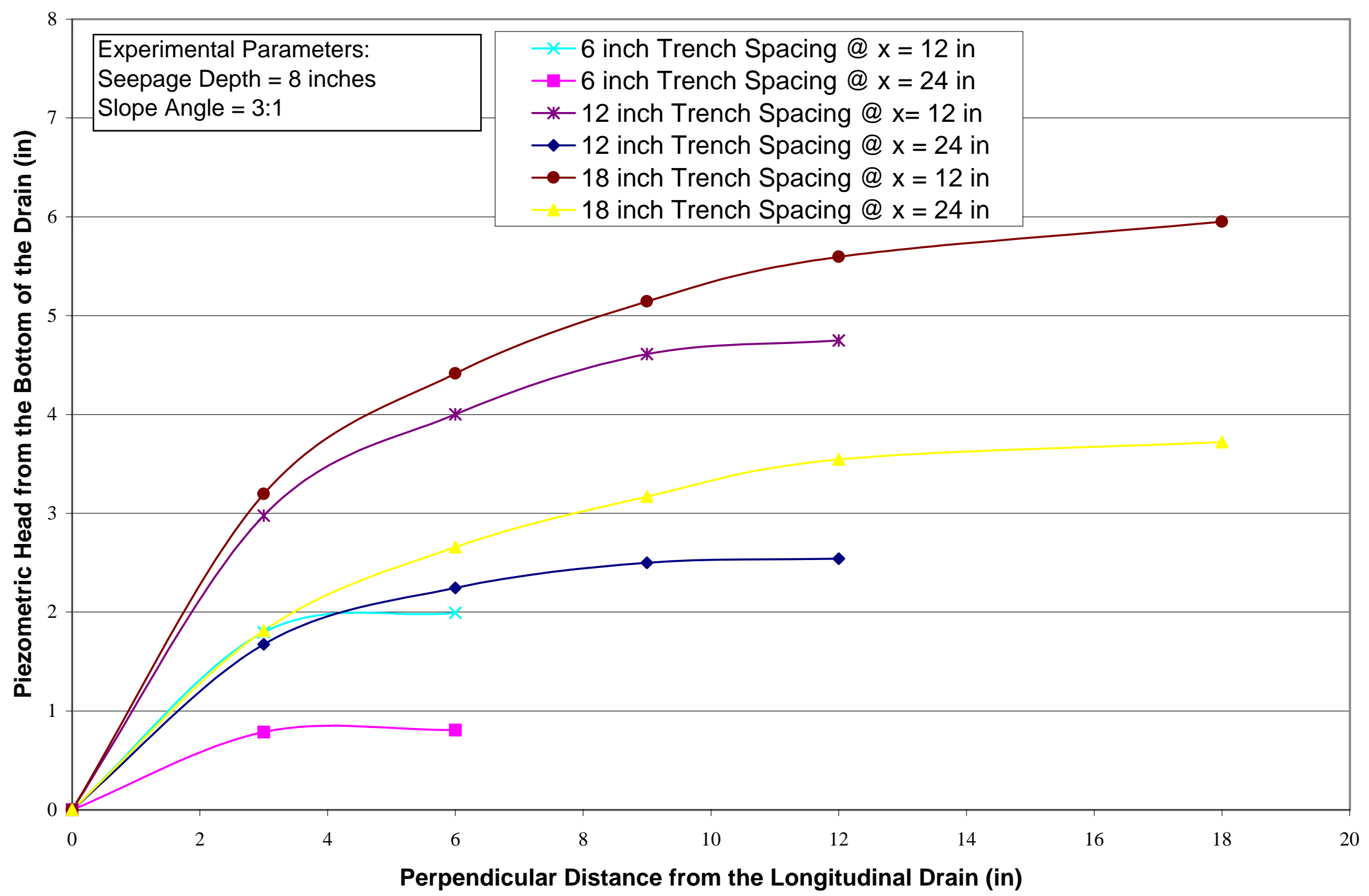

Figure E.11 Piezometric Head at Cross-Sections Perpendicular to the Drain for 8 inch Seepage Depth and 3:1 Slope Angle. 


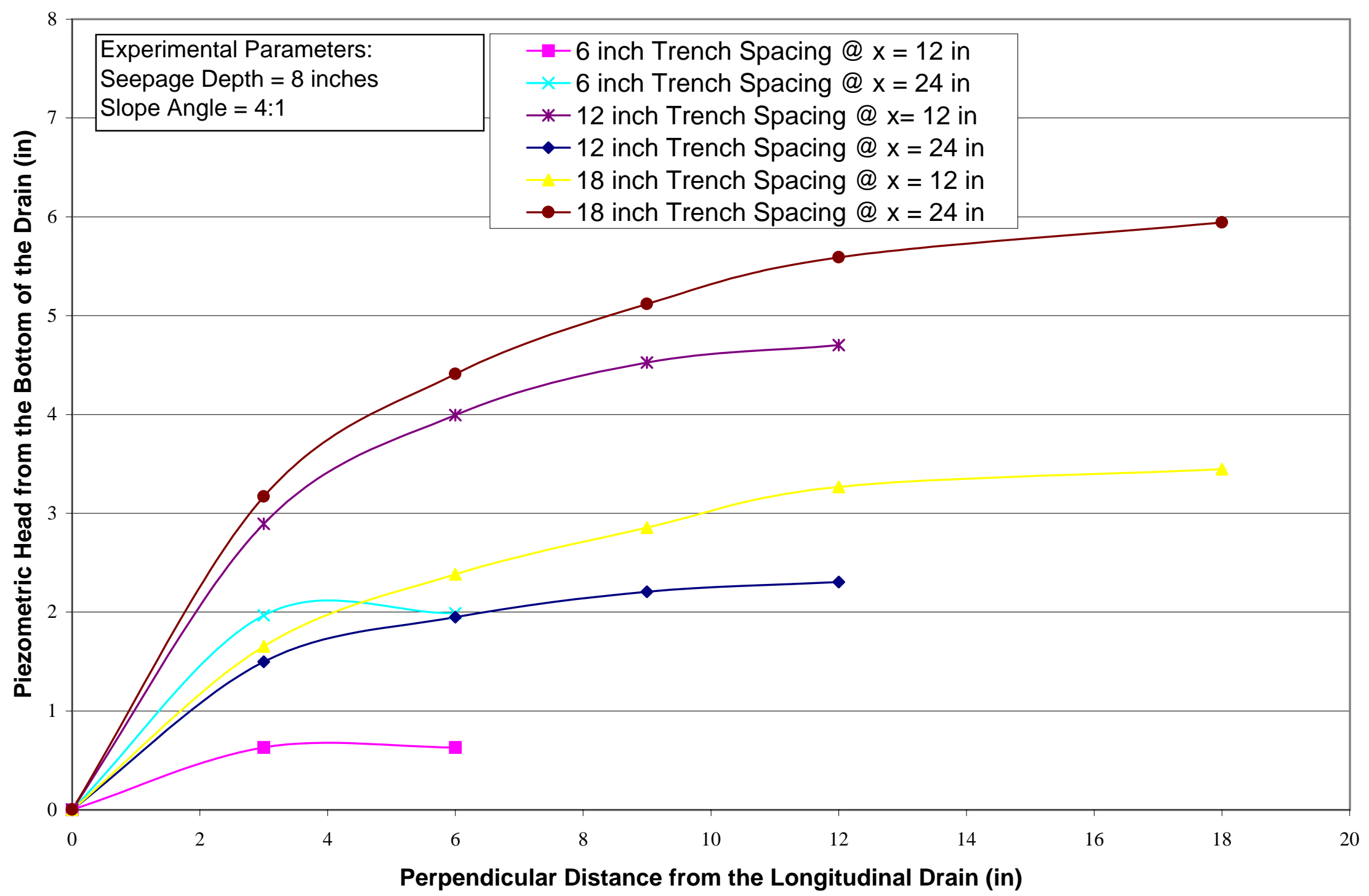

Figure E.12 Piezometric Head at Cross-Sections Perpendicular to the Drain for 8 inch Seepage Depth and 4:1 Slope Angle. 


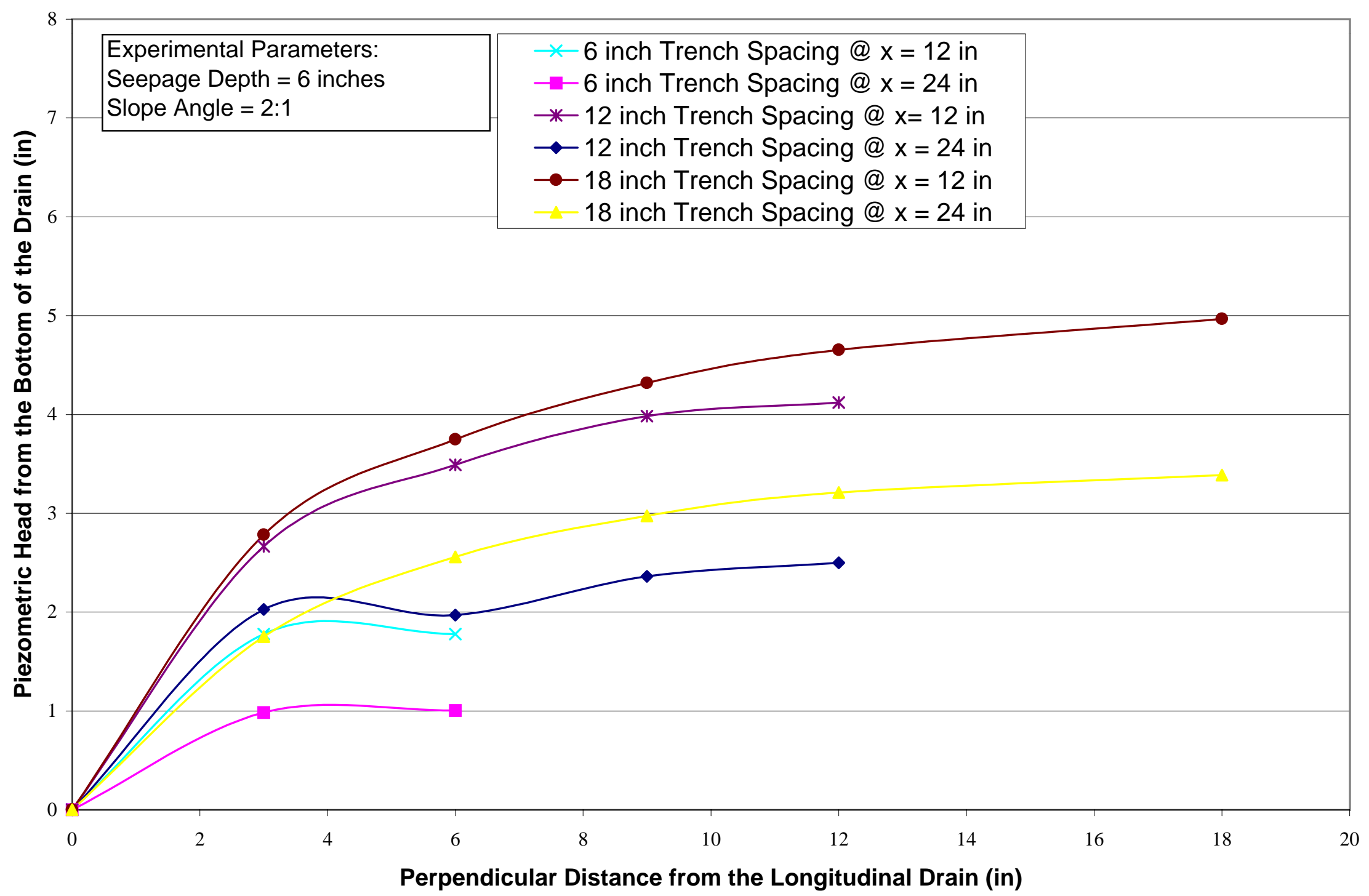

Figure E.13 Piezometric Head at Cross-Sections Perpendicular to the Drain for 6 inch Seepage Depth and 2:1 Slope Angle. 


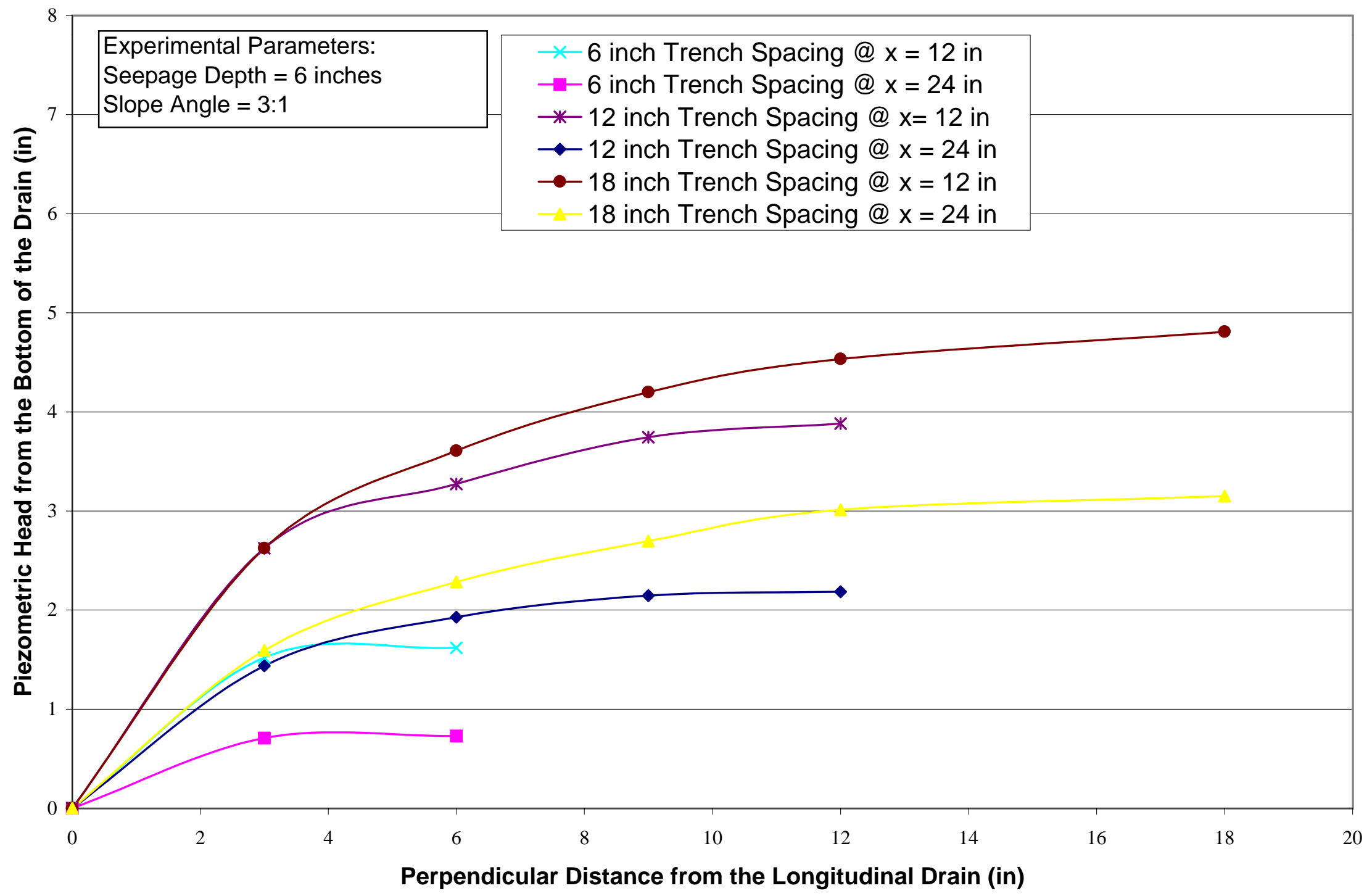

Figure E.14 Piezometric Head at Cross-Sections Perpendicular to the Drain for 6 inch Seepage Depth and 3:1 Slope Angle. 


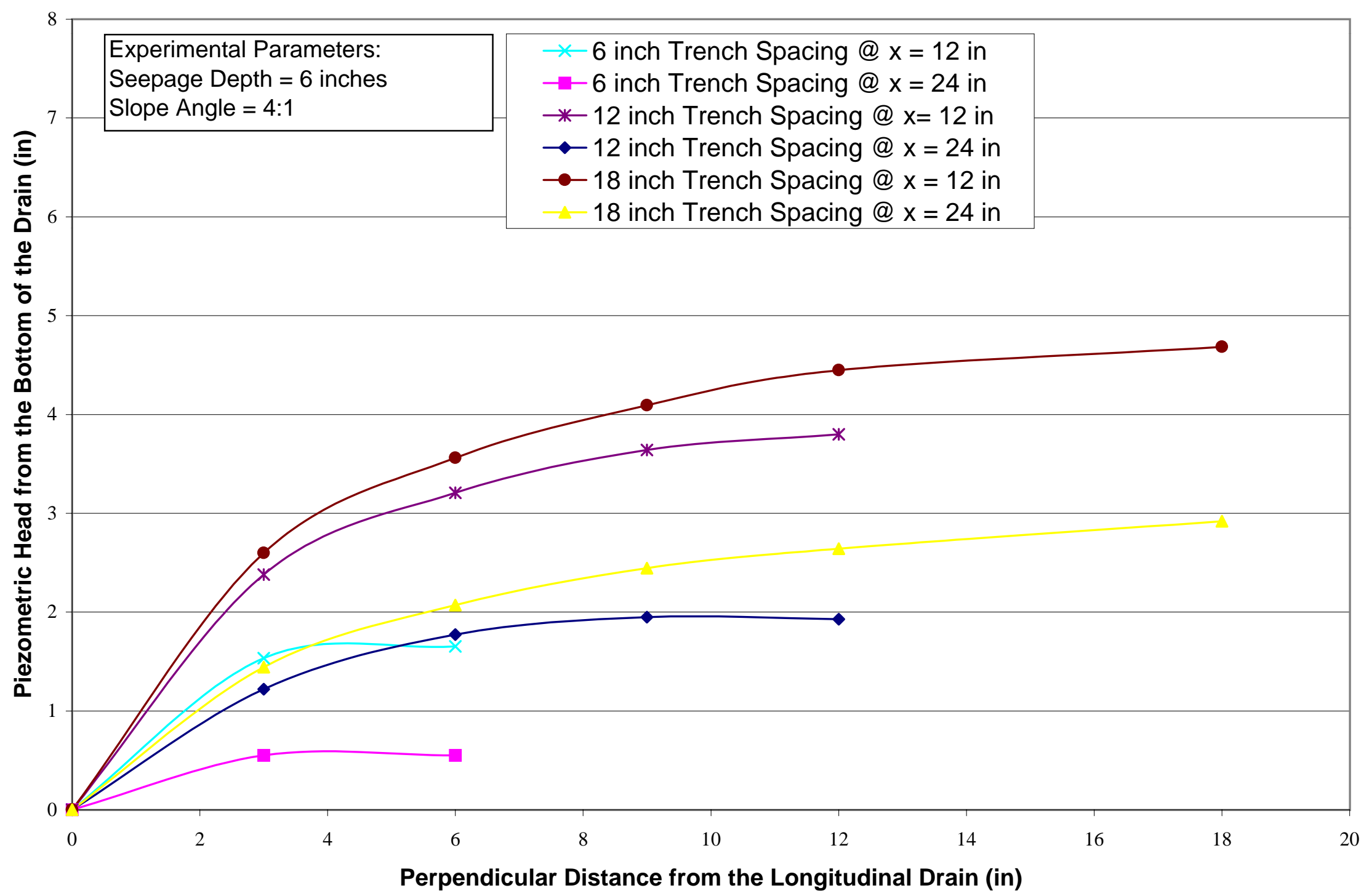

Figure E.15 Piezometric Head at Cross-Sections Perpendicular to the Drain for 6 inch Seepage Depth and 4:1 Slope Angle. 


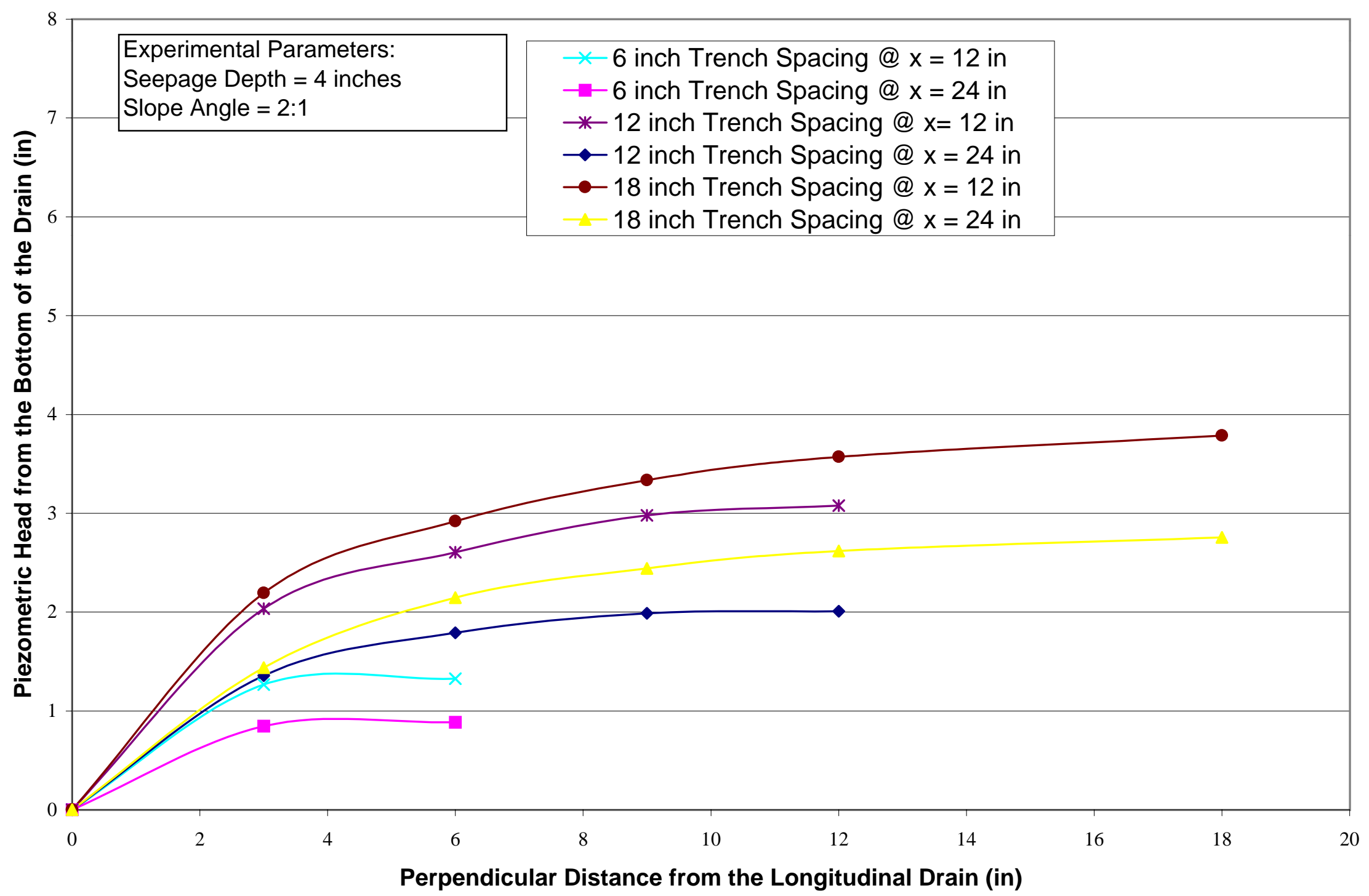

Figure E.16 Piezometric Head at Cross-Sections Perpendicular to the Drain for 4 inch Seepage Depth and 2:1 Slope Angle. 


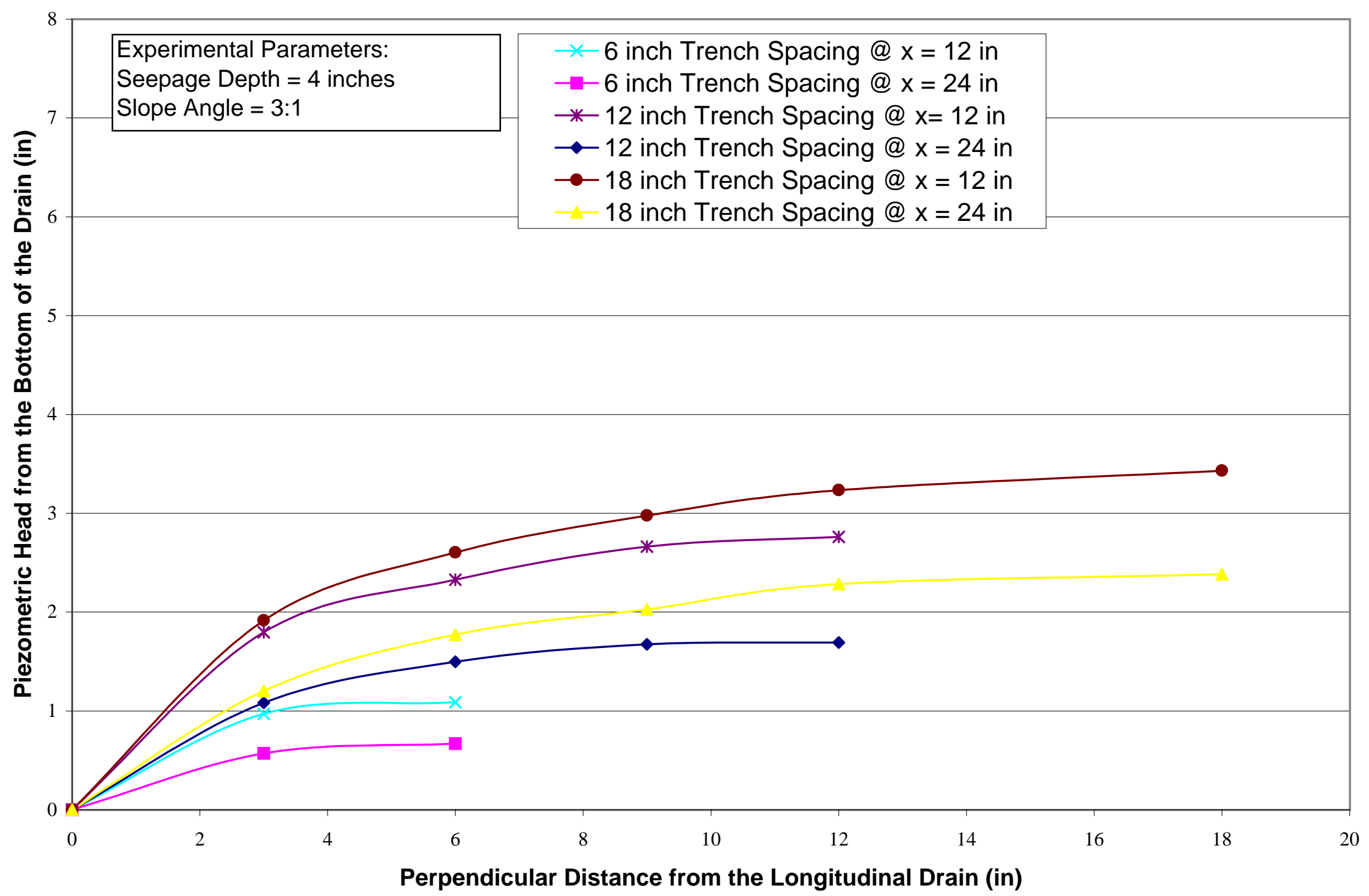

Figure E.17 Piezometric Head at Cross-Sections Perpendicular to the Drain for 4 inch Seepage Depth and 3:1 Slope Angle. 


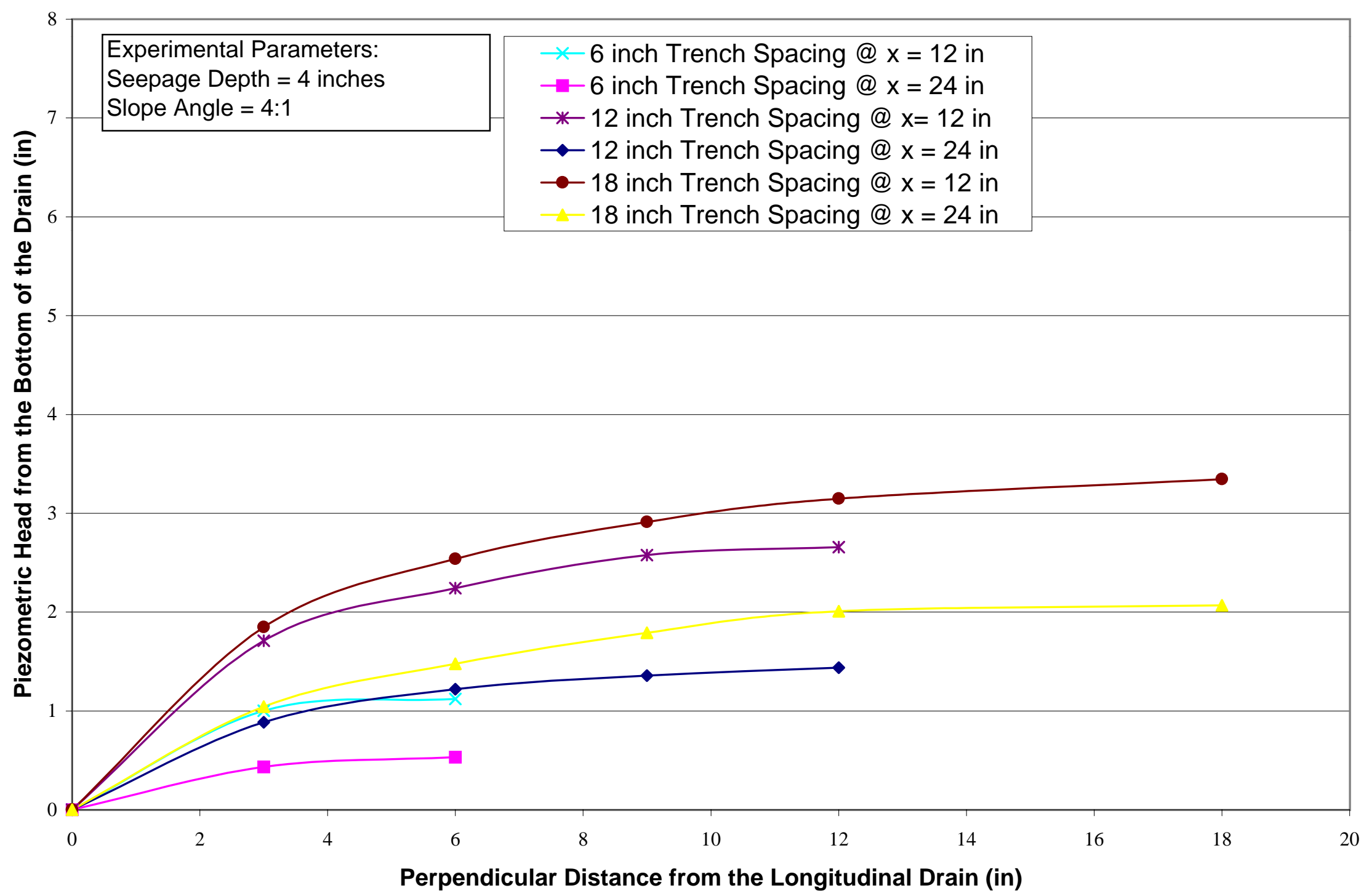

Figure E.18 Piezometric Head at Cross-Sections Perpendicular to the Drain for 4 inch Seepage Depth and 4:1 Slope Angle. 


\section{VITA}

Benjamin Thomas Staud was born in Elkins West Virginia in 1974. He graduated with a Bachelor of Science in Civil Engineering in 1997 from West Virginia University. Currently he is a Masters candidate specializing in Geotechnical and Environmental Engineering at West Virginia University. 